\title{
EXPLORANDO TECNOLOGIAS HIPERMÍDIA E DE TRABALHO COOPERATIVO EM UM AMBIENTE DE APOIO AO ENSINO
}

\author{
Alessandra Alaniz Macedo \\ Orientação: \\ Prof ${ }^{\mathrm{a}}$. Dr ${ }^{\mathrm{a}}$. Maria da Graça Campos Pimentel
}

Dissertação ${ }^{l}$ apresentada ao Instituto de Ciências Matemáticas e de Computação USP, como parte dos requisitos para a obtenção do título de Mestre em Ciências Área de Ciências de Computação e Matemática Computacional.

USP - São Carlos

Junho de 1999

${ }^{1}$ Trabalho realizado com apoio financeiro da FAPESP 
À minha mãe que me incentivou a fazer este trabalho. 


\section{AGRADECIMENTOS}

A Deus pelo amparo em todos os momentos.

À Fundação de Amparo à Pesquisa do Estado de São Paulo (FAPESP), que incentiva, financia e dá suporte à pesquisa neste país.

À minha orientadora, Graça Pimentel, por seus ensinamentos, críticas e sugestões que muito me ajudaram no desenvolvimento do trabalho.

Às professoras Renata Pontim M. Fortes e Sandra Aluísio pelo socorro nas horas difíceis.

Aos professores Edson dos Santos Moreira, José Carlos Maldonado, Marcos Santana, Fredy Valente, pelos conhecimentos transmitidos durante o período de aulas.

Ao pessoal do laboratório Intermídia, especialmente ao Marcinho (Taboca), Daniel Pires, Pissioli, Kutova, Fúlvio e Rudinei, pela ajuda em muitas etapas do mestrado.

Às secretárias da Pós-Graduação, Beth, Laura e Marília, a Sandra e Adriana do Departamento Financeiro e a Fernanda (PAE) pelos esclarecimentos e ajuda.

À minha família pelo apoio, carinho e amor eternos !!

Ao André, meu agradecimento especial, pela sua Fé, amizade, amor, companheirismo, preocupação e belos sorrisos de incentivo. 


\section{ÍNDICE}

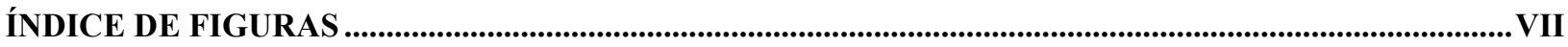

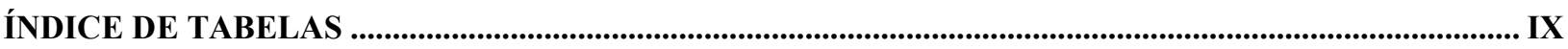

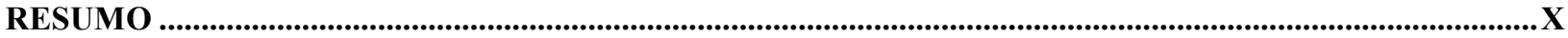

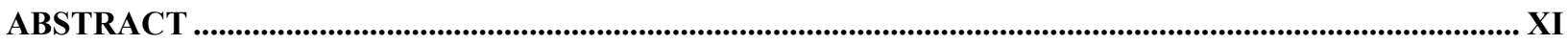

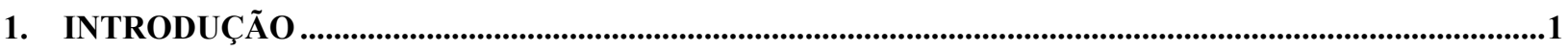

2. TRABALHO COOPERATIVO SUPORTADO POR COMPUTADOR …...................................................5

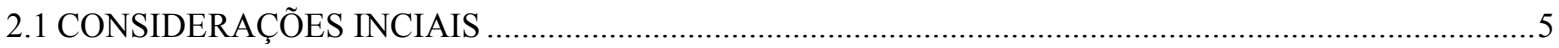

2.2 CARACTERIZAÇÃO E CLASSIFICAÇÃO DE SISTEMAS CSCW ……………...................................

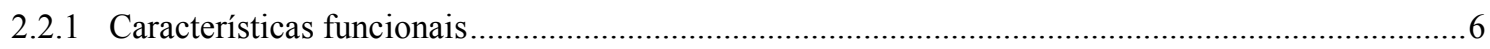

2.2.2 Classificação baseada em características funcionais ...................................................................

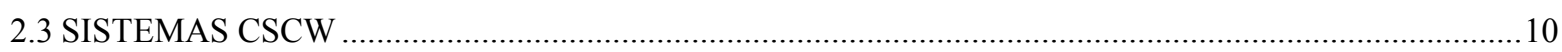

2.4 SISTEMAS CSCW UTILIZADOS PARA O DOMÍNIO DE APLICAÇÃO ENSINO ..................................11

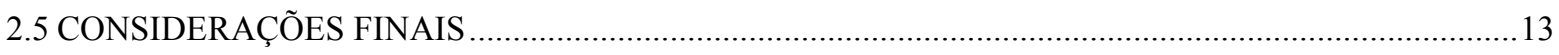

3. AMBIENTES DE APOIO À EDUCAÇÃO BASEADOS NA WEB ......................................................14

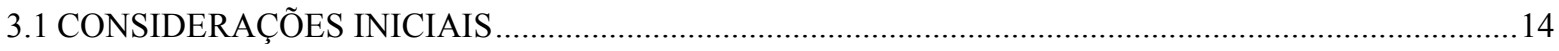

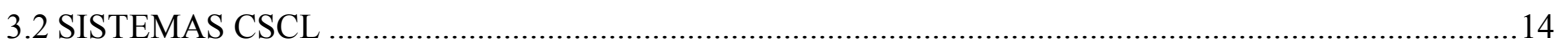

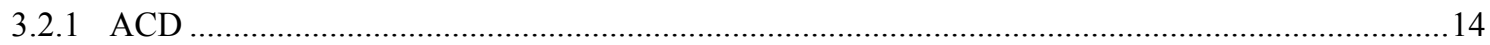

3.2.2 ARCOO

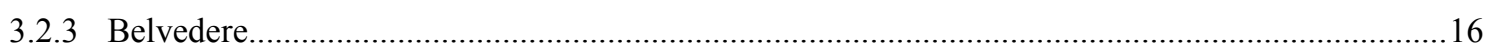

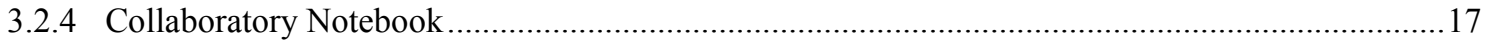

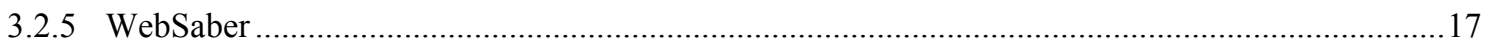

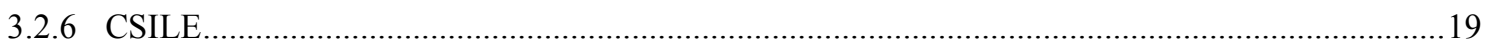

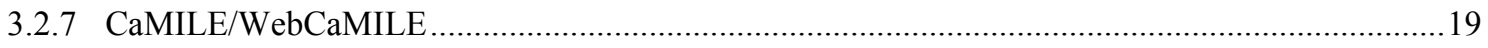

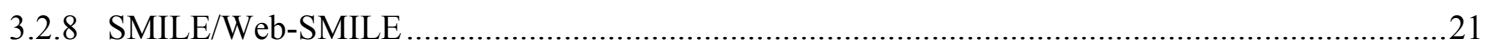

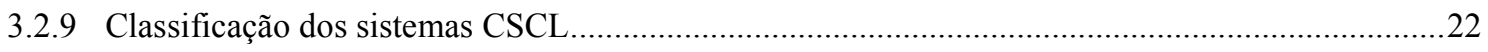

3.3 AMBIENTES DE AUTORIA E DISTRIBUIÇÃO DE MATERIAL DIDÁTICO .......................................24

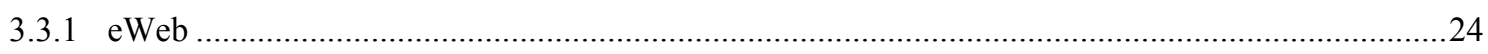

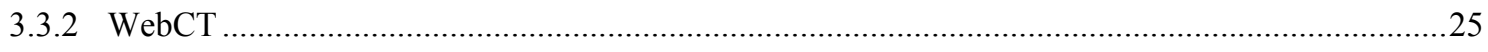

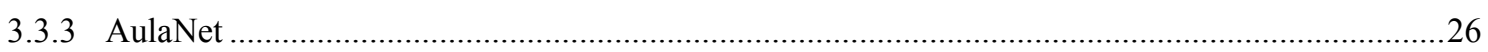

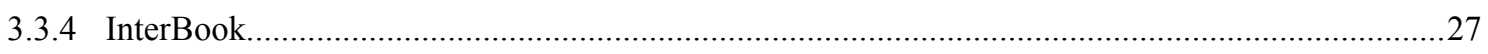

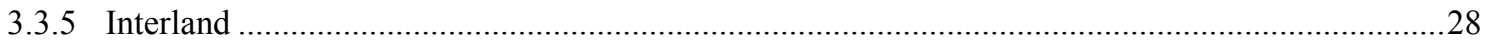

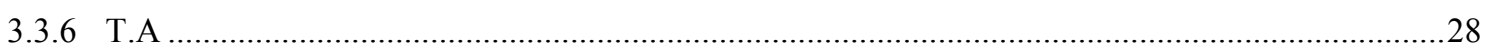

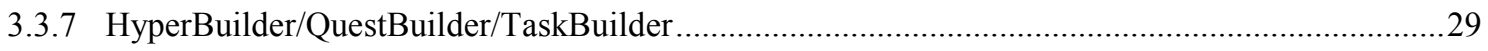

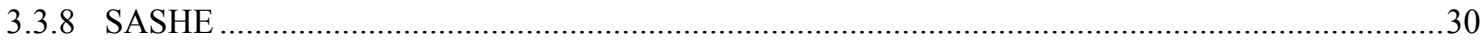




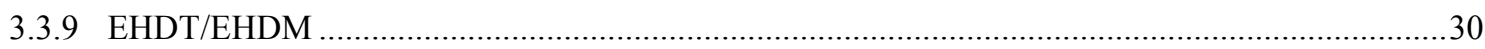

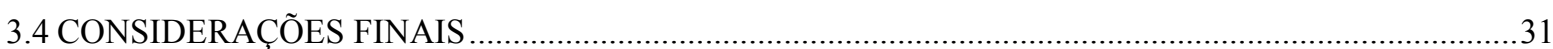

4. ESTRUTURAÇÃO E INTERCÂMBIO DE HIPERDOCUMENTOS .......................................................32

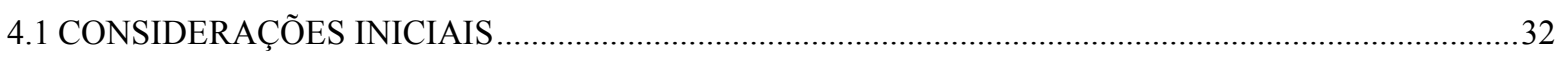

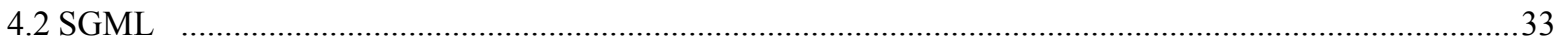

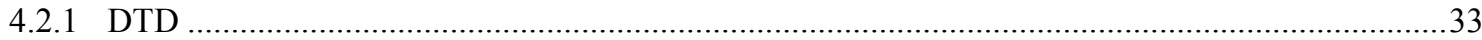

4.2.2 Vantagens e desvantagens da utilização de SGML ......................................................................34

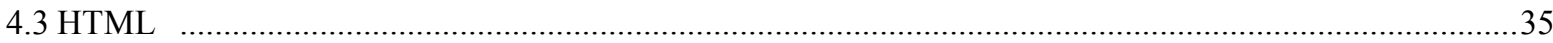

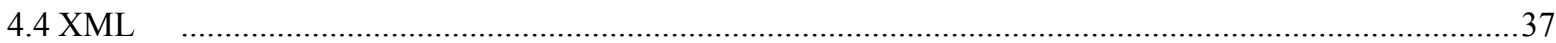

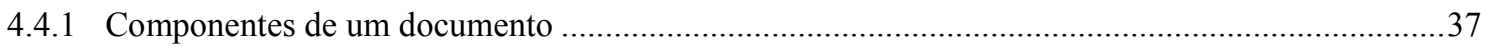

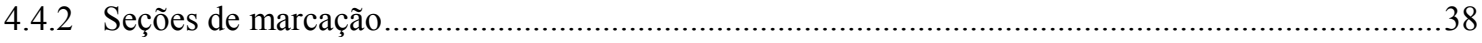

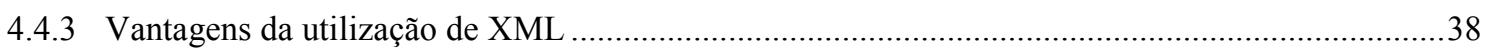

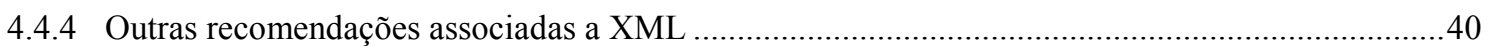

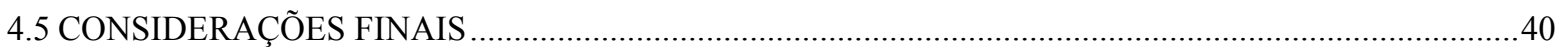

5. MODELAGEM DE APLICAÇÕES HIPERMÍDIA PARA A WEB ................................................42

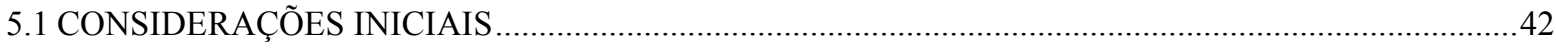

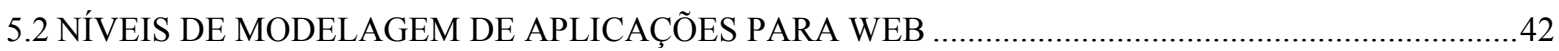

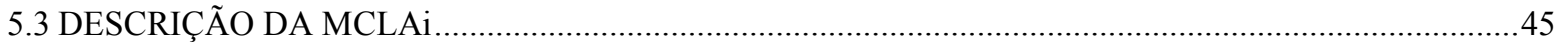

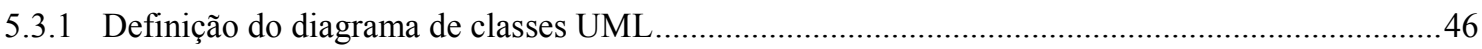

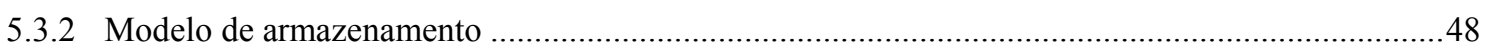

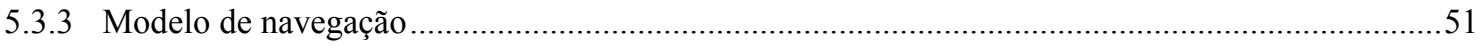

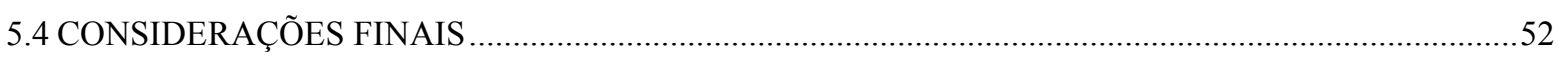

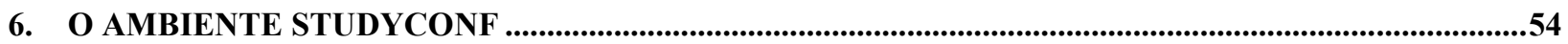

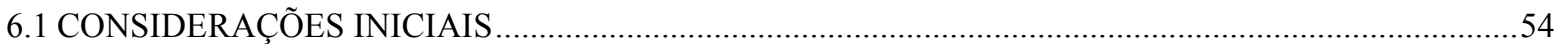

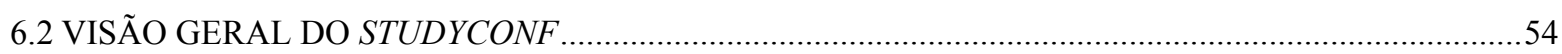

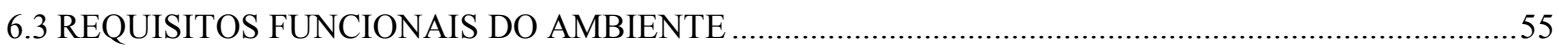

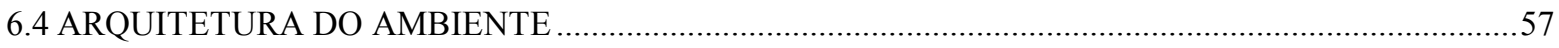

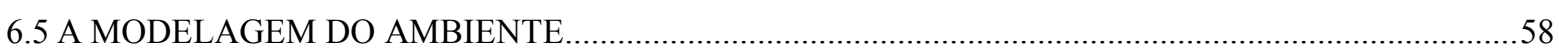

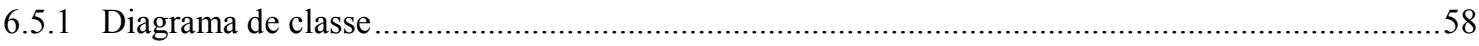

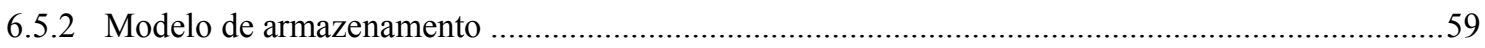

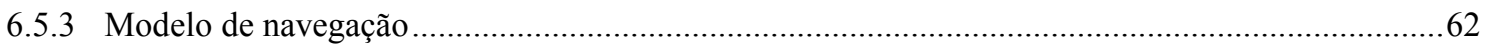

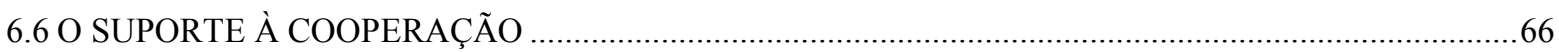

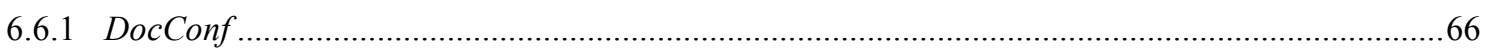

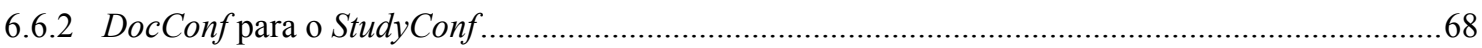

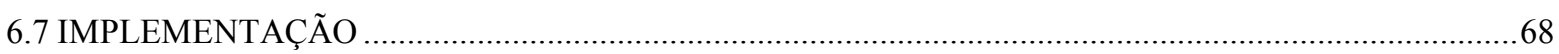

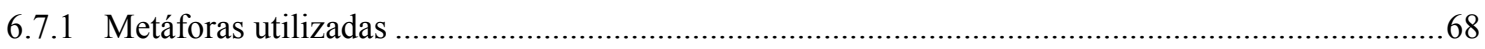

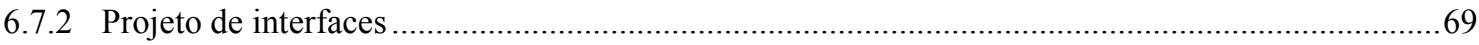


6.7.3 Diretrizes de implementação da versão atual .............................................................................

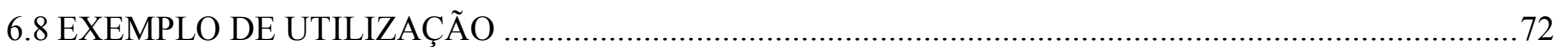

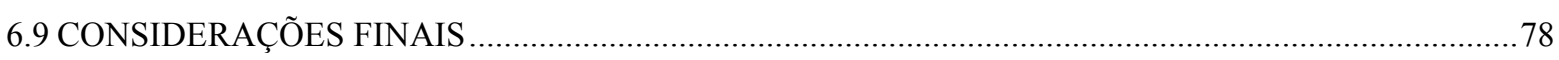

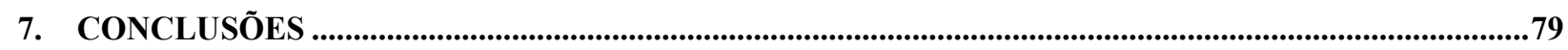

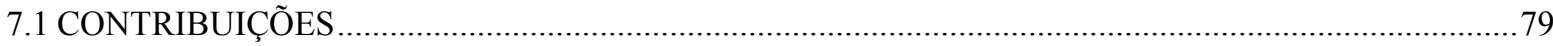

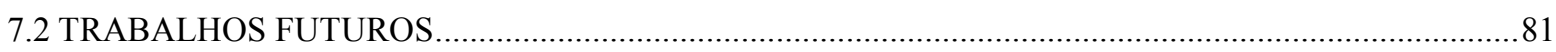

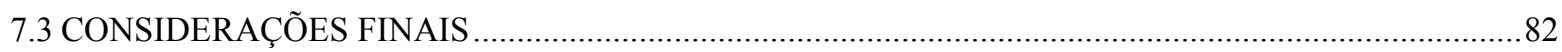

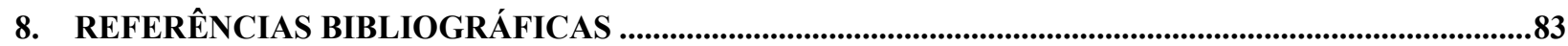




\section{ÍNDICE DE FIGURAS}

Figura 2.1 - Quatro situações nas quais um grupo pode trabalhar (Macaulay, 1995)............... 6

Figura 3.1 - Página principal do site ACD (ACD,1998)..................................................... 15

Figura 3.2a - Belvedere para Macintosh (Belvedere, 1998)................................................ 17

Figura 3.2b - Belvedere para WWW (Belvedere, 1998)...................................................... 17

Figura 3.3 - Página principal do site WebSaber (WebSaber, 1998)....................................... 18

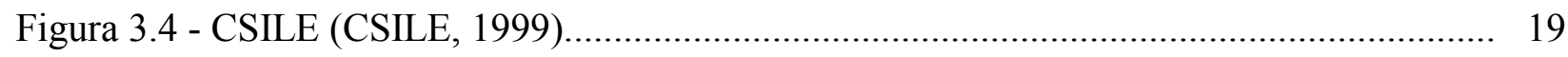

Figura 3.5a - Página inicial do Web-CaMILE (Guzdial, 1998)............................................ 20

Figura 3.5b - Página de apresentação de nota do Web-CaMILE (Guzdial, 1998)................... 20

Figura 3.6a - Página de criação de nota do Web-CaMILE (Guzdial, 1998)............................. 21

Figura 3.6b - Página de edição de nota do Web-CaMILE (Guzdial, 1998)................................ 21

Figura 3.7a - Whiteboard do Web-SMILE (Guzdial et al., 1997)........................................ 21

Figura 3.7b - Área de discussão do Web-SMILE (Guzdial et al., 1997)................................. 21

Figura 3.8 - eWeb com as ferramentas CSCW (eWeb, 1997) ............................................. 25

Figura 3.9 - Página principal do módulo de construção curso do WebCT (WebCT, 1997)....... 26

Figura 3.10 - Página principal do site do AulaNet (AulaNet, 1999) ...................................... 27

Figura 3.11 - Livro-texto com glossário e conteúdo (Brusilovsky et al., 1996)........................ 28

Figura 3.12a - Arquitetura básica para publicação de cursos na WWW ................................... 29

Figura 3.12b - Arquitetura estendida com HyperBuilder, QuestBuilder e TaskBuilder............. 29

Figura 5.1 - Níveis de modelagem de aplicações hipermídia (Isakowitz et al., 1998).............. 43

Figura 5.2 - Disposição dos elementos da MCLAi nos níveis de modelagem.......................... 45

Figura 6.1 - Arquitetura do StudyConf......................................................................... 57

Figura 6.2 - Diagrama de Classes do StudyConf ............................................................... 58

Figura 6.3 - Representação M-Rel das entidades do StudyConf ................................................ 59

Figura 6.4 - Apresentação das tabelas da base de dados do StudyConf ................................... 60

Figura 6.5a - Elementos para tabela aluno e seus campos................................................. 60

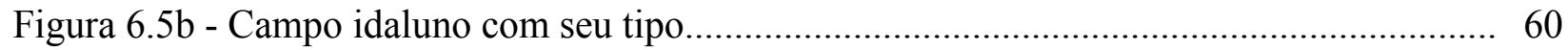

Figura 6.6 - DTD para a tabela aluno do banco de dados do StudyConf................................ 61

Figura 6.7 - Documento XML de uma instância da base de dados do StudyConf..................... 61

Figura 6.8 - Diagrama da Aplicação StudyConf ..................................................................... 63 
Figura 6.9 - Unidade de apresentação da página índice - página de índice principal de apresentaç̃o...

Figura 6.10 - DTD da unidade de apresentação da Figura 6.9

Figura 6.11 - Unidade de apresentação página Web - página de cadastro de usuários 64

Figura 6.12 - DTD da unidade de apresentação da Figura 6.11 65

Figura 6.13a - Telas de acesso ao ambiente DocConf. 65

Figura $6.13 \mathrm{~b}$ - Telas de acesso ao ambiente DocConf. 66

Figura 6.14 - Gerenciador de sessões do DocConf 66

Figura 6.15 - Exemplo de um cliente de sessão 67

Figura 6.16 - Página principal do StudyConf. 67

Figura 6.17a - Página para realização de ações no módulo aluno. 70

Figura $6.17 b$ - Página para realização de ações no módulo administrador. 70

Figura 6.18a - Página de estudo para cursos com navegação livre. 70

Figura 6.18 b - Página de estudo para cursos com navegação controlada. 71

Figura 6.19 - Páginas de identificação para acesso ao ambiente de estudo.... 71

Figura 6.20 - Página principal do módulo aluno. 73

Figura 6.21 - Página para escolha de curso a ser estudado. 74

Figura 6.22 - Primeira página de estudo do curso de Teoria da Computação. 75

Figura 6.23 - Página de acesso a referências bibliográficas extras. 76

Figura 6.24 - Página exemplo de estudo cooperativo do StudyConf...... 77 78 


\section{ÍNDICE DE TABELAS}

Tabela 3.1 - Classificação dos sistemas CSCL.......................................................................23

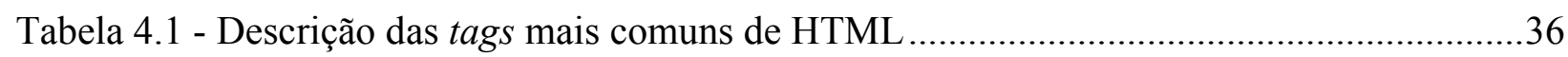


Muitos dos atuais sistemas computacionais de apoio ao ensino podem ser considerados parte de uma evolução que tem enfatizado a exploração de sistemas hipermídia em geral, e da Web em particular. A pesquisa associada ao trabalho aqui reportado tem como objetivo explorar as tecnologias de Hipermídia e Computer Supported Cooperative Work (CSCW) para viabilizá-las em um ambiente que suporte o acesso de alunos a hiperdocumentos de conteúdo didático de forma cooperativa - o ambiente StudyConf. Para promover a interação entre alunos que visitam um determinado hiperdocumento, o StudyConf controla suas navegações e gera, dinamicamente, sessões de discussão entre os mesmos. O StudConf mantém o registro das discussões realizadas na forma de hiperdocumentos estruturados, os quais podem ser utilizados, por exemplo, para a geração cooperativa de documentos, conforme proposto em várias ferramentas Computer Supported Cooperative Learning (CSCL). O trabalho aqui reportado colaborou, ainda, para o desenvolvimento de uma técnica que tem como objetivo orientar o projeto de aplicações hipermídia que manipulam informações na Web. 


\section{ABSTRACT}

Many of the current computational systems dedicated to support teaching and learning can be considered part of an evolution that has emphasized hypermedia systems in general, and the World Wide Web in particular. The work here reported aims at exploiting the technologies of hypermedia and Computer Supported Cooperative Work (CSCW) in an environment that supports collaborative access from students to hyperdocuments - supported in a tool called StudyConf. In order to promote interaction among students that navigate on the same hyperdocuments, StudyConf controls their navigation and generates dynamic discussion sessions with the students that visit the same material. StudyConf registers the discussions as structured hyperdocuments, which can be used to exploit proposals regarding the collaborative authoring of contents that are present in several Computer Supported Cooperative Learning (CSCL) tools. The work here reported has also contributed to the proposal of a technique aimed at guiding the development of general web-based hypermedia applications. 


\section{INTRODUÇÃO}

Muitas atividades humanas requerem a atuação de grupos para sua execução. Barros identifica a cooperação como um fenômeno que envolve vários processos: comunicação, negociação, coordenação, co-realização e compartilhamento (Barros, 1994). Portanto, para que as pessoas trabalhem cooperativamente, em um mesmo local ou geograficamente distribuídas, é necessário que exista entre elas um ambiente de apoio à comunicação.

O ambiente computacional que implementa os processos de apoio à cooperação, e assim possibilita o trabalho conjunto, bem como a necessária troca de informações, denomina-se sistema de trabalho cooperativo apoiado por computador (CSCW - Computer Supported Cooperative Work) ou groupware (Ellis et al., 1991; Borges et al., 1995). Já o ambiente computacional que apóia tarefas de ensino ou aprendizagem em grupo é chamado sistema de aprendizado cooperativo apoiado por computador (CSCL - Computer Supported Cooperative Learning) (Borges et al., 1995). Alguns autores consideram sistemas CSCL como uma subdivisão dos sistemas $\mathrm{CSCW}$ dedicados às aplicações educacionais, uma vez que, freqüentemente, suportam atividades básicas do trabalho cooperativo ao mesmo tempo em que agregam elementos associados a atividades de aprendizagem e tutoria (Barros, 1994). Um fato importante é que alguns sistemas CSCW são utilizados no processo de aprendizagem, apesar de não terem sido construídos para atender a este propósito.

A tecnologia de sistemas hipermídia é caracterizada por aplicações nas quais usuários navegam interativamente por documentos contendo ligações embutidas em seu conteúdo. Estes documentos são chamados hiperdocumentos ou aplicações hipermídia.

Desde sua introdução, sistemas hipermídia têm sido utilizados em ambientes de apoio ao ensino. Um exemplo é o Sistema Intermedia, desenvolvido na Brown University nos anos 80, utilizado como ferramenta de apoio em cursos de Literatura e Biologia, entre outros (Meyrowitz, 1986). A expansão da Internet, e do correspondente aumento da comunidade de usuários da World Wide 
$\mathrm{Web}^{2}$, tem provocado um crescente interesse pela disponibilização, nesses ambientes, de hiperdocumentos com conteúdo direcionado ao ensino.

A exploração conjunta das tecnologias de CSCW e hipermídia tem vários proponentes. Já no início da década de 90, Nielsen e Streitz sugeriram a exploração de ambientes cooperativos suportados por hiperdocumentos para facilitar a organização e coordenação de idéias (Nielsen, 1990; Streitz, 1991). Streitz comentava que essa união resultaria em sistemas hipermídia multi-usuários distribuídos, ao passo que as atividades de cooperação seriam beneficiadas com o suporte a documentos estruturados (Streitz, 1991). Nesse mesmo contexto, Ishii relatava que a tecnologia de hipertexto deveria beneficiar o suporte computacional ao trabalho em grupo, e sugeria que a própria memória de grupo fosse estruturada e suportada como um documento com referências hipertextuais a conteúdo multimídia (Ishii, 1991). De fato, o Sistema Intermedia foi um dos precursores no suporte a tarefas cooperativas com o uso de sistemas hipermídia (Catlin et al., 1989).

A possibilidade de cooperação sem restrições de tempo e espaço tem sido considerada uma forte motivação para a criação e uso de ambientes cooperativos. Em particular no contexto de sistemas CSCL, motivações complementares incluem (Otsuka \& Tarouco, 1997; Gudzdial et al., 1997):

- estudo em grupo favorece a análise crítica de idéias e estratégias, devido à existência de diferentes perspectivas dos companheiros no grupo, perante o mesmo assunto;

- o estudo em grupo aprimora qualidades pessoais, como liderança, comunicação e gerenciamento de tarefas;

- o processo de aprendizagem é motivado, pois os alunos contribuem com a sensação de posse da construção conjunta;

- alunos podem observar estratégias de aprendizagem dos seus companheiros ou dos grupos;

- professores podem acompanhar e avaliar seus alunos de acordo com as informações armazenadas no sistema. Os próprios alunos podem avaliar as contribuições de seus companheiros;

\footnotetext{
${ }^{2}$ Neste texto os termos WWW e Web são utizados como abreviatura de World Wide Web.
} 
- alunos tímidos podem expor suas idéias mais facilmente. Em aulas expositivas, eles perdem oportunidades de apresentar idéias e esclarecer dúvidas;

- alunos mais agressivos, ou mais participativos, possivelmente não dominarão o tempo destinado à discussão, como poderiam fazer em aulas expositivas.

O objetivo deste trabalho é explorar o uso das tecnologias de CSCW e de hipermídia no desenvolvimento de um ambiente cooperativo, denominado StudyConf, que explora a Internet em geral, e a WWW em particular, para apoio ao ensino. Nesse contexto, propõe-se ainda uma técnica, denominada MCLAi, para modelar o processo de desenvolvimento de aplicações hipermídia para a Web.

No ambiente StudyConf, usuários podem examinar e discutir, de forma cooperativa, hiperdocumentos didáticos disponibilizados na WWW. StudyConf foi modelado de acordo com os padrões, modelos e diagramas da técnica da MCLAi.

Os demais capítulos desta dissertação estão organizados como segue. O Capítulo 2 tem como objetivo apresentar as inúmeras facetas que envolvem a criação de sistemas cooperativos apoiados por computador (CSCW) e de sistemas cooperativos de apoio ao ensino (CSCL). Para isto são apresentadas características funcionais, classificações e tecnologias computacionais consideradas na construção dos sistemas CSCW. São apresentados também alguns sistemas CSCW de domínio público disponíveis na Internet.

No Capítulo 3 são caracterizados alguns sistemas CSCL e ambientes de autoria, estruturação e distribuição de material didático na forma de hiperdocumentos.

No Capítulo 4 são apresentados conceitos e definições de recomendações do World Wide Web Consortium (W3C) para representação e intercâmbio de documentos.

O Capítulo 5 apresenta uma técnica definida com o objetivo de orientar o projeto de aplicações hipermídia que manipulam informações na Web, desenvolvida pelo grupo no qual este trabalho se realizou. 
O Capítulo 6 traz a descrição do ambiente cooperativo de apoio ao estudo StudyConf. Inicialmente apresenta-se as características gerais, os requisitos funcionais e a arquitetura do ambiente. Em seguida são descritas a modelagem do StudyConf, seguindo a técnica apresentada no Capítulo 5, e a ferramenta cooperativa acoplada ao ambiente. Ao final são apresentados aspectos de implementação do ambiente e um exemplo de sua utilização.

No Capítulo 7 conclui-se esta dissertação, sumarizando-se as contribuições e discutindo-se propostas para trabalhos futuros. 


\section{TRABALHO COOPERATIVO SUPORTADO POR COMPUTADOR}

\subsection{CONSIDERAÇÕES INCIAIS}

Devido ao fato da área de CSCW ser intrinsecamente interdisciplinar, surgem diferentes definições para um mesmo termo. Neste contexto, é interessante discutir a definição do termo “cooperação". De acordo com alguns dicionários, cooperação refere-se ao trabalho de um grupo que tem um objetivo comum e trabalha em direção a esse objetivo. Entretanto, Lubich (Lubich, 1995) levanta algumas questões: o que significa o termo "cooperativo" na sigla CSCW? Estará descrevendo que um grupo de pessoas trabalha junto em um conjunto de tarefas? E o estilo de “dividir para conquistar" ainda é considerado trabalho cooperativo? Finalmente, no caso de reuso de trabalho realizado por outros para conseguir novos resultados, e onde não há qualquer interação entre os participantes, há cooperação?

Na primeira conferência européia sobre CSCW (ECSCW'89), o termo "trabalho cooperativo", muitas vezes foi substituído por "trabalho colaborativo", "trabalho de grupo" e "trabalho coletivo" (Lubich, 1995). Ainda se questionava, o quão essa diferenciação seria realmente importante no contexto do trabalho realizado pela comunidade. Alguns pesquisadores preferem definir como "colaboração" a realização de tarefas específicas pelos componentes do grupo a fim de alcançar um objetivo comum, e "cooperação" como a realização conjunta de tarefas específicas a fim de alcançar o objetivo comum. No contexto do trabalho aqui apresentado, os termos "colaboração" e "cooperação" são tratados como sinônimos.

O principal interesse de pesquisadores da área de CSCW está em facilitar a cooperação entre grupos de pessoas, através da tecnologia computacional, sejam estes grupos numerosos ou não. Para aumentar a eficiência dos sistemas $\mathrm{CSCW}$, estudiosos de várias outras áreas como ciências cognitivas, psicologia, sociologia, antropologia e administração vêm contribuindo com diferentes perspectivas e metodologias na aquisição de conhecimento sobre grupos, e sugerindo como o trabalho em grupo pode ser melhor apoiado. 
Os grupos de trabalho cooperativo nem sempre estão no mesmo local para discutirem e trabalharem em encontros do tipo face a face. Eles podem estar geograficamente distribuídos e, nesse caso, a comunicação via sistemas CSCW torna-se essencial e não facultativa como nos casos de encontros face a face. Independente do local, os membros de um grupo podem optar por se conectarem ao sistema ao mesmo tempo (trabalho síncrono) ou em tempos diferentes (trabalho assíncrono) (Macaulay, 1995). A Figura 2.1 identifica as quatro situações possíveis nas quais um grupo pode trabalhar, dependendo da sua distribuição geográfica e temporal.

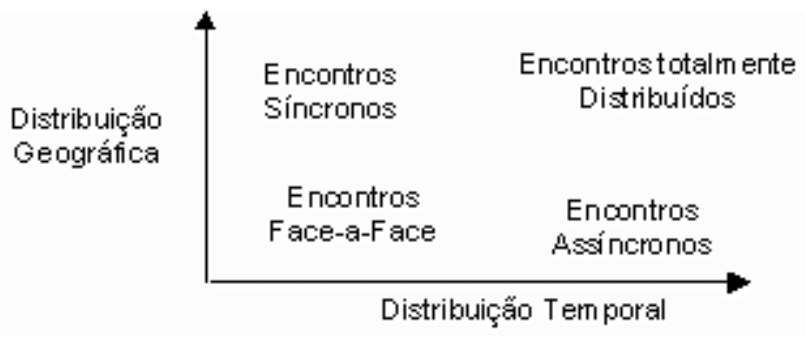

Figura 2.1 - Quatro situações nas quais um grupo pode trabalhar (Macaulay, 1995)

Outras formas de classificação de sistemas CSCW também podem ser encontradas na literatura (Ellis et al., 1991; Nunamaker et al., 1991; Borges et al., 1995).

Na Seção 2.2, sistemas CSCW são caracterizados e classificados e na Seção 2.3 alguns sistemas CSCW são brevemente descritos. Finalmente, na Seção 2.4, alguns sistemas CSCW utilizados em ambientes de ensino são discutidos.

\subsection{CARACTERIZAÇÃO E CLASSIFICAÇÃO DE SISTEMAS CSCW}

\subsubsection{Características funcionais}

As características funcionais de sistemas $\mathrm{CSCW}$, apresentadas a seguir, nem sempre são encontradas conjuntamente em todos os sistemas cooperativos. Dependendo do contexto, algumas delas são apenas desejáveis, enquanto outras são indispensáveis.

- Comunicação entre os membros do grupo. A comunicação é de extrema importância em situações de trabalho em grupo, seja ela para transmissão de informações ou para tomada de decisões. Muitas vezes, as decisões podem ser alcançadas num local no qual as pessoas 
podem ver e sentir as reações e comportamento umas das outras. Procurando suportar todas as ações dos membros de um grupo em encontros, ambientes de videoconferência provêm canais de áudio e vídeo nos quais os conteúdos de aparência, fala e escrita são transmitidos para todos os membros do grupo. Entretanto, a maioria das comunicações via computador ainda é restrita a canais textuais. A comunicação pode ser síncrona ou assíncrona, dependendo do momento em que os membros do grupo receberão as mensagens enviadas.

- Compartilhamento de informações. Esta característica é essencial para grupos devido à necessidade de prevenir esforços repetitivos e assegurar que todos os membros do grupo estejam utilizando a mesma informação, de forma que não haja inconsistências.

- Coordenação e controle de objetos. Em muitas situações, certos objetos devem ser compartilhados entre o grupo por alguma razão. Por exemplo, membros de um grupo de projetistas no desenvolvimento de um projeto realizam continuamente modificações neste. Por isso é importante que os outros projetistas estejam cientes de cada nova versão do trabalho. Para tanto, uma coordenação do trabalho se faz necessária. Além disso, controle de acesso é importante para garantir a integridade de cada versão manipulada.

- Compartilhamento de espaços de trabalho. Encontros face a face são geralmente auxiliados por lousas ou computadores, onde as pessoas escrevem suas idéias, às quais os outros componentes do grupo têm acesso. Por exemplo, os resultados de exercícios de brainstorming podem ser armazenados numa lista, que pode ser trabalhada pelo grupo. Uma pessoa pode ser responsável por escrever, mas todas devem ser capazes de ler e assim apresentar sugestões. Enfim, a lousa ou a tela do computador são consideradas espaços de trabalho que podem ser compartilhados.

- Organização e entendimento do processo de trabalho. As pessoas que trabalham em grupo devem definir a tarefa a ser realizada, entrarem em acordo sobre o conjunto de atividades a ser executado para a realização da tarefa e finalmente informar as decisões a todos.

Dentre as características apresentadas, apenas a última não é considerada essencial para o funcionamento satisfatório de um sistema CSCW. 


\subsubsection{Classificação baseada em características funcionais}

Existem várias tentativas de classificação de sistemas $\mathrm{CSCW}$, num esforço de entendimento de como esta tecnologia pode se enquadrar na complexidade do contexto social, organizacional e cultural em que o homem vive.

Como apresentado na Figura 2.1, sistemas CSCW podem ser classificados de acordo com tempo e local dos encontros cooperativos. Adicionalmente, outro tipo de classificação pode ser feito utilizando o tamanho do grupo como terceiro parâmetro (Nunamaker et al., 1991). Entretanto, a seguir, será considerada a classificação utilizada por Borges et al., que possui pontos comuns com a de Ellis et al. (Ellis et al., 1991; Borges et al., 1995). Esta classificação não se baseia nos parâmetros de tempo, espaço ou tamanho do grupo. Ela foi construída levando em consideração as principais características funcionais de sistemas CSCW. Neste trabalho, os tipos de sistemas $\mathrm{CSCW}$ foram relacionados com os tipos de encontros definidos na Figura 2.1. São sistemas CSCW:

- Sistemas de Mensagens suportam troca síncrona e assíncrona de mensagens textuais entre os participantes do grupo de cooperação. Exemplos de sistemas CSCW com tal funcionalidade, especificamente, são sistemas de e-mail, lista de interesses e quadros de aviso. Este tipo de sistema pode ser utilizado em qualquer encontro definido na Figura 2.1.

- Sistemas de Co-edição geralmente são editores multi-usuários utilizados por um grupo de pessoas para compor e editar textos e gráficos conjuntamente; alguns permitem a criação de anotações. A maioria desses editores possui característica de comunicação assíncrona. Já no caso de editores síncronos, existe a possibilidade de existência de um editor e vários revisores ou de um editor cooperativo que suporta mecanismos de atualizações para efetuar comunicações síncronas. São exemplos o QUILT (Dourish \& Bellotti, 1992) e o GROVE (Ellis et al., 1991). Naturalmente, sistemas de co-edição com características de comunicação assíncrona deverão ser utilizados em encontros assíncronos ou totalmente distribuídos, e os sistemas síncronos deverão ser utilizados em encontros síncronos ou em encontros face a face.

- Sistemas de Coordenação têm por objetivo coordenar tarefas complexas e inter-relacionadas, juntamente com as informações por elas geradas e utilizadas. Eles pretendem sistematizar e acelerar os processos de trabalho, movendo e coordenando os dados dentro do grupo de 
trabalho. Estes sistemas devem gerenciar dados estruturados, que incluem textos e gráficos. São exemplos os sistemas de Workflow e as ferramentas CASE (Computer Aided Software Engineering) em geral, que podem ser utilizados em qualquer tipo de encontro definido na Figura 2.1.

- Sistemas de Suporte à Reunião foram desenvolvidos com o intuito de apoiar as constantes reuniões, existentes em qualquer tipo de corporação, as quais têm por objetivo discutir problemas e tomar decisões. Este tipo de sistema pode ser basicamente dividido em:

- Sistemas de suporte à decisão (GDSS - Group Decision Support System), que são sistemas interativos que apoiam a solução de problemas utilizando mecanismos de votação, geração de idéias e identificação de alternativas. O IBIS (Conklin \& Begeman, 1987), QOC (Shum \& Hammond, 1994) e o DRL (Lee, 1990) são exemplos de GDSS.

- Salas eletrônicas, que são sistemas que oferecem ambientes especiais, com suporte de hardware e software para apoiar reuniões face a face, opcionalmente envolvendo estações interligadas em rede, uso de projetores e equipamentos de áudio e vídeo. Salas eletrônicas têm como representante o sistema PlexCenter Planning and Decision Support Laboratory da Universidade do Arizona (Ellis et al., 1991).

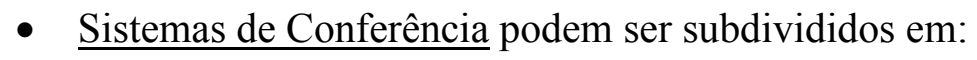

- Sistemas de conferências assíncronas, que são ambientes de encontro onde os participantes "comparecem" de acordo com sua própria disponibilidade, como é o caso de sistemas de newsgroup. Entretanto, este tipo de sistema não oferece condições para que se extraia resultados destas discussões, como fazem os GDSS. Estes sistemas são normalmente utilizados em encontros totalmente distribuídos de acordo com a Figura 2.1.

- Sistemas de conferências síncronas permitem a interação de grupos de usuários, através de terminais de computadores ou workstations. Neste tipo de conferência, os participantes utilizam também recursos de áudio para se comunicarem.

- Teleconferências são sistemas que utilizam recursos de telecomunicação para a transmissão de informações (dados, sons e imagens). Videoconferências são os maiores representantes deste tipo de conferência. Nunes et al. subdividem as teleconferências de acordo com a tecnologia utilizada (Nunes et al., 1998). 
A medida que a área de CSCW evolui, outras aplicações serão incluídas nesta classificação. Aplicações que hoje se destinam ao trabalho individual, em breve, ganharão versões para o trabalho em equipe.

\subsection{SISTEMAS CSCW}

Sistemas CSCW incluem sistemas de conferência (por exemplo, WIT, IRC, Yarn e o HyperNews), sistemas de mensagens (por exemplo, HyperMail), sistemas de videoconferência (por exemplo, CuSeeMe), sistemas de co-edição de textos ou gráficos (por exemplo, Collage), e, inclusive, sistemas que trabalham em realidade virtual com interação de multi-usuários (por exemplo, MUDS). As aplicações apresentadas a seguir são exemplos de sistemas CSCW que implementam mais de uma característica funcional identificadas na seção anterior:

- Alliance (Decouchant \& Salcedo, 1996) é um groupware que permite comunicação entre os participantes e a produção cooperativa de documentos estruturados.

- BSCW (Bentley et al., 1996) possui características funcionais para a implementação da comunicação e cooperação na WWW.

- CORE2000 (Collaborative Research Environment) é um ambiente que acopla funcionalidades cooperativas (videoconferência, votação, compartilhamento de arquivos, acesso a instrumentos remotos, compartilhamento de tela para co-edição - inclusive de objetos 3D - e para co-anotação) disponíveis na WWW (NCSA, 1998).

- $\quad$ DreSS (Bra \& Aerts, 1996) permite aos autores armazenarem e atualizarem documentos em servidores WWW sem utilizar funcionalidades da Internet como login, ftp ou e-mail. Estas facilidades cooperativas decorrem do fato dos documentos serem armazenados em espaços compartilhados no servidor WWW.

- QUORUM (Borges et al., 1995) é um sistema CSCW específico para suporte a decisão em grupo. Ele apóia tarefas de discussão, argumentação, estruturação do problema e possui um método para levar a uma conclusão final.

- SACE-CSCW (Santos et al., 1998a; Santos et al., 1998b) é outro CSCW específico para suporte a decisão em grupo. Sua utilização implica na criação de um grupo e, associado ao grupo, reuniões contendo pautas, agendas e atribuições destinadas a cada membro do grupo. 
- $\underline{\text { Zeno }}$ (Gordon et al., 1996) é também utilizado para decisão em grupo, o qual permite que pessoas localizadas em diferentes partes do mundo participem do processo de decisão através de uma interface gráfica disponível na WWW.

- Sistema de Bacelo \& Becker (Bacelo \& Becker, 1997) é um sistema de apoio à decisão em grupo que suporta reuniões remotas e assíncronas, além de integrar um modelo de argumentação para direcionar a reunião. Ele emprega técnicas de votação que impõem organização da reunião e utiliza o controle de um facilitador.

Além de aplicações específicas como as apresentadas, existem ferramentas, denominadas frameworks ou toolkits, que são utilizadas para a criação de sistemas CSCW. Exemplos significativos são GroupKit (GroupKit, 1998), Habanero (Habanero, 1998), Mushroom (Mushroom, 1998) e Groco (Walther, 1996).

\subsection{SISTEMAS CSCW UTILIZADOS PARA O DOMÍNIO DE ENSINO}

Apesar de alguns sistemas CSCW serem amplamente utilizados em ambientes educacionais, eles não podem ser classificados como sistemas CSCL por não serem construídos com funcionalidades específicas para apoiar os processos de ensino/aprendizagem.

$\mathrm{Na}$ área de educação, os sistemas de mensagens, sistemas de conferência síncrona e assíncrona são os mais utilizados entre alunos e professores para esclarecer dúvidas, distribuir e recolher exercícios, trabalhos e avisos.

Salas eletrônicas têm sido usadas como salas de aula em experimentos que buscam obter uma maior satisfação de alunos e professores, e introduzir novas propostas educacionais adequadas à tecnologia disponível. Nas salas eletrônicas, as aulas são ministradas sincronamente, estando alunos e professor distribuídos geograficamente ou não. Há três cenários para uma aula eletrônica síncrona (Barros, 1994):

- todos os alunos compartilham uma tela onde o professor faz a exposição do assunto;

- o professor interage com os alunos através de mensagens, enviando-lhes exercícios, recebendo e avaliando respostas, e esclarecendo dúvidas; 
- o professor prepara um tutorial a ser seguido pelos alunos, e coloca-se à disposição para esclarecer as suas dúvidas através da troca de mensagens.

Sistemas de co-edição podem ser utilizados por grupos de alunos para desenvolver um trabalho em conjunto. O compartilhamento do objeto em desenvolvimento é importante para permitir a equalização da participação dos membros do grupo sobre o trabalho. Assim, mesmo que ocorra uma divisão de tarefas, os alunos podem participar das tarefas dos outros, por exemplo, fazendo comentários (Araújo, 1995).

Aiken utilizou um sistema de suporte à decisão em grupo para apoiar cursos de Gerência de Sistemas de Informação da Universidade de Mississipi (Aiken, 1992). Os alunos desenvolveram projetos em conjunto e utilizaram ferramentas de apoio para geração de idéias (brainstorming), e para seleção de idéias através de mecanismos de votação. Embora o sistema não usasse formas estruturadas de negociação, os alunos discutiam através de sistemas de mensagens. Segundo Aiken, o grau de envolvimento de satisfação dos alunos e a qualidade dos trabalhos foram muito superiores, comparados com resultados da modalidade convencional de ensino (Aiken, 1992).

Outro trabalho interessante tem sido desenvolvido na linha de suporte a trabalho colaborativo em laboratórios de pesquisa, como apresentado por Kouzes et al. (Kouzes et al., 1996; Kouzes, 1997). O termo Collaboratories foi definido para descrever "um centro de pesquisa sem paredes, no qual pesquisadores podem realizar suas pesquisas independentemente de localização geográfica, podendo interagir com colegas, ter acesso a instrumentos, compartilhar dados e recursos computacionais, e acessar informações em bibliotecas digitais" (Kouzes et al., 1996). Um dos objetivos específicos desses ambientes é suportar a colaboração do tipo "professorestudante", na qual o aluno pode aprender técnicas de aquisição ou análise de dados, por exemplo. Entre os recursos de tal ambiente estão os providos por sistemas CSCW como, por exemplo: ambiente de videoconferência, ambiente de chat e compartilhamento de tela de computador, de electronic notebooks, de arquivos e de whiteboards. 


\subsection{CONSIDERAÇÕES FINAIS}

Observa-se, do levantamento bibliográfico apresentado, que são muitas e diversas as características encontradas em sistemas CSCW em geral, e sistemas CSCW aplicados ao ensino em particular.

No próximo capítulo são apresentadas as principais características de alguns trabalhos que visam explorar o uso dos computadores como ferramenta de apoio ao ensino. Os ambientes apresentados incluem sistemas CSCL (ambientes cooperativos destinados exclusivamente para apoiar o processo de ensino/aprendizagem) e ambientes para a autoria, estruturação e distribuição de material didático. 


\subsection{CONSIDERAÇÕES INICIAIS}

Sistemas CSCL (Computer Supported Cooperative Learning) são ambientes computacionais que implementam processos de apoio à cooperação para possibilitar a realização de tarefas de ensino/aprendizagem em grupo (Borges et al., 1995).

No contexto da exploração da tecnologia de sistemas hipermídia para aplicações no domínio de ensino, ênfase tem sido dada ao provimento de ambientes para criação de material por um professor isoladamente. Muitas vezes, entretanto, os ambientes integram alguma funcionalidade para apoio ao trabalho colaborativo entre professores e alunos. Estes ambientes, sejam colaborativos ou não, são aqui classificados como ambientes de autoria, estruturação e distribuição de material didático.

Os sistemas CSCL e os ambiente de autoria e distribuição de material didático são apresentados respectivamente nas Seções 3.2 e 3.3 deste capítulo.

\subsection{SISTEMAS CSCL}

Para obter uma visão geral das soluções existentes para apoio computacional ao estudo cooperativo foram pesquisados alguns sistemas CSCL. Esses sistemas são apresentados a seguir.

\subsubsection{ACD}

ACD (Aprendizagem Cooperativa a Distância) é um site brasileiro que abriga as atividades cooperativas mais marcantes da Biblioteca Virtual do projeto Kidlink-Br (Santos \& Ferreira, 1998). O hiperdocumento ACD possui forma quase linear para evitar a desorientação dos usuários e a sobrecarga cognitiva (Santos, 1998). As principais atividades do 
site incluem seminários, tutoriais, salas para estudo individual ou em grupo, oficinas de aprendizagem e infra-estrutura para curso.

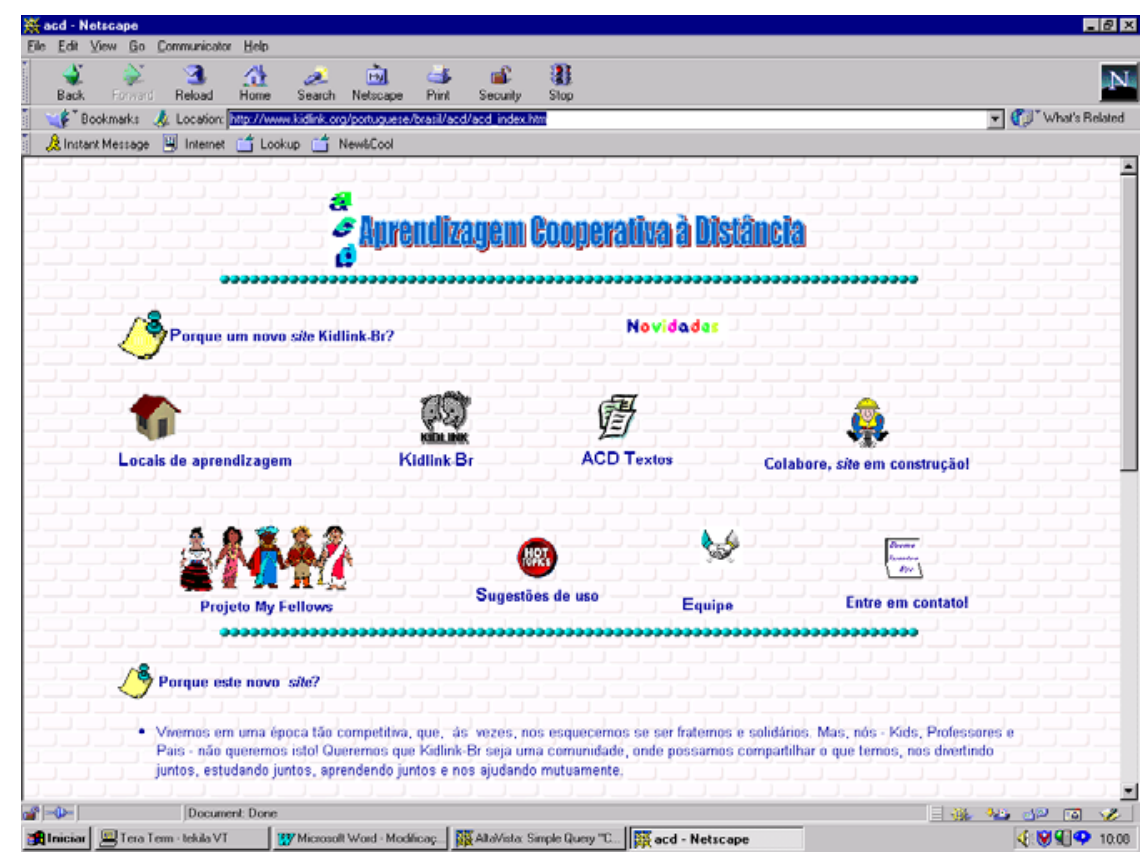

Figura 3.1 - Página principal do site ACD (ACD,1998)

$\mathrm{Na}$ oficina de aprendizagem, o aprendiz tem a oportunidade de participar de soluções cooperativas de problemas, através do ambiente WebSaber apresentado a seguir (WebSaber,1998). O AulaNet (Lucena et al., 1998), apresentado na Seção 3.3, foi utilizado para a composição dos cursos e seminários apresentados pelo ACD. Tanto o WebSaber quanto o AulaNet podem ser acessados através do ACD.

\subsubsection{ARCOO}

O ARCOO (Aprendizagem Remota Cooperativa Orientada a Objetivos) foi desenvolvido com o objetivo de apoiar aprendizagem cooperativa em ambientes distribuídos, onde ocorre interação entre pares na busca da solução de um problema durante a realização de um projeto (Barros, 1994).

A metáfora adotada no ambiente é a sala de estudos. O estudante envolvido com um projeto irá desencadear a aprendizagem de novos conceitos ou o aprofundamento de outros já 
desenvolvidos em sala de aula. As salas de estudo possuem os seguintes recursos: estantes de livros, arquivos com informações, telas para assistir conferências e "auxiliares invisíveis".

O ambiente ARCOO é formado por quatro subsistemas, com as seguintes funcionalidades:

- subsistema de socialização - gerencia a comunicação entre os participantes do grupo de três formas distintas: conversa, reuniões face a face e conferências;

- subsistema de solução de problemas - permite o co-planejamento (divisão das tarefas e o planejamento das atividades), a co-execução (execução das tarefas individualmente utilizando ferramentas externas ao ambiente e posterior integração dos resultados) e a co-avaliação (através de comentários durante as reuniões) das tarefas do grupo;

- subsistema de co-gestão - permite a definição e manutenção da organização temporal das atividades do grupo;

- subsistema de modelagem do conhecimento - permite a criação e manutenção de mapas de conceitos e bases de informações que comporão o conhecimento coletivo, criando a memória compartilhada em um hiperdocumento.

\subsubsection{Belvedere}

Belvedere é um ambiente cooperativo para suporte à prática de discussão crítica de teorias científicas e questões política (Belvedere, 1998). O ambiente também fornece facilidades para edição de documentos que podem ser acessados e copiados pelos estudantes. A utilização destas facilidades levou à construção de algumas coleções de informações em vários campos de conhecimento científico. Estas coleções de informações estão disponíveis através do Belvedere.

Inicialmente o Belvedere foi implementado em LISP e tinha como plataforma exclusiva máquinas Macintosh (Figura 3.2a). Entretanto, ele foi estendido para servir como um browser WWW, através de implementações de applets Java, permitindo que autores utilizem ferramentas HTML existentes, e para referenciar páginas WWW que contenham informações relevantes à discussão (Figura 3.2b). 


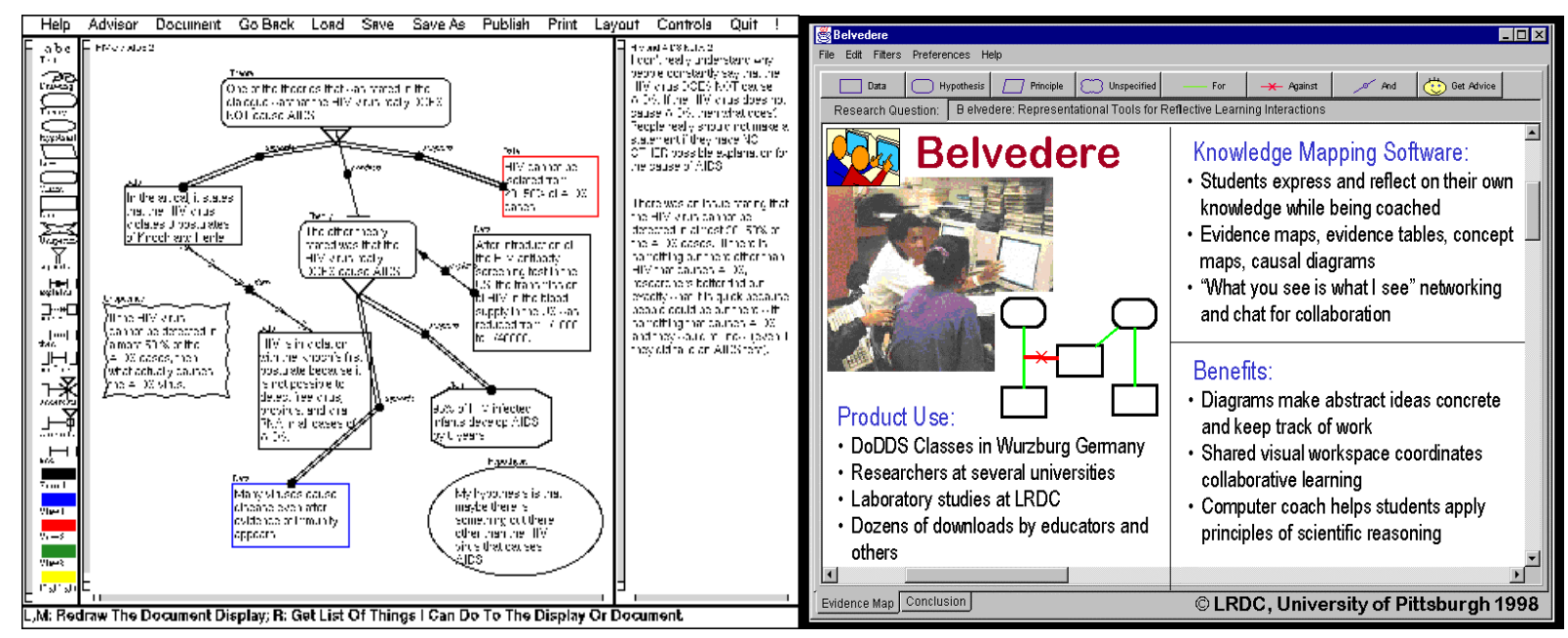

(a)

(b)

Figura 3.2 - (a) Belvedere para Macintosh e (b) Belvedere para WWW (Belvedere, 1998)

Atualmente, os desenvolvedores do Belvedere estão projetando documentos SGML que representem a estrutura lógica e retórica do ambiente.

\subsubsection{Collaboratory Notebook}

O Collaboratory Notebook é um ambiente multimídia em rede que estende a metáfora do notebook do laboratório do cientista, através de facilidades para compartilhar questionamentos entre os parceiros em projetos científicos que podem estar geograficamente distribuídos (O’Neill et al., 1995). O sistema fornece uma estrutura de suporte a diálogos científicos, direcionada para as tentativas do aluno de aprender sobre ciência através de projetos.

A base de dados do Collaboratory Notebook é baseada na metáfora de uma biblioteca, e os elementos de interface são prateleiras de livros, notebooks e páginas. As páginas escritas pelos usuários são associadas a ícones que descrevem seu conteúdo e em seguida são relacionadas através de ligações hipertexto a outras com o mesmo tipo de conteúdo.

\subsubsection{WebSaber}

O WebSaber é um ambiente construído sobre a Internet, voltado para a resolução cooperativa de problemas (WebSaber, 1998). O ambiente está organizado segundo um modelo de hipertexto e é 
apoiado pelo editor cooperativo Microsoft NetMeeting (NetMeeting, 1999), um bloco de notas e em algumas ferramentas de comunicação e cooperação (lista de discussão e chat) da Internet.

O WebSaber propõe que o problema a ser resolvido seja analisado, que algumas hipóteses sejam levantadas, ainda que de forma não explícita, e que se procure chegar à solução seguindo etapas de coleta exaustiva de informação, pré-seleção de idéias potencialmente relevantes, depuração, seleção e testes destas idéias através das etapas de planejamento e execução da solução.

O sistema visa fornecer um ambiente amigável para o trabalho educacional cooperativo, através da metáfora de uma sala de reunião (Meeting Room) composta de:

- Hall - que apresenta a relação de problemas disponíveis;

- SittingRoom - com bloco de notas, formulários para cadastro de participantes, agenda para as sessões de chat (Conferencing Room), lista de discussão e cronograma de atividades;

- WorkRoom - que apresenta links para: o editor cooperativo, as sessões de chat, a lista de discussão e os bloco de notas.

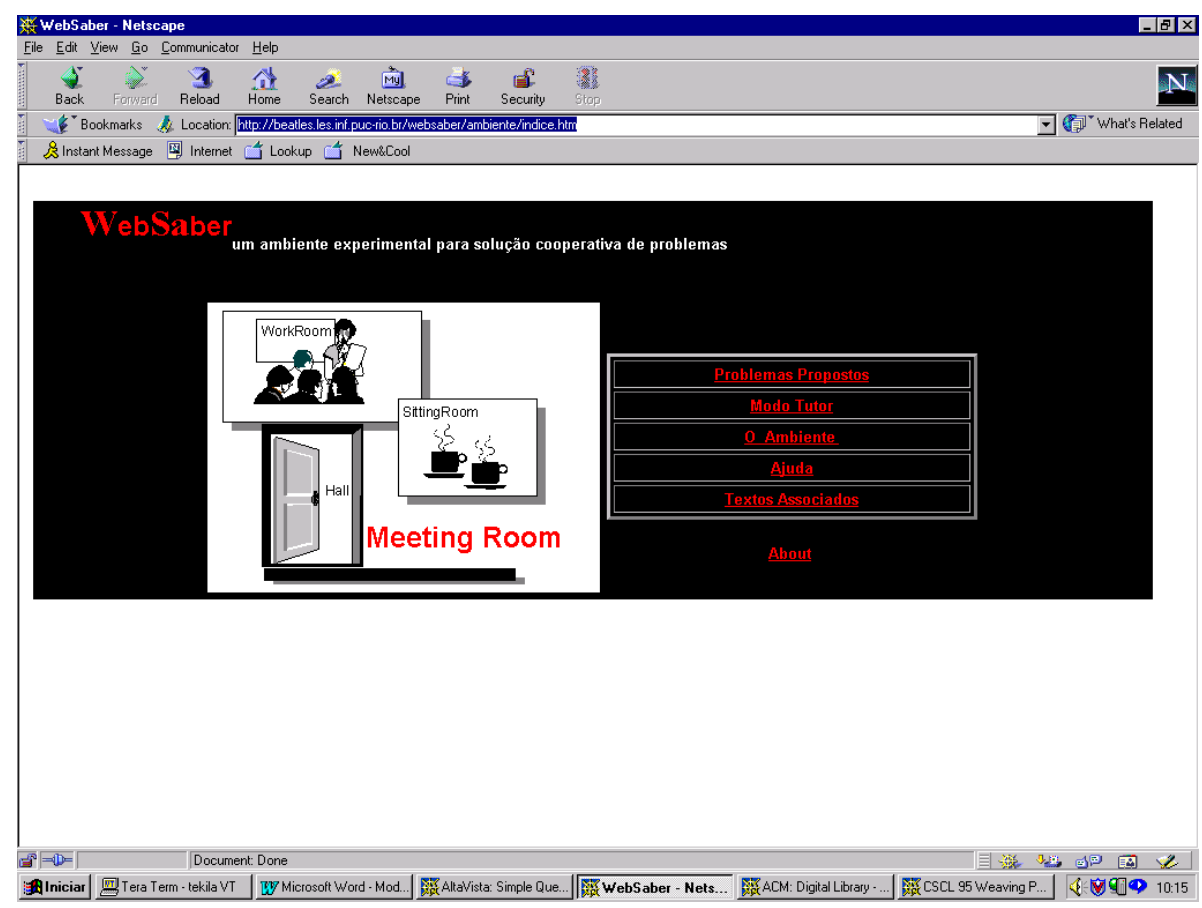

Figura 3.2 - Página principal do site WebSaber (WebSaber, 1998) 


\subsubsection{CSILE}

CSILE (Computer Supported Intentional Learning Environments) é um ambiente educacional cooperativo multimídia com uma base de dados coletiva, em rede, disponível para todos os participantes. A base de dados é composta de nós que contém anotações textuais ou gráficos de estudantes (CSILE, 1999).
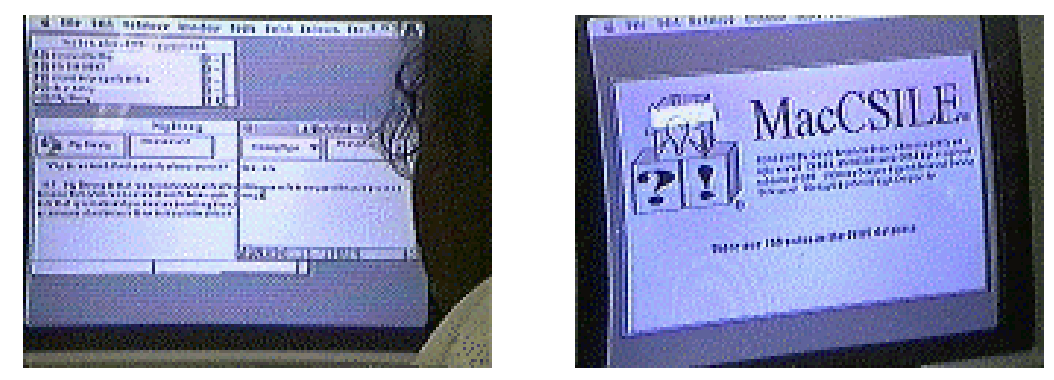

Figura 3.4 - CSILE (CSILE, 1999)

Estudantes geram os nós contendo suas idéias relevantes ao tópico em estudo. Estes nós, que devem ser identificados pelo autor, são indexados e organizados de maneira que possam ser acessados por outros estudantes que estudam diferentes tópicos. Os estudantes produzem informação, formulam questões, provêem feedback e avaliação.

\subsubsection{CaMILE/WebCaMILE}

CaMILE (Collaborative and Multimedia Interactive Learning Environment) é um ambiente assíncrono de suporte à cooperação (Guzdial et al., 1997). Seu objetivo é estimular a aprendizagem através de foruns de discussões com múltiplos grupos ou uma classe inteira. Similar ao CSILE, o CaMILE solicita ao estudante a identificação do tipo de nota (comentário, nova idéia, questão, refutação) que ele está adicionando. São oferecidas sugestões de frases iniciais para serem adicionadas a cada um dos tipos de nota. A diferença fundamental entre o CaMILE e o CSILE é que o CaMILE possibilita a integração de elementos multimídia às notas. Uma versão do CaMILE para WWW foi denominada de WebCAMILE. Todos os acessos ao WebCAMILE são realizados através de um browser Web que acessa um único servidor. 
As discussões neste ambiente são contextualizadas como em newsgroup, porém, o contexto é persistente, e está sempre disponível para os usuários, não desaparecendo após a visualização (Figura 3.5a). Quando o usuário selecionar uma nota através de qualquer link de nota da Figura 3.5a, uma nova página Web será criada com as seguintes informações sobre a nota selecionada: tipo, autor, título, conteúdo e links para objetos multimídia (Figura 3.5b).

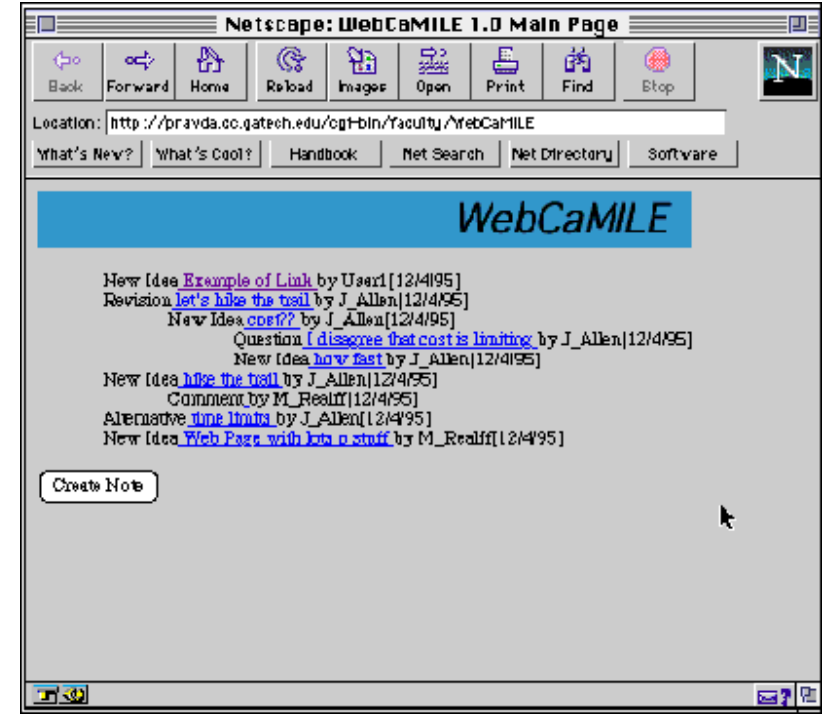

(a)

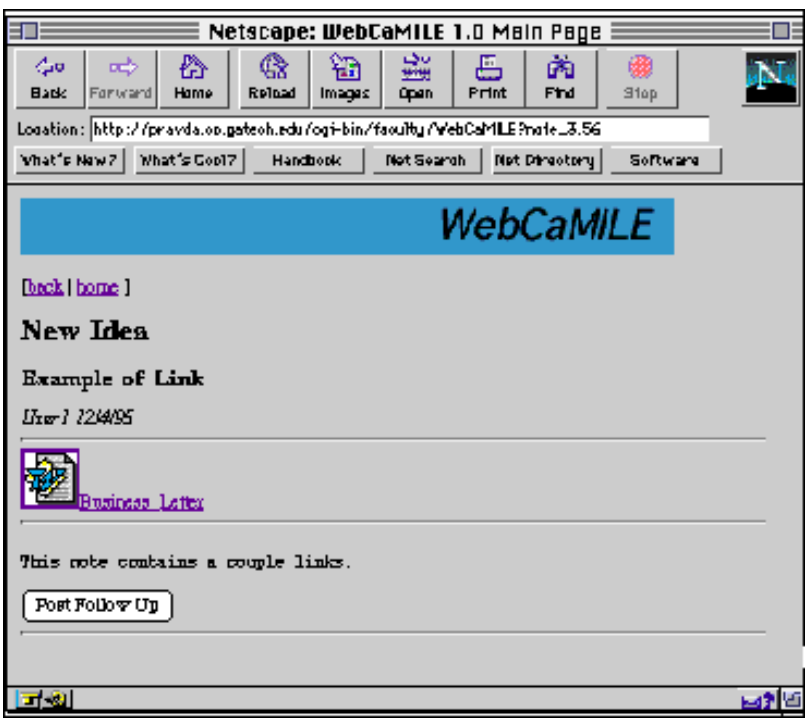

(b)

Figura 3.5 - (a) página inicial e (b) página de apresentação de nota do Web-CaMILE (Guzdial, 1998)

No caso do usuário pressionar o botão "Create Note", aparecerá uma página como a da Figura 3.6a. Nela, o usuário deverá identificar o tipo de nota a ser criada e ele poderá começar a editá-la pressionando o botão "Start Composing Note". Durante a composição da nota algumas informações deverão ser fornecidas: título da nota, tipo da nota, autor da nota e o texto a ser inserido (Figura 3.6b). 


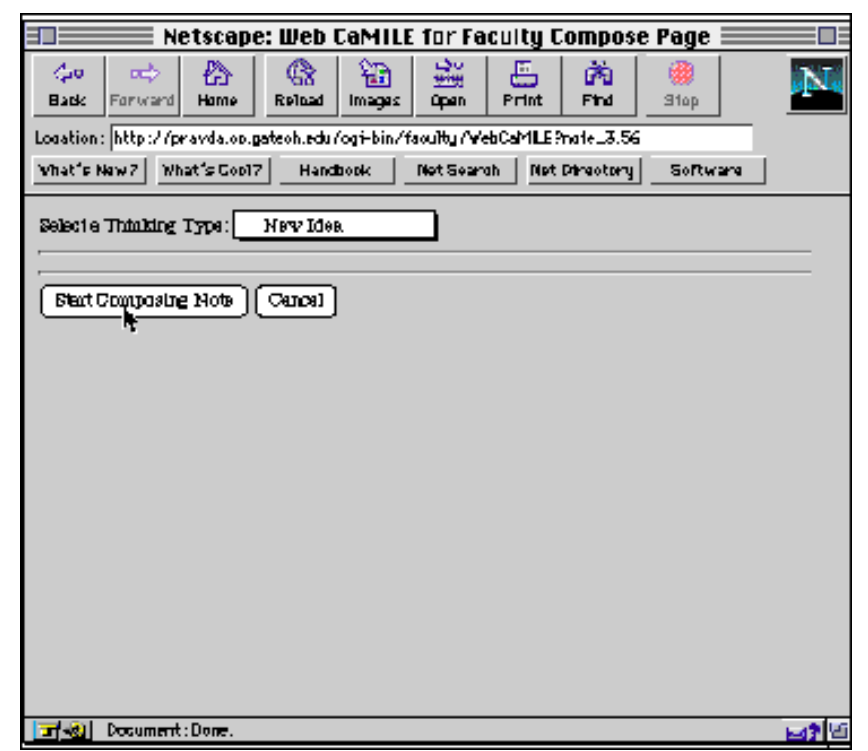

(a)

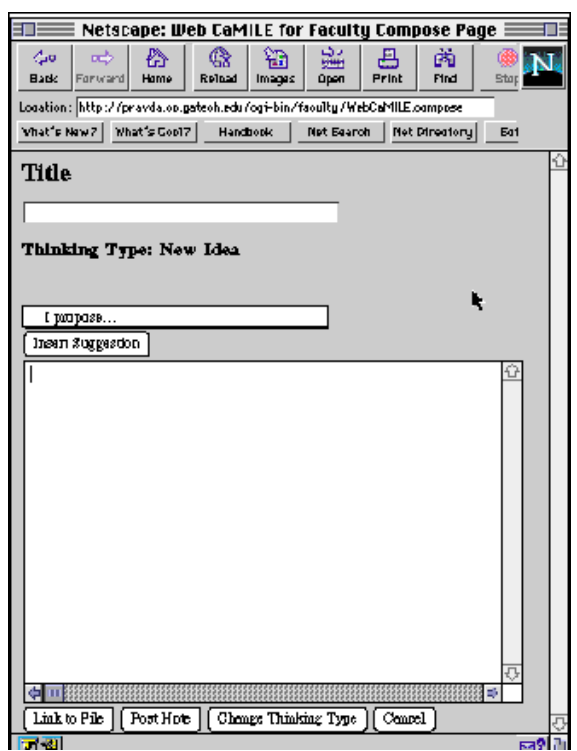

(b)

Figura 3.6 - (a) página de criação de nota e (b) página de edição de nota do Web-CaMILE (Guzdial, 1998)

\subsubsection{SMILE/Web-SMILE}

SMILE é um ambiente cooperativo de estudo suportado por computador, que fornece aos estudantes uma área para armazenamento de suas idéias e conhecimentos (whiteboard) (Figura 3.7a) e outra para a discussão de conceitos e soluções (Figura 3.7b). Esta característica é bastante vantajosa, pois permite a ocorrência de interação em diferentes níveis. A transferência de informações entre as áreas é bastante fácil e rápida. Todas as outras características de cooperação deste ambiente são similares às do CaMILE. Para a disponibilização do SMILE na WWW foi criado o Web-SMILE (Gudzial et al., 1997).

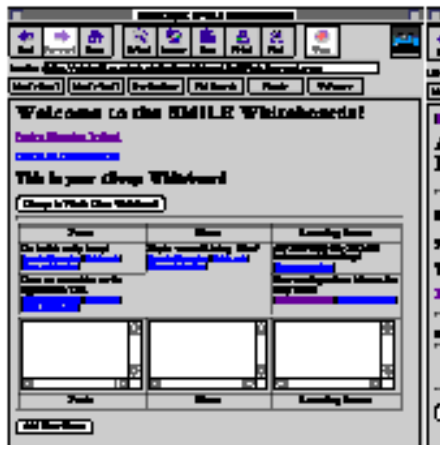

(a)

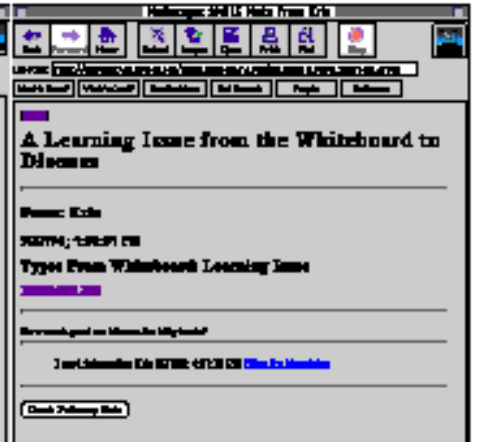

(b)

Figura 3.7 - (a)Whiteboard e (b) área de discussão do Web-SMILE (Guzdial et al., 1997) 


\subsubsection{Classificação dos sistemas CSCL}

Os ambientes apresentados foram classificados, no contexto deste trabalho, de acordo com os seguinte aspectos: (a) teoria de aprendizagem adotada pelo ambiente, (b) metáfora utilizada, (c) domínio de aplicação, (d) tipo de comunicação existente no ambiente, (e) grau de interação do usuário, (f) plataforma de utilização do ambiente e (g) relação com outras áreas. O resultado desta classificação é apresentado na Tabela 3.1.

A Tabela 3.1 permite notar que a maioria dos ambientes estudados fundamenta-se em teorias de aprendizagem construtivistas e tem como enfoque a construção colaborativa de algum tipo de conhecimento ou a solução de problemas de modo colaborativo. O ACD não apresenta referências explícitas à base teórica de aprendizagem. Ainda analisando a Tabela3.1, percebe-se que a maioria dos sistemas CSCL possui um bom grau de interação do usuário com o sistema. Tal aspecto é decorrente da satisfatória exploração das tecnologias de comunicação (síncrona e/ou assíncrona) disponíveis. Outro aspecto extremamente marcante foi o fato da maioria dos ambientes serem disponíveis para utilização na WWW. O SMILE e o CaMILE inicialmente foram construídos para serem utilizados em plataforma Macintosh mas, posteriormente foram desenvolvidas versões para a WWW. 
Tabela 3.1 - Classificação dos sistemas CSCL

\begin{tabular}{|c|c|c|c|c|c|c|c|}
\hline 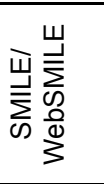 & $\begin{array}{l}0 \\
\sum^{\infty} \\
\sum^{ \pm} \\
0 \\
0 \\
0 \\
0\end{array}$ & 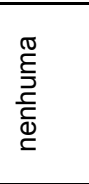 & 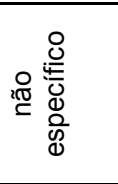 & 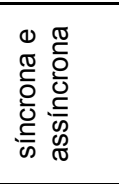 & 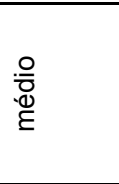 & 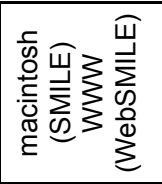 & 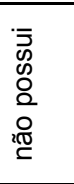 \\
\hline 崖 & 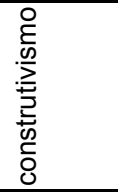 & 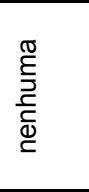 & 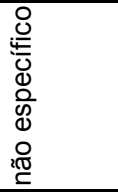 & $\begin{array}{l}\frac{\pi}{0} \\
\frac{0}{0} \\
\frac{0}{0} \\
0 \\
0 \\
0\end{array}$ & 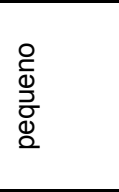 & 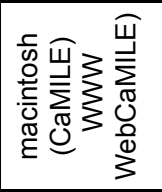 & 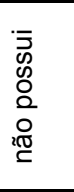 \\
\hline$\frac{\text { U్ }}{\bar{D}}$ & 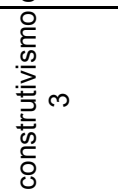 & 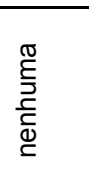 & 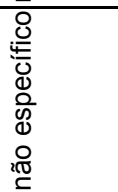 & 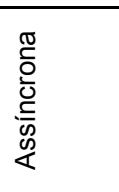 & $\begin{array}{l}\stackrel{\circ}{\circ} \\
\stackrel{\oplus}{\varepsilon}\end{array}$ & 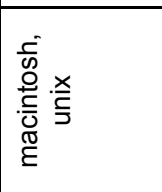 & 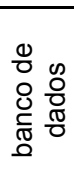 \\
\hline $\begin{array}{l}\overline{0} \\
\frac{1}{0} \\
0 \\
0 \\
0 \\
3\end{array}$ & 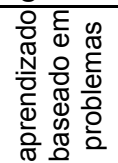 & 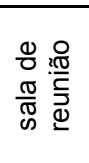 & 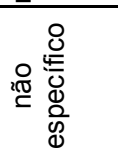 & 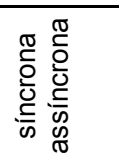 & $\begin{array}{l}\stackrel{\circ}{\overline{0}} \\
\stackrel{\oplus}{\varepsilon}\end{array}$ & $\sum_{3}^{3}$ & 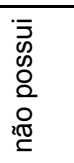 \\
\hline 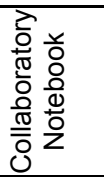 & 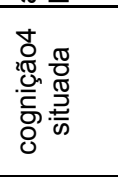 & 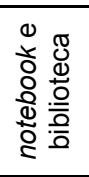 & 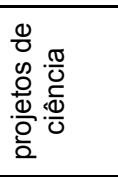 & $\begin{array}{l}\frac{\pi}{2} \\
\frac{0}{0} \\
\frac{0}{0} \\
\frac{0}{0} \\
\frac{0}{4}\end{array}$ & $\begin{array}{l}\stackrel{\circ}{\overline{0}} \\
\stackrel{\mathscr{\varrho}}{\varepsilon}\end{array}$ & 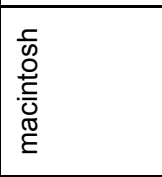 & $\begin{array}{l}0 \\
0 \\
0 \\
0 \\
0 \\
0 \\
0 \\
0 \\
0 \\
0\end{array}$ \\
\hline $\begin{array}{l}\frac{0}{\Phi} \\
\frac{0}{0} \\
\stackrel{\infty}{D} \\
\infty\end{array}$ & 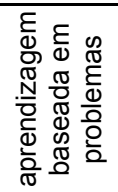 & 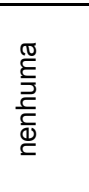 & 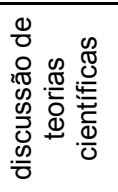 & 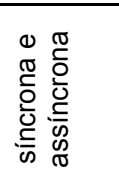 & $\begin{array}{l}\frac{0}{0} \\
\frac{\pi}{\pi} \\
\frac{\pi}{\sigma}\end{array}$ & 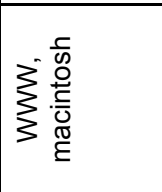 & 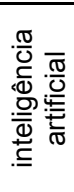 \\
\hline $\begin{array}{l}8 \\
\text { O } \\
\frac{x}{4}\end{array}$ & 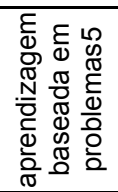 & 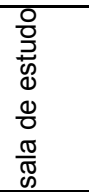 & 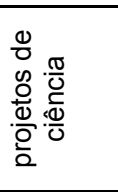 & 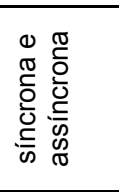 & $\begin{array}{l}\frac{0}{0} \\
\frac{\pi}{\pi} \\
\frac{\pi}{\sigma}\end{array}$ & 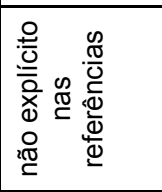 & 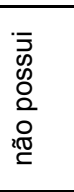 \\
\hline O) & 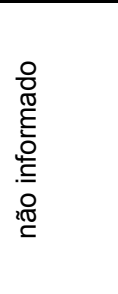 & 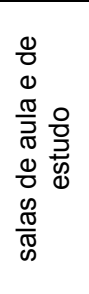 & 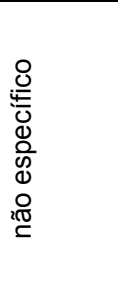 & $\begin{array}{l}\frac{\pi}{0} \\
\frac{0}{0} \\
\frac{0}{0} \\
0 \\
0 \\
0 \\
0 \\
\frac{\pi}{0} \\
\frac{0}{0} \\
\frac{0}{\omega}\end{array}$ & $\begin{array}{l}\frac{0}{0} \\
\frac{\pi}{\pi} \\
\frac{\pi}{\sigma}\end{array}$ & $\sum_{3}^{3}$ & 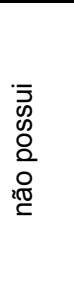 \\
\hline 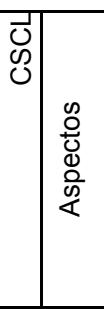 & 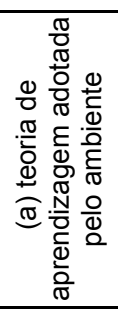 & 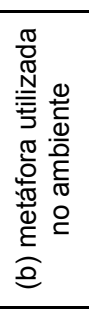 & 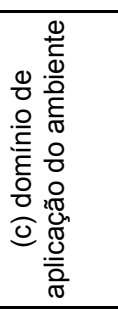 & 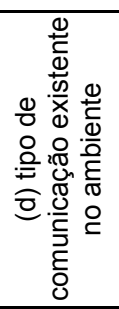 & 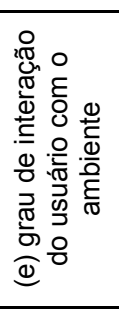 & 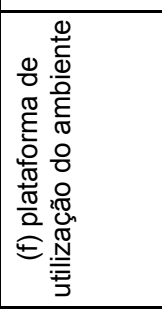 & 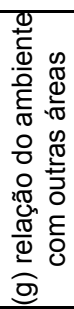 \\
\hline
\end{tabular}

\footnotetext{
${ }^{3}$ No construtivismo o aprendiz é participante ativo no processo de aquisição de conhecimento. A instrução é relacionada a contextos e experiências pessoais

${ }^{4}$ Aprendizagem ocorre em função da atividade, contexto e cultura e ambiente social na qual está inserida

${ }^{5}$ Esta teoria se inicia com um problema a ser resolvido. Ela é centrada no aprendiz e contextualizada
} 


\subsection{AMBIENTES DE AUTORIA E DISTRIBUIÇÃO DE MATERIAL DIDÁTICO}

A seguir são apresentadas ferramentas para criação de material didático por um professor isoladamente. Estas ferramentas podem integrar funcionalidades para apoio ao trabalho colaborativo entre professores e alunos.

\subsection{1 eWeb}

O ambiente eWeb, desenvolvido em 1996 por Young Zhao, da Michigan State University, Estados Unidos, é baseado em um servidor WWW.

eWeb oferece um conjunto de ferramentas multifuncionais para a criação de cursos, propiciando aos autores a inclusão, o desenvolvimento e o gerenciamento de materiais multimídia a fim de conduzir projetos de aprendizagem colaborativa, observar, monitorar e informar o desempenho dos estudantes (eWeb, 1997). Em particular para apoio ao trabalho colaborativo, o ambiente eWeb fornece ferramentas CSCW tradicionais integradas ao seu contexto (Figura 3.8). Assim, o conjunto de ferramentas inclui:

- eWeb Forum - ambiente estruturado para produção de projetos colaborativos.

- eWeb Bulletin Board - plataforma para publicação de mensagens para um grupo de alunos, ou uma turma, como um todo.

- eWeb Assignments - local para a publicação de questões a serem discutidas.

- eWeb_Chat - espaço para discussões on line em qualquer tópico, fornecendo transcrições das mensagens trocadas nas sessões de $c h a t$. 


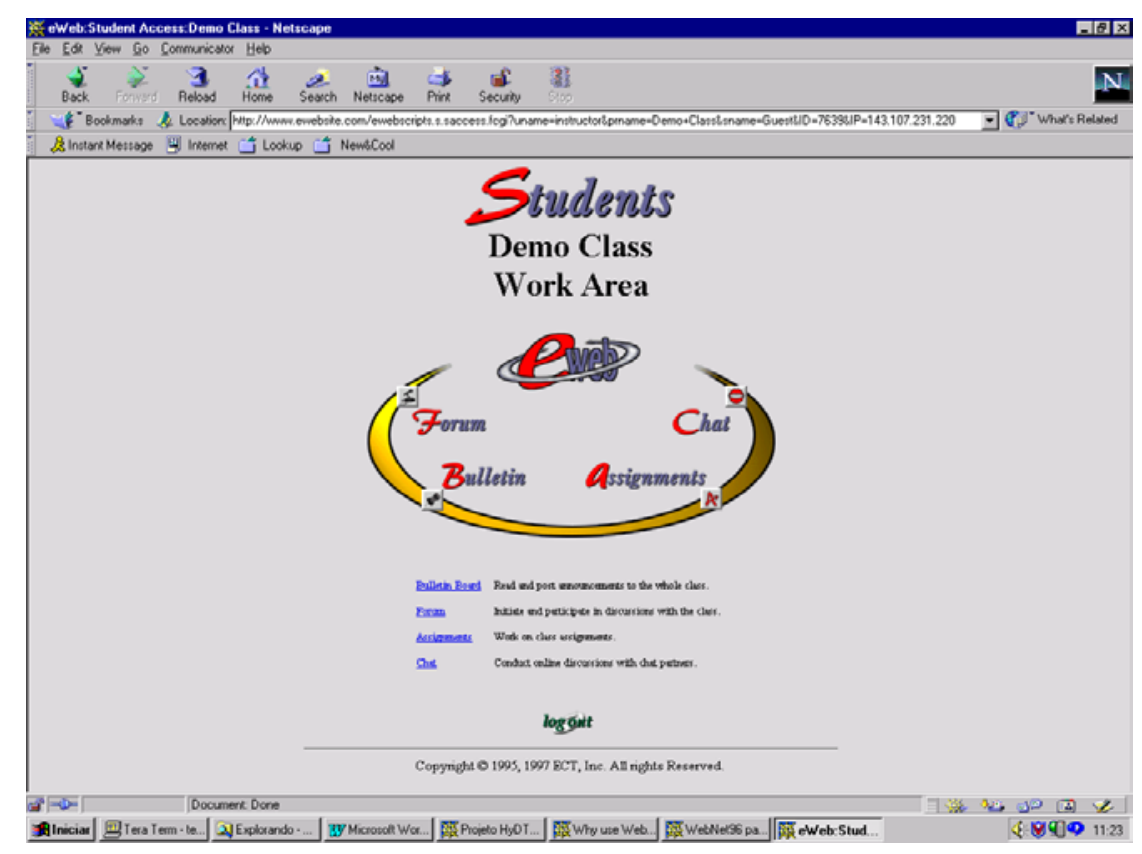

Figura 3.8 - eWeb com as ferramentas CSCW (eWeb, 1997)

\subsubsection{WebCT}

WebCT, criado pelo grupo de Murraw W. Goldberg, da University of British Columbia, Canadá, em 1996, consiste em um conjunto de ferramentas que apóia a criação e o estudo de cursos educacionais baseados no ambiente WWW (WebCT, 1997).

O ambiente WebCT é apresentado aos usuários, alunos e professores, como um documento principal, a partir do qual se tem acesso aos tópicos dos cursos e às demais ferramentas disponíveis para criação de material educacional. Nesse ambiente, através do módulo de criação de cursos apresentado na Figura 3.9, o professor pode criar material didático e acompanhar o desempenho dos alunos. Tanto aluno como professores dispõem de correio eletrônico e ambientes de navegação pelo material didático criado.

Em particular para suporte ao trabalho cooperativo, o WebCT oferece ferramentas de bulletin board e chat similares ao ambiente eWeb. 


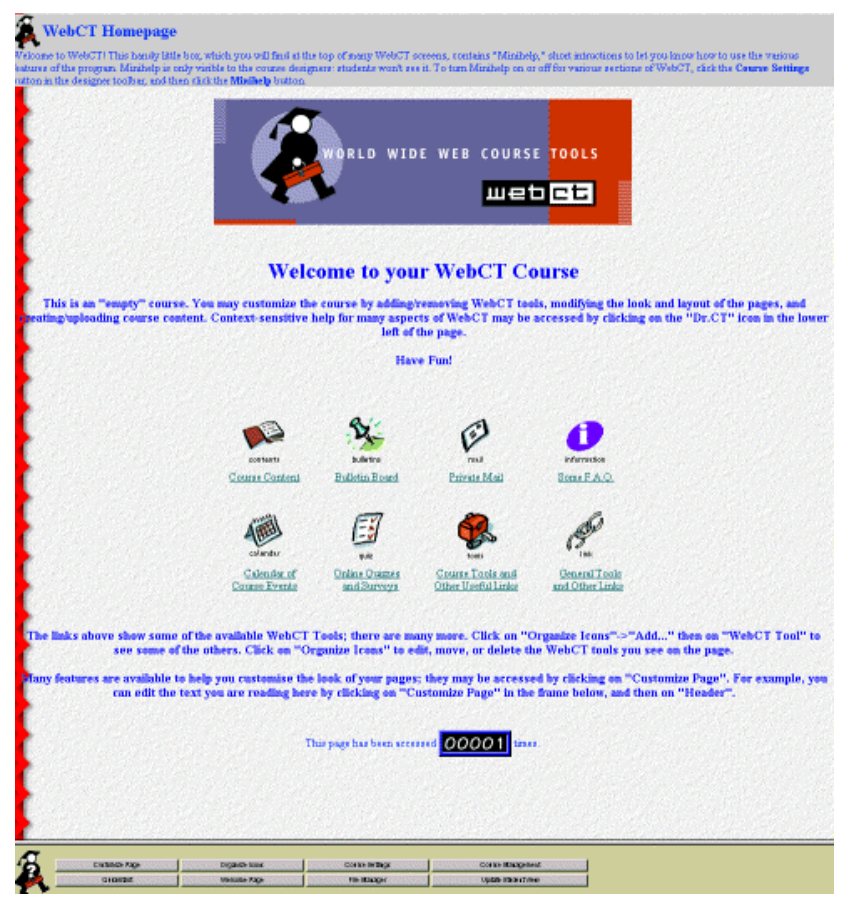

Figura 3.9 - Página principal do módulo de construção curso do WebCT (WebCT, 1997)

\subsubsection{AulaNet}

AulaNet é um ambiente para desenvolvimento de cursos baseados na Web criado pelo grupo do Laboratório de Engenharia de Software da Puc-Rio (Lucena et al, 1998). Lucena diferencia o AulaNet dos outros ambientes de autoria de material didático, enfatizando que a maioria deles é courseware, isto é, ambientes apenas de edição e apresentação do material, enquanto que o AulaNet enfatiza aspectos de learningware ao combinar as características do courseware com várias formas de interação entre os aprendizes e entre o aprendiz e o professor.

Explorando ferramentas freeware disponíveis na Internet, o AulaNet provê suporte a uma série de recursos didáticos (Grupo de Interesse, Grupo de Discussão e Debate), os quais são mapeados para serviços AulaNet suportados por ferramentas associadas (Lucena et al, 1998).

Para suporte aos recursos didáticos "Grupo de Interesse" e "Grupo de Discussão" são associados, respectivamente, os serviços de news e listas de discussão. Já ao recurso de "Debate" estão associados serviços de chat e videoconferência. A página de apresentação do AulaNet pode ser visualizada na Figura 3.10. 


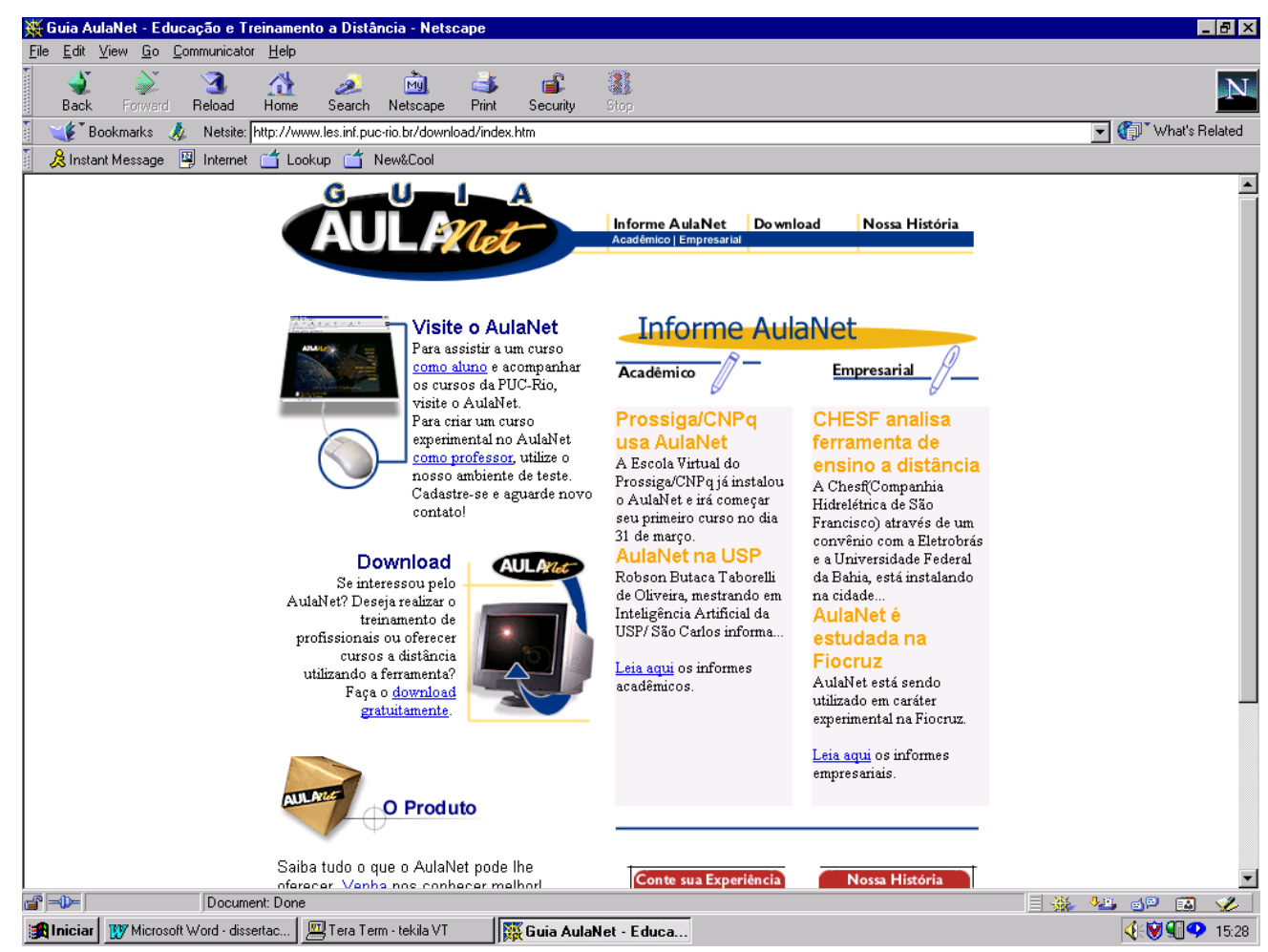

Figura 3.10 - Página principal do site do AulaNet (AulaNet, 1999)

\subsubsection{InterBook}

InterBook é um ambiente de autoria e publicação de livros-texto adaptativos na WWW (Brusilovsky et al., 1996). Os livros-texto são compostos basicamente por duas unidades: glossário e conteúdo. O conteúdo corresponde a um conjunto de nós que descreve o domínio da aplicação. Já o glossário é considerado a estrutura visual representativa deste conjunto de nós. Cada nó do domínio é representado por uma entrada do glossário, e as ligações entre os nós especificam os caminhos de navegação. Além disso, cada entrada do glossário possui ligações para todas as seções do livro-texto que introduzem o conceito do nó. Pode-se notar que os glossários dos livros-texto, criados no InterBook, integram características de índice e de glossário. A Figura 3.11 ilustra uma página de um livro-texto criado com o auxílio do InterBook.

Um livro-texto é estruturado hierarquicamente em unidades com diferentes níveis: capítulos, seções e subseções. Durante o processo de autoria, o autor fornece os títulos das unidades e para cada um deles, ele pode inserir uma anotação com um conjunto de conceitos relacionados com a unidade e o papel (pré-requisito ou resultado) do conceito na unidade (Brusilovsky et al., 1996). 


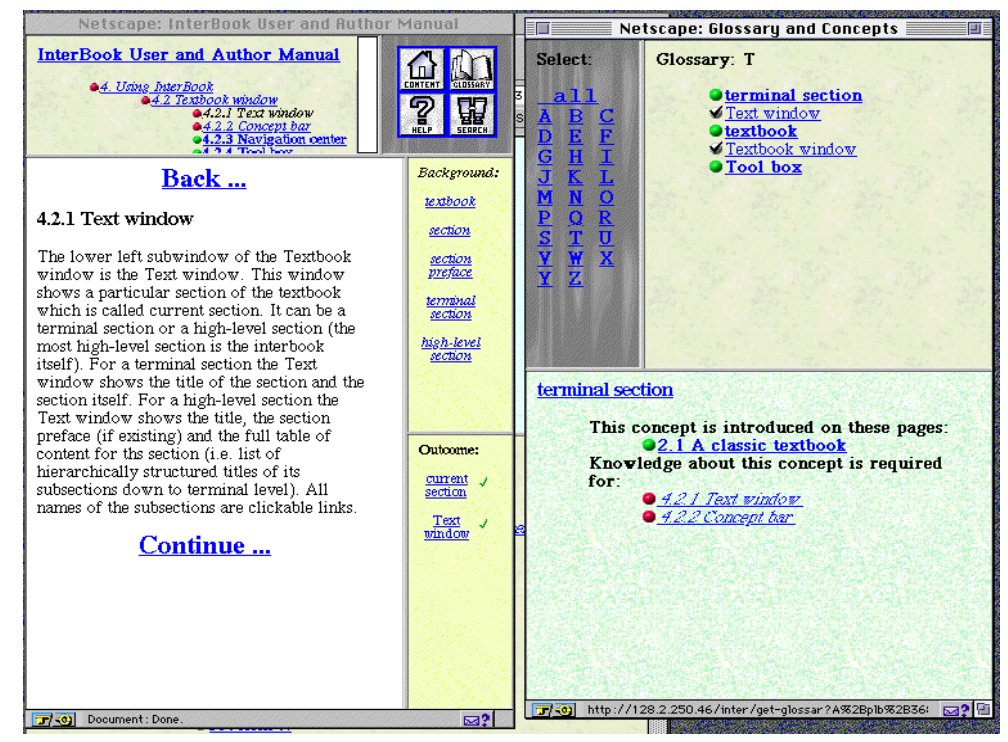

Figura 3.11 - Livro-texto com glossário e conteúdo (Brusilovsky et al., 1996)

\subsubsection{Interland}

Interland é um sistema direcionado para atividades de treinamento e ensino assistido, no qual animações, vídeos, simulações e hiperdocumentos podem ser utilizados como ferramentas de auxílio ao aprendizado (Castro et al., 1997). Os módulos implementados baseiam-se na arquitetura da WWW, e permitem a incorporação de componentes com tarefas específicas a documentos didáticos já existentes. Esses componentes geralmente são utilizados em atividades de acompanhamento e avaliação, enriquecimento do material didático através de vídeo, simulações, e inserção de mecanismos de cooperação/comunicação como chat e videoconferência

\subsubsection{T.A}

T.A (Teaching Assistant) de Castro foi proposto para auxiliar o professor na preparação do material didático dentro do sistema Interland (Castro, 1997). Suas principais funções são: oferecer modelos e conjuntos de páginas WWW, prover ferramentas para o desenvolvimento de componentes com tarefas específicas e uso de recursos interativos e multimídia a serem inseridos no material, apresentar informações dos usuários para avaliação e acompanhamento, e permitir acesso a aplicativos para a montagem de aulas. 


\subsubsection{HyperBuilder/QuestBuilder/TaskBuilder}

HyperBuilder, QuestBuilder e TaskBuilder correspondem a ferramentas que permitem a autoria e publicação de hiperdocumentos didáticos, questionários de avaliação e atividades dirigidas (Pimentel et al., 1998a, 1998c). Os hiperdocumentos são armazenados em um formato que facilita o seu reuso e intercâmbio. Outra contribuição destas ferramentas ao processo de criação do material didático é que o autor não precisa ter conhecimentos prévios sobre detalhes técnicos das linguagens de desenvolvimento de documentos para WWW. As ferramentas atuam como uma camada que separa os usuários dessas tecnologias.

A arquitetura básica para a publicação de cursos didáticos na WWW encontra-se na Figura 3.12a, enquanto que na Figura 3.12b pode ser visualizada a arquitetura estendida com as ferramentas que permitem a autoria, publicação e apresentação de documentos XML manipulados com Java e JavaScript. As setas da Figura 3.12 indicam as Interfaces entre o autor e a linguagem utilizada na WWW.

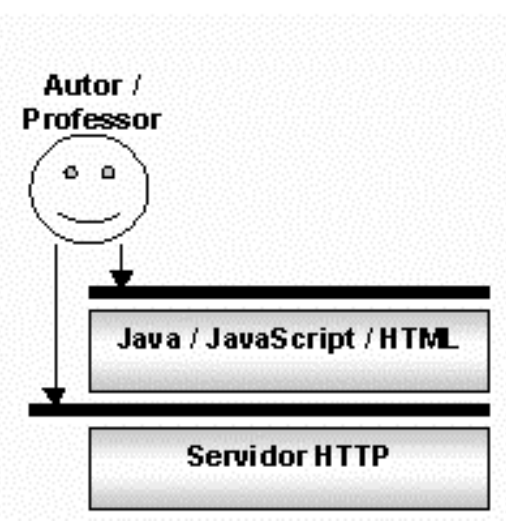

(a)

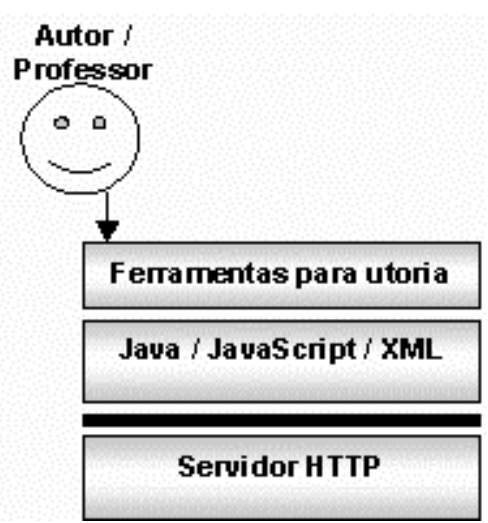

(b)

Figura 3.12 - (a) Arquitetura básica para publicação de cursos na WWW e (b) Arquitetura estendida com HyperBuilder, QuestBuilder e TaskBuilder (Pimentel et al., 1998a, 1998c)

No contexto da arquitetura acima, as ferramentas oferecidas ao autor/professor possuem as seguintes funcionalidades:

- definição de estruturas de hiperdocumentos baseadas em um índice de tópicos de materiais;

- geração automática de roteiros de navegação em relação ao índice de tópicos;

- construção e disponibilização de questionários de avaliação de aprendizado, no qual poderão ser inseridas questões descritivas, de múltipla escolha, verdadeiro e falso e questões de relacionamento de opções (matching); 
- construção de exercícios contendo imagens, textos e testes de múltipla escolha, para serem inseridos no material didático;

- provimentos de mecanismos para publicação de hiperdocumentos de textos didáticos, questionários e exercícios em um servidor HTTP (Hypertext Transfer Protocol), de maneira transparente ao autor.

\subsubsection{SASHE}

SASHE (Sistema de Autoria e Suporte Hipermídia para Ensino) é um ambiente de autoria e navegação de hiperdocumentos para aplicações de ensino (Santos et al., 1997).

No módulo de autoria do SASHE, o autor pode criar hiperdocumentos, desde os mais simples aos mais complexos e com vários níveis de aninhamento. A qualidade do hiperdocumento está diretamente relacionada à estruturação organizacional e de apresentação proposta pelo autor. De modo geral, são apresentados recursos hipermídia do Modelo de Contextos Aninhados (MCA) (Soares et al., 1994), estendidos para conter características existentes em hiperdocumentos de ensino O modelo MCA é um modelo conceitual de dados hipermídia que tem como principal característica o tratamento de nós de hiperdocumentos que podem estar recursivamente aninhados. A construção de roteiro, no SASHE, é flexível, pois permite que o autor defina estratégias e seqüências de aprendizado que o estudante deve observar quando do processo de navegação pelos hiperdocumentos. Para editar o hiperdocumento, conceitos como nó terminal (texto, áudio, gráfico e vídeo), nó de composição (trilha, contexto de usuário) e elo são utilizados.

No módulo de navegação do SASHE, o aluno encontra janelas que apresentam o material didático e botões associados a: caracterização do material (“Está Fácil” e "Está Difícil”), ajuda, apresentação de exercícios, bibliografia, localização do usuário, histórico, forward e backward.

\subsubsection{EHDT/EHDM}

Os ambientes apresentados não utilizam bases metodológicas para a autoria dos hiperdocumentos. Um trabalho multidisciplinar nessa área é apresentado por Pansanato e Nunes, 
que propõem o Método para Projeto de Hiperdocumentos para Ensino (EHDM - Educational Hyperdocuments Design Method). O EHDM provê uma abordagem sistemática para apoiar o projeto e o desenvolvimento de aplicações hipermídia para ensino. O EHDM pode ser utilizado também como base para o desenvolvimento de ferramentas de análise e projeto de hiperdocumentos para ensino. Um protótipo de uma ferramenta, denominado EHDT (Educational Hyperdocuments Development Tool), utiliza o EHDM como base metodológica e foi desenvolvido como uma ferramenta de suporte automatizado integrada ao SASHE (Pansanato \& Nunes, 1999).

\subsection{CONSIDERAÇÕES FINAIS}

Foram apresentados trabalhos que visam explorar o uso dos computadores como ferramenta de apoio ao ensino e ambientes para a autoria, estruturação e distribuição de material didático

Outros trabalhos têm explorado a Web como ambiente para autoria de material colaborativo como suporte ao aprendizado(Guzdial, 1997; Puntambekar et al., 1997). Nesse contexto, aplicações relacionadas a disciplinas específicas, como Computer Aided Design (Guzdial et al., 1998) e ao suporte à aprendizagem com estudo de casos (Shabo et al., 1997), também têm sido desenvolvidas.

A WWW apresenta-se como uma tecnologia capaz de fornecer inúmeros serviços aos pesquisadores da área de ensino à distância, possibilitando a implementação de soluções para o problema do oferecimento de educação e treinamento em larga escala, permitindo a criação e publicação de material didático, a aplicação de tutoriais e a comunicação entre os aprendizes.

No próximo capítulo um sucinto levantamento bibliográfico sobre estruturação e intercâmbio de documentos hipermídia (hiperdocumentos) é apresentado. Ênfase é dada ao padrão XML, proposto para permitir que documentos hipermídia possam ser descritos apenas em termos de estrutura e conteúdo, e assim, processados em quaisquer aplicações, independentemente da plataforma computacional. O padrão XML, apresentado no próximo capítulo, foi utilizado na modelagem e implementação do StudyConf . 


\subsection{CONSIDERAÇÕES INICIAIS}

Algumas classes de documentos possuem uma estrutura bem definida. Um livro, por exemplo, pode possuir título e vários capítulos, os quais, por sua vez, são organizados em seções. Esta estrutura varia significativamente quando se muda o tipo de documento, por exemplo, uma carta.

Alguns documentos também possuem elementos tais como citações, palavras destacadas e palavras de outro idioma, os quais devem ser tratados de maneira diferente (ex: citação) ou apresentados de modo diferente (ex: palavras em idioma). A necessidade de representar os diferentes tipos de estruturas de documentos levou à definições de padrões para representação de documentos.

Um padrão para representação de documentos deve considerar, além da estrutura interna do mesmo, também a possibilidade de ligação entre vários documentos. Essas ligações podem ocorrer, por exemplo, em referências bibliográficas que levam aos documentos originais, ou ainda em palavras-chave, que são interligadas a documentos mais específicos. Quando o leitor ativa/processa uma ligação, ele é levado a outro ponto no mesmo documento ou a um novo documento.

A padronização do formato de representação de diferentes tipos de documentos facilita o intercâmbio das informações contidas nas instâncias de documentos específicos. Esta característica é extremamente importante, visto que o mercado de aplicações hipermídia é atualmente composto por inúmeros fabricantes que utilizam tecnologia proprietária para a codificação e armazenamento de seus documentos.

Nas seções deste capítulo, são brevemente apresentados os padrões SGML e HTML. XML é discutido em mais detalhes, visto que ele é utilizado na formalização de documentos relevantes ao trabalho aqui reportado. 


\subsection{SGML}

O padrão SGML (Standard Generalized Markup Language) foi proposto para permitir que documentos armazenados eletronicamente pudessem ser definidos conforme seu conteúdo e estrutura, independente de sua forma de apresentação (ISO, 1986).

SGML é uma meta-linguagem genérica para a descrição da estrutura lógica de documentos, que permite a definição de linguagens específicas, por exemplo, para livros, para cartas, para artigos, etc (Herwijnen, 1994). Portanto, cada tipo de documento está associado um DTD (Document Type Definition) que o define. Assim, a linguagem definida em um DTD especifica uma classe de documentos que é compartilhada por muitas instâncias de documentos (Herwijnen, 1994).

A estrutura lógica de um documento, definida por um DTD, é descrita através de marcas padronizadas (markups). Markups identificam o início e o fim de cada item lógico (elemento SGML) e permitem a especificação de seus atributos. É possível atribuir um identificador único a um elemento SGML, de modo que ele possa ser referenciado em qualquer ponto de um documento. Esta característica pode ser utilizada, por exemplo, para a especificação de links.

\subsubsection{DTD}

Um DTD define as regras para a especificação de uma classe de documentos. DTDs declaram:

- os tipos de elementos que podem existir em um documento. Por exemplo, um livro pode conter título, capítulo, seções, subseções, etc;

- os atributos que esses elementos podem ter. Por exemplo, o elemento título pode ter um atributo formato, que será uma característica específica para aquele elemento;

- como as instâncias destes elementos estão hierarquicamente relacionadas. Por exemplo, um livro contém capítulos, os quais contêm seções, etc.

A estrutura especificada em um DTD descreve apenas a estrutura lógica de uma classe de documentos, não sendo fornecida informação sobre a semântica de apresentação do mesmo (Brown, 1989). Devido a este fato, a aplicação que processa um documento SGML é responsável 
por especificar como as instâncias dos elementos devem ser visualizadas no documento final. Esta tarefa é normalmente realizada através de Style Sheets que armazenam os atributos relativos à apresentação. O padrão DSSSL (Document Style Semantics and Specification Language) formaliza a especificação de Style Sheets (ISO, 1996).

Um DTD define três tipos de comandos de marcação:

- elementos - objetos lógicos do documento;

- atributos - qualificadores dos elementos;

- entidades - caracteres especiais, imagens, fotos ou textos de outros documentos.

Para assegurar que as marcações de um documento estejam consistentes, livres de erros, e possam ser interpretadas corretamente, todo sistema conformante deve conter uma aplicação que reconheça markups em seus documentos. Essa aplicação é denominada de parser, e deve possuir mecanismos que chequem se o DTD de um documento segue a sintaxe estabelecida por SGML e se documentos estão de acordo com esse DTD.

\subsubsection{Vantagens e desvantagens da utilização de SGML}

As principais vantagens da utilização do padrão SGML, são:

- possibilidade de representação da estrutura hierárquica dos elementos em um documento. Esta característica facilita quaisquer operações de processamento sobre os documentos.

- flexibilidade dos documentos. Os tipos de elementos e relacionamento entre eles é definido pelo projetista da classe de documentos.

- especificação formal dos elementos contidos no documento SGML. Os elementos são declarados de modo formal no DTD. O programa que utilizar o documento SGML processa esse documento em conjunto com a declaração, o que permite validá-lo.

- conteúdo textual manipulado em qualquer editor e compreendido com facilidade.

Entretanto, as principais desvantagens de SGML são:

- SGML não é poderoso o suficiente para lidar com documentos multimídia e hipermídia, que podem possuir relações temporais ou ligações hipertexto complexas.

- SGML é difícil de utilizar. 
Para tentar solucionar os problemas com documentos multimídia e hipermídia, um comitê da ISO (International Organization for Standardization), desenvolveu a linguagem HyTime (Hypermedia / Time-based Structuring Language), uma extensão da SGML (ISO, 1992).

\subsection{HTML}

HTML (Hypertext Markup Language) tornou-se uma linguagem amplamente utilizada como formato para hiperdocumentos disponibilizados na WWW e reconhecida pelos browsers existentes (Berners-Lee et al., 1994). A partir da versão 2.0, HTML é formalmente definida por um DTD SGML, sendo parte do conjunto de especificações do World Wide Web Consortium (W3C). Assim, o DTD determina a maneira pela qual um conjunto de elementos deve estar estruturado para compor um documento, bem como a definição de links entre os elementos e a inclusão de outras mídias no corpo do documento (HTML, 1997).

A navegação em documentos HTML se faz através das seguintes operações básicas definidas pela tecnologia: seleção livre de relacionamento, complementada por operações de backtracking e controle de caminho percorrido (histórico de navegação) (Pimentel \& Hagui, 1996). Tentando proporcionar maior interação aos documentos HTML, a especificação atual inclui o suporte a outras tecnologias, por exemplo, folhas de estilo e scripts.

A maioria dos documentos existentes hoje na WWW não está em completa conformidade com DTD SGML que define HTML. Este fato ocorre porque os browsers atuais processam documentos HTML com flexibilidade e sem utilizar todas as características de validação exigidas por SGML. A título de ilustração, a Tabela 4.1 apresenta os elementos mais comumente utilizados em documentos HTML. 
Tabela 4.1 - Descrição das tags mais comuns de HTML

\begin{tabular}{|c|c|}
\hline TAG & DESCRIÇÃO \\
\hline$<\mathrm{HTML}>\ldots</ \mathrm{HTML}>$ & Declara a página da Web a ser criada em HTML \\
\hline$<\mathrm{HEAD}>\ldots</ \mathrm{HEAD}>$ & Delimita o cabeçalho da página \\
\hline$<$ STITLE $>\ldots</$ TITLE $>$ & Define o título interno do documento (não exibido na página) \\
\hline$<$ BODY> ... </BODY> & Delimita o corpo da página \\
\hline$<\mathrm{H} n>\ldots</ \mathrm{H} n>$ & Delimita um cabeçalho de nível $n$ \\
\hline$<\mathrm{B}>\ldots</ \mathrm{B}>$ & Ativa/Desativa negrito \\
\hline$<|>\ldots</|>$ & Ativa/Desativa itálico \\
\hline$<U L>\ldots</ U L>$ & Delimita uma lista desordenada com marcadores \\
\hline$<\mathrm{OL}>\ldots</ \mathrm{OL}>$ & Delimita uma lista numerada \\
\hline$<$ MENU $>\ldots</$ MENU $>$ & Delimita um menu de $<$ LI $>$ itens \\
\hline$<\mathrm{LI}>$ & Inicia um item de lista \\
\hline$<\mathrm{BR}>$ & Força uma quebra de linha \\
\hline$\langle\mathrm{P}>$ & Inicia um novo parágrafo (</P> é opcional) \\
\hline$<\mathrm{HR}>$ & Define uma subdivisão horizontal \\
\hline$<$ IMG SCR = ".." > & \begin{tabular}{|l|} 
Carrega uma imagem \\
\end{tabular} \\
\hline$<$ A HREF $=“ \ldots$. $>$ > $\ldots</ A>$ & Define um link \\
\hline
\end{tabular}

A simplicidade do padrão HTML implica em inúmeras limitações (Bosak, 1997):

- HTML não é extensível. Um padrão extensível permite que os desenvolvedores de aplicações definam elementos específicos para situações diversas.

- HTML não possui estrutura semântica alguma, o que dificulta o processamento ou reuso do conteúdo dos documentos.

- HTML mistura estruturas lógicas de um documento (títulos, parágrafo, etc) com elementos de apresentação (negritos, itálicos, alinhamentos, etc).

- documentos HTML com ligações embutidas não permitem a separação dos dados sendo referenciados e de suas referências (links), dificultando a reutilização destes sem a herança obrigatória das relações.

- em documentos HTML, só podem ser estabelecidas ligações do tipo "ponto a ponto" unidirecionais, sempre expressando uma relação do tipo "go to".

Com o objetivo de estabelecer um padrão que possa fornecer benefícios não existentes em HTML e ao mesmo tempo ser mais fácil de utilizar que SGML, foi proposto o padrão XML, descrito a seguir. 


\subsection{XML}

XML (Extensible Markup Language) é uma meta-linguagem definida como um subconjunto de SGML. Ela foi especificada para que projetistas pudessem criar linguagens próprias de marcação para os documentos manipulados por suas aplicações. XML pretende satisfazer, de maneira rápida, eficiente e lógica, as necessidades específicas das aplicações (Connolly et al., 1997). Ela tem por objetivo fornecer benefícios não existentes em HTML e ser mais fácil de utilizar do que SGML.

A definição de componentes nos documentos XML é expressa em DTDs, realizadas de acordo com a meta-linguagem XML. Assim, o DTD define a gramática associada ao documento, sendo o veículo utilizado pelo projetista para definir que elementos e atributos devem aparecer e quais são opcionais na sua linguagem. Um documento em conformidade com um DTD XML possui elementos, atributos, entidades e instruções de processamento. Por construção, todo DTD e todo documento XML está em conformidade com SGML.

\subsubsection{Componentes de um documento}

Elementos XML correspondem aos componentes estruturais da linguagem. Cada documento XML contém um ou mais elementos. Cada elemento tem um tipo, identificado por um nome, e pode ter um conjunto de especificações de atributos a ele associado. Cada especificação de atributo compõe-se de um par nome/valor. Sua ocorrência em um documento é identificada por marcações delimitadas por "<" e ">", chamadas start-tag e end-tag. Por exemplo, um DTD pode conter a declaração:

\section{$<$ !ELEMENT Aluno (\#PCDATA)>}

a qual permite a ocorrência, em um documento associado, de:

\section{<Aluno $>$ Marcos de Almeida </Aluno $>$}

Um elemento pode ser classificado qualitativamente através de atributos. Um atributo é especificado por um par (nome, valor) presente na start-tag do elemento, logo após seu nome., como no exemplo: 


\section{<Aluno ingresso="1998"> Marcos de Almeida </Aluno $>$.}

As unidades físicas de um documento são definidas por entidades, as quais podem ser internas ou externas ao documento principal, chamado entidade raiz. Entidades externas referem-se a arquivos contendo documentos, imagens, etc. (como em \&capítulo1;). Entidades internas normalmente se referem a caracteres de língua "estrangeira" (por exemplo: Pra\&ccedil; $a$ representa Praça) ou um símbolo reservado para a marcação (por exemplo: $a \& l t ; b$ representa $a<b$ ). Além disso, entidades são utilizadas para definições e abreviaturas, como no exemplo:

\section{<Estuda> \&Disciplina; </Estuda>.}

que estaria associado à definição, no DTD, de:

\section{<!ENTITY Disciplina "Engenharia de Software" >}

Como em SGML, em XML pode-se fazer comentários cujo conteúdo é ignorado pelos processadores e aplicações XML. Um comentário começa com " < ! -- " e termina com " -->".

Instruções de processamento (IPs) são recursos para fornecer informações a uma aplicação, e não fazem parte do texto do documento. É tarefa do processador XML passar a informação para a aplicação correspondente. Um exemplo para a inclusão de scripts escritos em php seria:

$$
<\text { ?php echo "<html> Hello World!</html>" ?> }
$$

\subsubsection{Seções de marcação}

Uma seção marcada com CDATA instrui o parser para ignorar todos os caracteres reservados da linguagem XML daquela seção, como por exemplo, aqueles encontrados em expressões como "x $+y<z+t "$.

\subsubsection{Vantagens da utilização de XML}

Referindo-se ao trabalho do W3C, Rada et al. comentam que os padrões formam o corpo e a alma da Web (Rada et al., 1998). De fato, W3C vem investindo inúmeros esforços com o 
objetivo de garantir que o crescimento da Web se dê de modo aberto e padronizado, por exemplo, ao definir recomendações que regulam a formalização da estrutura de documentos e do seu formato de apresentação. Especificamente, XML permite que projetistas de aplicações definam uma estrutura lógica para os documentos suportados (XML, 1999). O objetivo é prover interoperabilidade entre aplicações e, assim, XML pode ser vista como a proposta do W3C de modelo de representação de dados para aplicações da Web (Bosak, 1997; Connolly, 1998).

O uso de XML como formato de intercâmbio de dados fornece muitas vantagens, conforme discutido em (Bosak, 1997) e (Connolly, 1998). Em particular, do ponto de vista do projeto de aplicações na Internet em geral - e não apenas na Web, o uso de XML permite explorar as seguintes vantagens:

- interoperabilidade entre aplicações: não é necessário que aplicações de terceiros tenham conhecimento da estrutura de uma base de dados em particular: é suficiente ter acesso a uma especificação XML, que define a sintaxe da informação para poder processar as instâncias que apresentam seu conteúdo;

- processamento distribuído: aplicações na Internet estão ficando cada vez mais comuns, e o uso de XML para transferência de informações entre os diversos módulos permite maior controle no processamento das informações pelos módulos;

- processamento customizado: aplicações distintas ou módulos de aplicações distribuídas podem apresentar as informações recebidas de acordo com a preferência e/ou necessidade de seu usuário local;

- pesquisa independente: o intercâmbio de documentos permite a busca de informações de interesse local, de maneira mais independentemente e eficiente por parte da aplicação;

- tráfico reduzido: o intercâmbio de documentos estruturados permite o processamento local da informação pela aplicação e assim, possibilita uma redução da quantidade de dados transmitidos pela rede.

Como os documentos XML não possuem recursos para especificar informações a respeito da apresentação de seu conteúdo, CSS (Cascading Style Sheets) (CSS, 1997) e XSL (Extended Style Language) (XSL, 1999) podem ser utilizadas para permitir que qualquer tipo de informação possa ser associado ao mesmo. Um exemplo é a criação de um documento HTML que contém 
informações de apresentação a partir do conteúdo de um documento XML, através do processamento de uma folha de estilo XSL.

\subsubsection{Outras recomendações associadas a XML}

O W3C tem coordenado a promoção de vários outros formatos e padrões para a Web, com o objetivo de suportar o intercâmbio de informações entre aplicações. Neste sentido, várias recomendações associadas a XML têm sido desenvolvidas. Alguns exemplos importantes, em fase de elaboração, são:

- XSL (Extensible Stylesheet Language) é uma linguagem para a definição de Style Sheets, que permitem especificar transformações associadas a um documento XML. Um exemplo de transformação é a geração de um documento XML a um documento HTML. Por exemplo, ao elemento Disciplina é possível o associar o elemento de apresentação P (parágrafo). Assim, XSL permite transformar um documento XML em outro no qual informações referentes à apresentação estão incluídas (XSL, 1999).

- XLink (XML Linking Language) especifica construtores que podem ser inseridos em documentos XML para descrever ligações entre objetos. Objetos podem ser quaisquer porções de dados, e as ligações podem ser internas ou externas aos documentos, uni ou multidirecionais, entre outras características (XLink, 1998).

- XPointer (XML Pointer Language) especifica construtores que suportam endereçamento dentro da estrutura interna de documentos XML (por exemplo, o terceiro parágrafo da segunda seção do quarto capítulo) (XPointer, 1998).

Várias outras recomendações estão concluídas ou em fase de elaboração. Percebe-se que, de posse desse tipo de especificações, o processamento e o intercâmbio de informações na Web se dará de maneira muito mais eficiente e poderosa. Assim, cresce a importância do projeto de aplicações em consonância com as recomendações do W3C em geral, e com XML e particular.

\subsection{CONSIDERAÇÕES FINAIS}

Muitos sistemas hipermídia ainda estão sendo desenvolvidos como sistemas auto-contidos, o que dificulta a reusabilidade da informação manipulada. O ideal seria que aplicações desenvolvidas 
em plataformas diferentes pudessem utilizar objetos de outras. Por isso, cada dia mais, a comunidade científica reconhecendo a importância de viabilizar hiperdocumentos, tem dirigido esforços no desenvolvimento de padrões como SGML, XML e outros.

Sistemas CSCW e CSCL podem tirar grande proveito dos avanços na área de documentos estruturados. Nesses ambientes é vital o compartilhamento de informações, assim a estruturação de documentos através de DTDs XML, garante o acesso aos dados armazenados nos hiperdocumentos independentemente da aplicação que tenha gerado esse hiperdocumento, da maneira como os dados foram armazenados ou de qual linguagem foi utilizada. 


\section{MODELAGEM DE APLICAÇÕES HIPERMÍDIA PARA A WEB}

\subsection{CONSIDERAÇÕES INICIAIS}

Características antes encontradas apenas em aplicações de grande porte estão presentes, atualmente, em aplicações de pequeno porte construídas para a Web. Assim, aspectos de processamento distribuído, armazenamento e recuperação de informações em banco de dados, interfaces de acesso contendo informações geradas dinamicamente, e interação com o usuário sobre essas informações, devem ser cuidadosamente tratados durante o processo de desenvolvimento de aplicações para Web. Além disso, quando as informações possuem ligações que podem ser ativadas pelo usuário para navegação, a aplicação adquire características de aplicação hipermídia e, como tal, sujeita aos desafios dessa tecnologia.

Modelos de ambientes complexos, como aplicações hipermídia para Web, são definidos para facilitar o projeto, implementação e documentação das aplicações. Conforme a complexidade do ambiente cresce, também cresce a importância de boas técnicas de modelagem.

Neste capítulo discute-se como XML, a linguagem UML e o modelo relacional são combinados para a definição da técnica Modelagem Conceitual e Lógica Aplicações hipermídia para Web (MCLAi), em desenvolvimento por um grupo de pesquisadores do ICMC (Macedo et al., 1999c). MCLAi tem como objetivo apioar o projeto, desenvolvimento e manutenção de aplicações e, ao mesmo tempo, facilitar o intercâmbio de informações entre essas aplicações. Os elementos da técnica MCLAi estão distribuídos entre os níveis de modelagem de aplicações Web, conforme descrito a seguir.

\subsection{NÍVEIS DE MODELAGEM DE APLICAÇÕES PARA WEB}

Para discutir as contribuições da MCLAi, é importante diferenciar os três níveis de modelagem de uma aplicação para Web, conforme discutidos por Isakowitz et al. (Isakowitz et al., 1998) e ilustrados na Figura 5.1. 


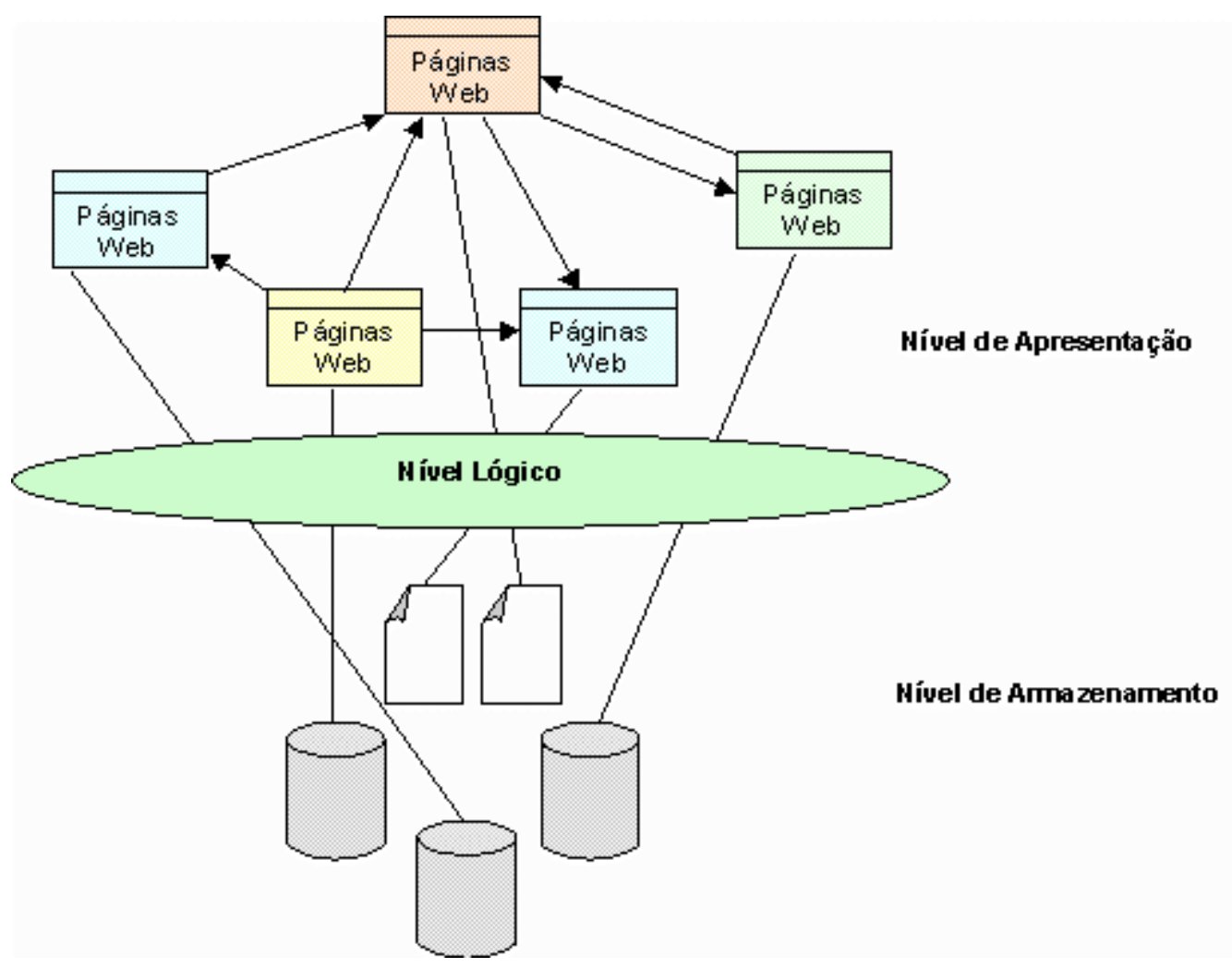

Figura 5.1 - Níveis de modelagem de aplicações hipermídia (Isakowitz et al., 1998)

No nível de apresentação são considerados aspectos de aparência da aplicação. É neste nível que o projetista deve decidir como a informação será apresentada ao usuário. Ele deve escolher quais informações serão colocadas juntas, ou separadas em hyperlinks, dentro das unidades de apresentação (por exemplo, páginas Web). No nível de armazenamento deve-se descrever como a informação será armazenada fisicamente, quais aplicativos serão necessários (editores gráficos, base de dados), quais arquivos serão utilizados etc. Entre o nível de apresentação e o de armazenamento existe o nível lógico que é responsável por mapear as informações armazenadas na base de dados e servidores Web em páginas Web que podem ser visualizadas pelo usuários.

A integração conceitual entre os três níveis é necessária para auxiliar, por exemplo, no mapeamento da informação entre o nível de armazenamento e o de apresentação. Geralmente, este mapeamento ocorre num nível cognitivo do pensamento do desenvolvedor da aplicação. Entretanto, a MCLAi - através de seus elementos de modelagem: diagrama de classe, diagrama da aplicação, modelo relacional e documentos XML - auxilia na formalização deste mapeamento de modo a facilitar a implementação, bem como manutenção e reutilização de componentes da aplicação. 
Os elementos de modelagem da MCLAi pretendem:

- modelar o domínio da informação (modelagem conceitual) em diagrama de classe UML;

- definir um diagrama da aplicação que permite uma visão global da mesma e dos relacionamentos entre as unidades de apresentação;

- especificar DTDs que formalizem os caminhos de navegação da aplicação Web e definam campos de entrada e saída de dados das unidades de apresentação do diagrama de aplicação. O conjunto destes DTDs é denominado N-DTDs;

- gerar documentos XML em conformidade com os N-DTDs e com os DTDs especificados a partir das tabelas do banco de dados. Estes documentos facilitam o intercâmbio de informações e a implementação das aplicações distribuídas.

A distribuição dos elementos da MCLAi nos níveis de modelagem de aplicações hipermídia é apresentada na Figura 5.2.

A técnica de modelagem proposta e seus elementos podem ser utilizados para a definição do modelo de armazenamento e do modelo de navegação. A definição destes modelos é apresentada na Seção 5.3. 

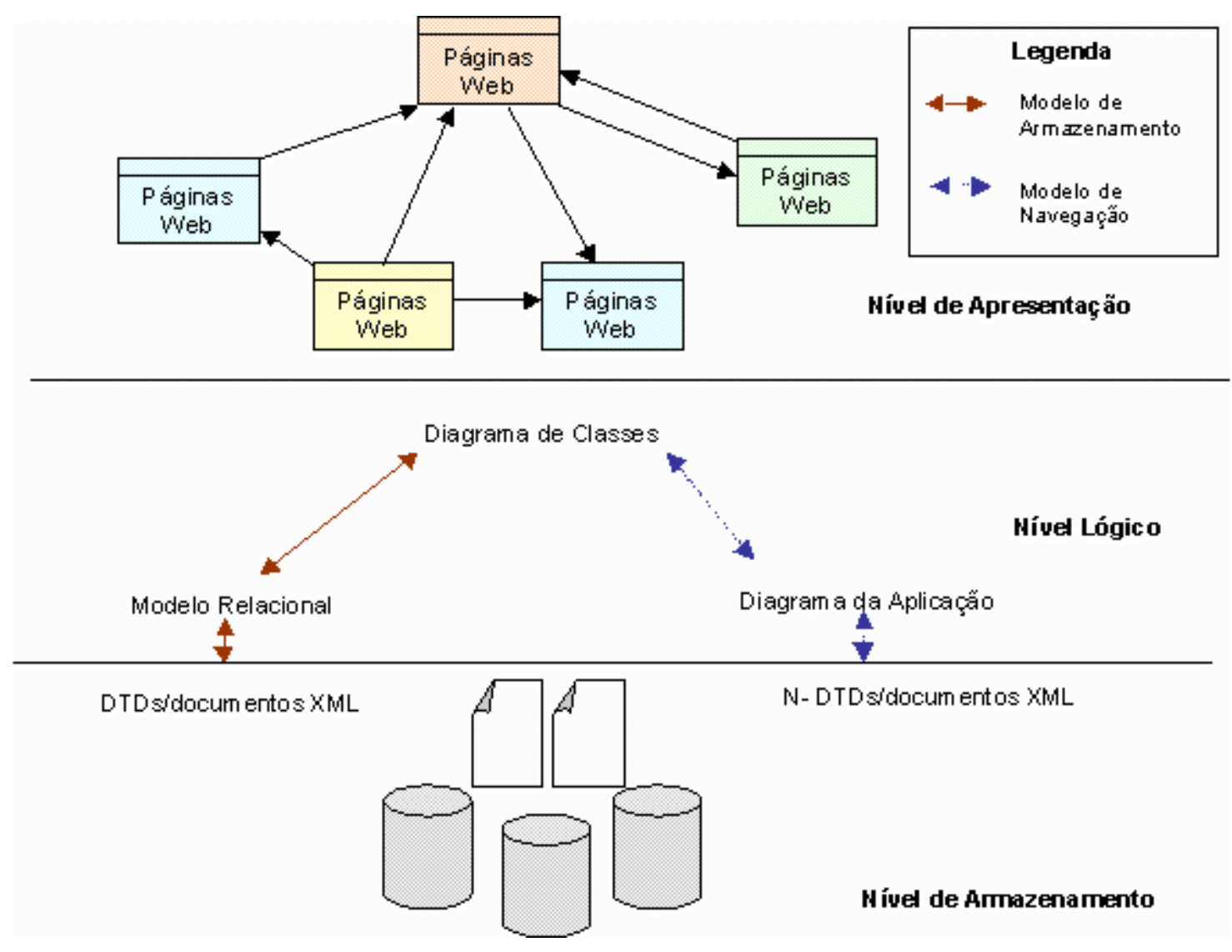

Figura 5.2 - Disposição dos elementos da MCLAi nos níveis de modelagem

No Capítulo 6 são definidos os modelos de armazenamento e de navegação para o StudyConf a partir da MCLAi.

\subsection{DESCRIÇÃO DA MCLAi}

A modelagem conceitual no projeto de aplicações, em geral, tem como objetivo traduzir os conceitos do mundo real em representações de esquemas de modelos conceituais. Esta tarefa é realizada por meio de identificação e representação abstrata de alguns objetos e seus relacionamentos, procurando uma melhor representação semântica da aplicação. Na MCLAi a modelagem conceitual é representada pelo diagrama de classes da meta-linguagem UML.O diagrama de classes orienta o desenvolvimento tanto do modelo de armazenamento como o do modelo de navegação das aplicações Web modeladas com a MCLAi.

Através do modelo de armazenamento, pretende-se modelar as informações que serão armazenadas fisicamente na base de dados que suportará a aplicação. A utilização do diagrama 
de classes UML não é suficiente para oferecer um modelo que possa ser usado para suportar a implementação da base de dados. A tradução de esquemas do modelo conceitual (diagrama de classes) para um modelo de dados, no caso modelo relacional (M-Rel), é necessária para a composição da base de dados. A modelagem apoiada no M-Rel oferece condições para que todas as relações estejam de acordo com aplicação. Ainda para o modelo de armazenamento, são definidos DTDs a partir das tabelas da base de dados e documentos XML oriundos da instanciação dos DTDs. Os documentos XML têm como objetivo facilitar o processamento das informações para armazenamento e recuperação na base de dados através de parsers XML.

A definição do modelo navegacional é uma visão do modelo conceitual que permite o relacionamento das tarefas a serem executadas através da aplicação hipermídia, além da representação do conteúdo de suas estruturas. Diferentes modelos navegacionais podem ser construídos para um mesmo modelo conceitual, o que torna possível a construção de várias aplicações para diferentes usuários. De acordo com a MCLAi, para a definição do modelo navegacional são necessários os seguintes elementos: diagrama de classes, diagrama da aplicação, N-DTDs que auxiliam na definição do conteúdo, especificação e verificação dos elos de ligação do diagrama da aplicação e, por último, documentos XML que podem ser utilizados para apresentação da aplicação através dos padrões XSL e CSS.

Os elementos da MCLAi utilizados na definição do modelo de armazenamento e do modelo de navegação são apresentados respectivamente nas Seções 5.3.2 e 5.3.3. O diagrama de classe UML é apresentado uma única vez na Seção 5.3.1, visto que este é utilizado em ambos os modelos.

\subsubsection{Definição do diagrama de classes UML}

Com o sucesso das linguagens de programação orientadas a objeto como $\mathrm{C}++$ e SmallTalk, a necessidade de métodos que suportassem o conceito de objeto fez surgir vários modelos. Atualmente, os modelos orientados a objetos mais usados são Booch, OMT, OOSE/Objectory, Fusion e Coad/Yourdon. Cada um desses modelos tem suas próprias notações, processos e ferramentas. Isso faz com que a decisão de escolha entre eles torne-se importante: Qual seria o melhor para um determinado projeto? Procurando resolver este problema, Grady Booch e James 
Rumbaugh do Rational Software Corporation, começaram a trabalhar para criar um novo modelo, o Unified Method, que mais tarde, juntamente com Ivar Jacobson, seria chamado de UML (Unified Modeling Language) (Jacobson et al., 1998). Mesmo que as principais características da UML sejam baseadas no método OOSE, OMT e Booch, os projetistas também incluíram conceitos do Fusion, Coad/Yourdon e outros.

A aplicabilidade da UML é muito abrangente, podendo ser utilizada em projetos que possuem estrutura estática e comportamento dinâmico, como por exemplo, o desenvolvimento de software para a Web.

Os elementos de modelagem da UML são divididos em 4 partes: Visões, Diagramas, Modelos de Elementos e Mecanismos Gerais. As Visões são abstrações que consistem de um número limitado de Diagramas. Cada Visão mostra aspectos particulares do sistema, e a junção delas apresenta a imagem do todo. Diagramas são gráficos que descrevem o conteúdo de uma Visão. Modelos de Elementos utilizam conceitos da orientação a objetos: como classes, objetos, mensagens, associações, dependências e generalizações. Os Mecanismos Gerais fornecem comentários extras, informações ou semântica sobre a modelagem dos elementos.

A definição das classes e relacionamentos de um sistema é realizada através da especificação de seus elementos. O diagrama de classes da UML modela esses elementos através de uma estrutura estática das classes do sistema. Uma classe representa uma entidade que pode se relacionar com outra de várias maneiras: associação, dependência, especialização e generalização. Um sistema pode possuir vários diagramas de classe, e uma classe pode participar de mais de um diagrama.

O diagrama de classes da UML foi escolhido devido às suas vantagens:

- a UML é uma meta-linguagem e não um método, o que permite o uso de seus elementos de modelagem da maneira mais adequada, como parte de um método de projeto para aplicações;

- a UML possui diversos conceitos novos de modelagem, que aumentam significativamente seu poder de modelagem quando comparado aos métodos tradicionais como OMT e Fusion;

- a UML é uma meta-linguagem, o que facilita a definição de meta-modelos; 
- a UML permite a identificação e definição de padrões de projeto e frameworks, que podem ser utilizados para facilitar a especificação e desenvolvimento de sistemas de uma maneira geral, aumentando a reusabilidade em nível de projeto;

- a UML possui mecanismos de extensão, o que permite que seja utilizada mesmo quando seus recursos não são suficientes para uma aplicação específica;

- a UML foi aceita como padrão pelo OMG (Object Management Group), o que significa que uma série de produtos para seu suporte está sendo produzida e disponibilizada.

\subsubsection{Modelo de armazenamento}

É fundamental a utilização de elementos de modelagem quando se pretende criar uma base de dados relacional para armazenar informações pertinentes a aplicações Web ou não. Por isso, na MCLAi, utiliza-se o diagrama de classes UML para definir as classes e relacionamentos entre os objetos que compõem o domínio da aplicação, para assim ser possível selecionar as informações que deverão estar presentes na base de dados. Já o mapeamento do diagrama de classes para o modelo relacional permite a tradução dos esquemas concebidos de um modelo de conteúdo semântico mais alto (diagrama de classes) para uma implementação utilizando um modelo (modelo relacional), que preserva as propriedades do modelo mais rico.

Deste modo, DTDs e documentos XML são criados para especificação da estrutura formal dos documentos a serem gerados na modelagem, de modo a auxiliar na implementação, processamento e intercâmbio dos mesmos. Os documentos XML são instanciados de acordo com a linguagem especificada para armazenamento e recuperação do conteúdo da base de dados.

Os elementos de modelagem da MCLAi para o modelo de armazenamento - modelo relacional, DTDs e documentos XML - são apresentados a seguir.

\subsubsection{Definição do modelo relacional}

A tradução de esquemas concebidos de um modelo de conteúdo semântico mais alto (diagrama de classe da UML), para um modelo relacional (M-REL) que tenta preservar as propriedades do modelo mais rico, permite a implementação e composição de um banco de dados adequado. Porém, esta tradução pode trazer perdas semânticas significativas se não for feito da forma 
adequada, ou seja, seguindo regras de mapeamento. Isso, naturalmente, significa uma limitação muito grande, e representa a contrapartida do uso de um banco de dados relacional em vez de um banco de dados orientado a objeto.

A utilização de uma modelagem puramente orientada a objetos para construção de modelos conceituais de uma aplicação pode trazer benefícios, se for utilizado um banco de dados também orientado a objetos para armazenar as relações geradas ao término da modelagem. Assim, não seria preciso traduções de um modelo para outro, e sim de uma única técnica que modelasse as características da aplicação diretamente no banco de dados orientado a objetos capaz de comportá-las.

Entretanto, quando a aplicação fizer uso de um banco de dados relacional, esse benefício não se aplica. Esse é o caso da maioria das aplicações em desenvolvimento hoje na Internet, dada a disponibilidade de gerenciadores de banco de dados relacionais de excelente qualidade a um custo baixo, e muitas vezes nulo.

A modelagem apoiada no M-REL oferece condições para que todas as relações criadas estejam de acordo com as especificações produzidas para a aplicação. Portanto, a vantagem de utilizar o M-REL é que, ao término do processo, é possível criar uma base de dados com base nas relações geradas no modelo. A passagem do diagrama de classes UML para o M-REL pode ser feita através de regras de mapeamento que permitem a tradução.

Os passos utilizados para mapear o diagrama UML no M-REL são baseados no trabalho de Chen, que os utiliza para fazer o mapeamento a partir de modelos Entidade-Relacionamento Extendido (ME-RX) (Chen, 1976).

Quando se obtém uma modelagem no Modelo Relacional, cada relação, e a própria base de dados, devem ser colocadas em um determinado grau de normalização, adequado à utilização que se pretende da base de dados resultante. A modelagem apoiada no M-REL obtida pela aplicação do algoritmo de mapeamento sempre leva todas as relações para a $3^{\text {a }}$ Forma Normal, condição para uma relação estar de acordo com a aplicação (Date, 1986). 
5.3.2.2 Modelagem da base de dados para definição de DTDs e documentos XML

DTDs XML que correspondam ao modelo relacional são definidas após a modelagem da base de dados com suas tabelas e campos. É possível modelar uma base de dados, suas tabelas e campos, como uma hierarquia de profundidade 3 , tendo como nó inicial a descrição da base de dados com suas tabelas, no nível 2 uma tabela com seus campos, e no nível 3 cada campo com seu tipo. A hierarquia funciona como se segue: uma base de dados consiste de uma série de tabelas, que por sua vez consiste de uma série de campos e que, por sua vez, define o tipo de campo (Rel, 1998). Esse processo é ilustrado a seguir:

a) Definição das tabelas da base de dados:

$<$ nome da base de dados $>$

$<$ tabela $1>\ldots<$ tabela $1>$

$<$ tabela $2>\ldots</$ tabela $2>$

$\ldots$

$<$ tabela $n>\ldots</$ tabela $n>$

$</$ nome da base de dados $>$

b) Especificação da configuração interna das tabelas:

$<$ nome da tabela $>$

$<$ campol $>$... $</$ campo $1>$

$<$ campo $2>\ldots</$ campo $2>$

$\ldots$

$<$ campo $n>\ldots</$ campo $n>$

$</$ nome da tabela $>$

c) Definição dos campos:

$<$ nome do campo $>$

type $=t$

$</$ nome do campo $>$

Após esta modelagem, a identificação dos elementos do banco de dados, torna-se sistemática. DTDs XML podem ser definidos a partir dos elementos do banco de dados, e documentos XML instanciados podem ser processados por aplicações XML, que podem, por exemplo, armazenar as informações em um banco de dados para posterior recuperação e apresentação caso necessária. 


\subsubsection{Modelo de navegação}

MCLAi utiliza o modelo de armazenamento para manipulação dos dados, e o modelo de navegação para definição das informações presentes nas páginas da aplicação Web e da estrutura de navegação.

O modelo de navegação é determinado através da criação de um diagrama da aplicação, que promove uma visão global da aplicação, e da especificação de DTDs para as unidades de apresentação do diagrama da aplicação. Essas unidades de apresentação são: a) páginas Web, que possuem campos de entrada e saída de dados e elos de ligações; e b) páginas de índice que contêm apenas elos de ligações. Portanto, para uma página Web são especificados DTDs que descrevem suas informações e elos de ligações e para páginas de índice são especificados DTDs que apenas especificam os elos de ligações. A união dos DTDs das páginas Web e das páginas de índice é denominada N-DTDs.

\subsubsection{Definição do diagrama da aplicação}

O diagrama da aplicação provê uma visão global da aplicação hipermídia através do relacionamento entre as unidades de apresentação que compõem a aplicação Web. Este diagrama provê uma visão final da aplicação ao projetista e ao usuário. A simplicidade e a natureza flexível do diagrama da aplicação permitem sua utilização, tanto na fase de implementação quanto de manutenção da aplicação.

\subsubsection{Definição dos N-DTDs e documentos XML}

Depois de modelado o domínio da aplicação através do diagrama de classe UML e criado o diagrama da aplicação, um DTD é construído para cada unidade de apresentação do diagrama da aplicação. Cada DTD especifica informações das unidades de apresentação e/ou elos de ligações com os DTDs das demais unidades. Um DTD, de acordo com o modelo de navegação da técnica MCLAi, é composto por:

- elementos de dois tipos: a) elementos que nomeiam ligações da unidade de apresentação especifica por um DTD com DTDs de outras unidades de apresentação, e b) elementos que especificam campos de entrada e saída de dados das unidades de apresentação. 
- atributos do tipo idref que indicam o destino de cada ligação, identificada por um elemento de ligação.

A união dos DTDs é chamada de N-DTDs. Um exemplo de N-DTDs é apresentado na Seção 6.5.3.

A modelagem de aplicações Web, através da especificação de N-DTDs, torna sistemática a identificação dos caminhos de navegação e das informações nelas contidas. Documentos XML instanciados a partir dos N-DTDs podem ser utilizados para a apresentação da aplicação através dos padrões XSL e CSS, além de poderem ser processados por aplicações quaisquer.

\subsection{CONSIDERAÇÕES FINAIS}

Os níveis de modelagem lógico e de armazenamento são etapas importantes no desenvolvimento de quaisquer aplicações hipermídia. Com o objetivo de explorar as contribuições de técnicas no projeto de aplicações para a Web em particular, e a Internet em geral, este capítulo apresentou uma abordagem que utiliza diagramas UML, modelos relacionais de banco de dados e documentos XML, como elementos a serem utilizados na modelagem lógica e de armazenamento de aplicações. O objetivo é orientar o projeto de aplicações em sintonia com as recomendações do W3C, no sentido de facilitar o intercâmbio de informações entre aplicações distribuídas na Web.

A especificação da modelagem lógica e de armazenamento de uma aplicação através da MCLAi pode trazer maior eficiência e clareza na definição de estrutura dos documentos que compõem a modelo lógico da aplicação. Além disso, pode auxiliar desenvolvedores e analistas, aumentando a reusabilidade de componentes das aplicações.

A MCLAi possui diversas vantagens e propriedades interessantes para a modelagem de aplicações para a Web. Algumas das vantagens vêm do fato de utilizar a UML para a especificação do diagramas de classes que compõem a aplicação. A UML possui grande poder de modelagem, permite a criação de meta-modelos, conseqüentemente facilitando a identificação e definição de padrões de projeto (Paolini \& Garzotto, 1999) e frameworks para aplicações. 
MCLAi explora as vantagens de XML na construção de aplicações distribuídas, com o objetivo de especificar a estrutura dos documentos gerados pela aplicação, facilitando, assim, o processamento dos mesmos e o intercâmbio de informações entre as aplicações distribuídas na Web.

A UML e o modelo M-REL oferecem uma notação concisa para examinar o ambiente e seus elementos dentro do contexto da aplicação. A utilização das especificações XML auxiliam na fase de implementação da aplicação, em particular no que diz respeito ao processamento, armazenamento e recuperação das informações. Para o contexto navegacional existem vantagens advindas da construção do diagrama da aplicação que fornece uma visão global da aplicação, e dos N-DTDs que aliam as vantagens deste tipo de documento à especificação de caminhos de navegação nas aplicações.

A técnica de modelagem - MCLAi pode ser expandida de maneira a:

- permitir o mapeamento do diagrama de classe que compõem a aplicação para o modelo de dados orientado a objetos;

- estender o modelo a fim de gerar OODTDs (Object Oriented DTDs) a partir da base de dados e dos diagramas UML. 


\section{O AMBIENTE STUDYCONF}

\subsection{CONSIDERAÇÕES INICIAIS}

O levantamento bibliográfico realizado foi direcionado para o objetivo inicial deste trabalho: explorar o uso das tecnologias de trabalho cooperativo e de hipermídia no desenvolvimento de um ambiente cooperativo que explora a Internet em geral, e a WWW em particular, para apoio ao ensino. Assim, foi realizado o projeto e implementação do StudyConf, um ambiente de apoio ao estudo cooperativo de hiperdocumentos didáticos disponibilizados na WWW.

Na Seção 6.2, são apresentados os diferenciais do StudyConf e suas características gerais. Os requisitos funcionais levantados para implementação do ambiente são mencionados na Seção 6.3. A arquitetura do StudyConf é descrita na Seção 6.4 e sua modelagem é apresentada na Seção 6.5. A Seção 6.6 descreve a ferramenta de comunicação e cooperação utilizada pelo ambiente. Finalmente, a Seção 6.7 apresenta as metáforas utilizadas, o projeto de interface e diretrizes de implementação do ambiente.

\subsection{VISÃO GERAL DO STUDYCONF}

StudyConf é um ambiente voltado para o apoio ao estudo cooperativo de material didático disponível na WWW. StudyConf é organizado, basicamente, em três módulos: módulo de acesso a ferramentas para elaboração de material didático que é o módulo professor, módulo administrador e módulo aluno. Esses módulos foram criados na tentativa de estruturar o sistema como um ambiente escolar, onde existem professores, alunos e a secretária que gerencia o material de um grupo de professores. No StudyConf, a secretária é representada pelo administrador.

O módulo de acesso a ferramentas para elaboração de material didático permite o acesso a página de download das ferramentas HyperBuilder, QuestBuilder e TaskBuilder, apresentadas no Capítulo 3, pois estas não são implementadas para Internet. O módulo administrador fornece 
mecanismos para manutenção dos materiais disponíveis para estudo na WWW, e finalmente, o módulo aluno suporta as atividades do aluno. Este último módulo embute uma ferramenta de CSCW que permite a execução de sessões de trabalho cooperativo, utilizando a Internet como plataforma de comunicação. Esta ferramenta, denominada DocConf, fornece recursos de chat, whiteboard e votação para a troca de diferentes tipos de mensagens entre os membros de um grupo (Pimentel et al., 1998b).

StudyConf diferencia-se de alguns ambientes de apoio à educação baseados na Web por:

- integrar ao seu contexto tanto ferramentas de comunicação e cooperação, DocConf, como ferramentas de autoria de material didático: HyperBuilder, QuestBuilder e TaskBuilder;

- permitir a apresentação de questionários de avaliação do material estudado. Estes questionários serão automaticamente corrigidos pelo QuestBuilder;

- controlar a apresentação do material estudado baseado em notas dos alunos, nos questionários apresentados. Esta característica é opcional, visto que o StudyConf disponibiliza material de estudo com navegação livre;

- deixar livre a escolha de utilização da ferramenta DocConf, permitindo assim que o aluno opte pelo estudo individual ou em grupo;

- permitir controle da disponibilização de material no ambiente. O administrador do ambiente pode inserir e disponibilizar os tópicos de um cursos, à medida que o professor os cria;

- permitir que o ambiente seja utilizado não só para fins de estudo didático, visto que existem outras fontes de informações, como, por exemplo, manuais técnicos e cursos de treinamento, que podem ser estudados através do StudyConf. Para isto, basta que o material a ser estudado seja incluído no ambiente pelo administrador como se fosse um curso didático qualquer, disponível na WWW.

\subsection{REQUISITOS FUNCIONAIS DO AMBIENTE}

O StudyConf, em versão atual, visa fornecer apoio ao estudo cooperativo, em browser Web, O ambiente possui as seguintes funcionalidades:

- fornecer um ambiente de trabalho para o administrador do sistema. Neste ambiente, o administrador do StudyConf pode incluir usuários e cursos que estão disponíveis na WWW. Podem ser cadastrados cursos didáticos com navegação livre e cursos didáticos com 
navegação controlada. Os cursos com navegação livre podem ser cadastrados de uma só vez, através da inserção da sua URL (Unified Resource Location) principal. Já os cursos com navegação controlada são divididos em tópicos, os quais devem ser cadastrados separadamente. É importante ressaltar que a ordem de inserção dos tópicos é fundamental, pois, a partir dela é que se define a navegação permitida ao aluno. Além disso, durante o cadastro dos tópicos, deve-se verificar a existência de exercícios e notas de aprovação. Caso existam, a navegação deverá ser controlada pela ordem de inserção dos tópicos e pelas notas obtidas pelos alunos nos exercícios correspondentes.

- controlar o acesso de alunos e do administrador do ambiente aos respectivos módulos;

- gerar e-mails automáticos para avisar login e senha dos usuários cadastrados no StudyConf;

- permitir a manutenção das senhas dos alunos e do administrador;

- fornecer um ambiente aos alunos para que eles possam fazer matricula nos cursos e estudá-los;

- permitir o estudo cooperativo e individual;

- dar acesso a páginas da Internet que contenham material similar ao que esta sendo estudado;

- permitir a apresentação de questionários de avaliação do material estudado;

- apresentar um boletim informativo com as notas e os cursos estudados;

- permitir estudo com navegação livre ou controlada;

- criar mecanismo que orientem o aluno durante o estudo controlado;

- fornecer uma página com links para sites de entretenimento;

- permitir acesso a textos relacionados ao ambiente e seu contexto;

- ser independente de plataforma.

As funcionalidades do DocConf que foram mantidas na versão embutida no StudyConf são:

- suporte a sessões síncronas e assíncronas;

- percepção da presença dos demais participantes do grupo cooperativo;

- percepção das ações do grupo;

- armazenamento de dados relativos às sessões;

- início e término de funcionalidades a qualquer momento.

DocConf possui os requisitos básicos para sistemas CSCW, descritos no Capítulo 2: comunicação entre os membros do grupo, compartilhamento de informações, coordenação e 
controle de objetos, e compartilhamento de espaço de trabalho. Entretanto, DocConf oferece ainda uma ferramenta de votação.

\subsection{ARQUITETURA DO AMBIENTE}

Para atender aos requisitos, o ambiente foi modelado seguindo a técnica de modelagem MCLAi, apresentada no Capítulo 5, e é constituído do DocConf, das ferramentas de autoria e de componentes da Internet (cliente WWW, servidor HTTP, base de dados e protocolos de comunicação) manipulados através das linguagens JavaScript e Java, incluindo a API (Aplication Program Interface) JDBC que possibilita a conexão ao DMBS (Data Model Base System) relacional PostgreSQL95. O StudyConf apresenta a arquitetura da Figura 6.1.

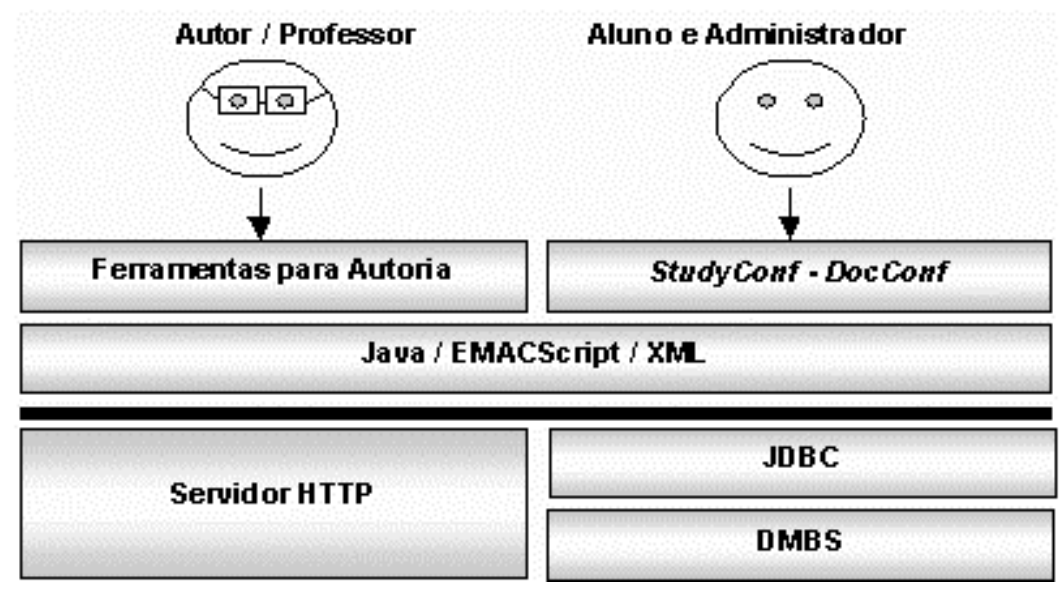

Figura 6.1 - Arquitetura do StudyConf

A arquitetura do sistema utiliza as funcionalidades da Internet. O cliente WWW dá suporte para as interações com os usuários (professores, administrador e alunos) procurando juntamente com o servidor e a base de dados fornecer as informações adequadas. O servidor HTTP executa e gerencia as requisições dos usuários logados no ambiente. Ele ativa, através dos formulários enviados pelos clientes, os programas servlets ${ }^{6}$ do ambiente que manipulam as informações para permitir as ações dos usuários. Os servlets acessam a base de dados via recursos JDBC.

\footnotetext{
${ }^{6}$ Servlets são programas Java que funcionam dentro de um servidor Web que deve oferecer suporte a API servlet para definições de aspectos da comunicação servidor Web e servlet (JavaSun, 1999)
} 


\subsection{A MODELAGEM DO AMBIENTE}

O StudyConf foi modelado de acordo com a técnica de modelagem MCLAi, apresentada no Capítulo 5. Nas Seções 6.5.2 e 6.5.3 são apresentadas, respectivamente, a modelagem de armazenamento do StudyConf e a modelagem dos aspectos navegacionais. A Seção 6.5.1 apresenta o diagrama de classes do StudyConf utilizado tanto pela modelagem de armazenamento quanto pela modelagem de navegação.

\subsubsection{Diagrama de classe}

O diagrama de classe UML que modela o domínio do StudyConf pode ser visualizado na Figura 6.2.

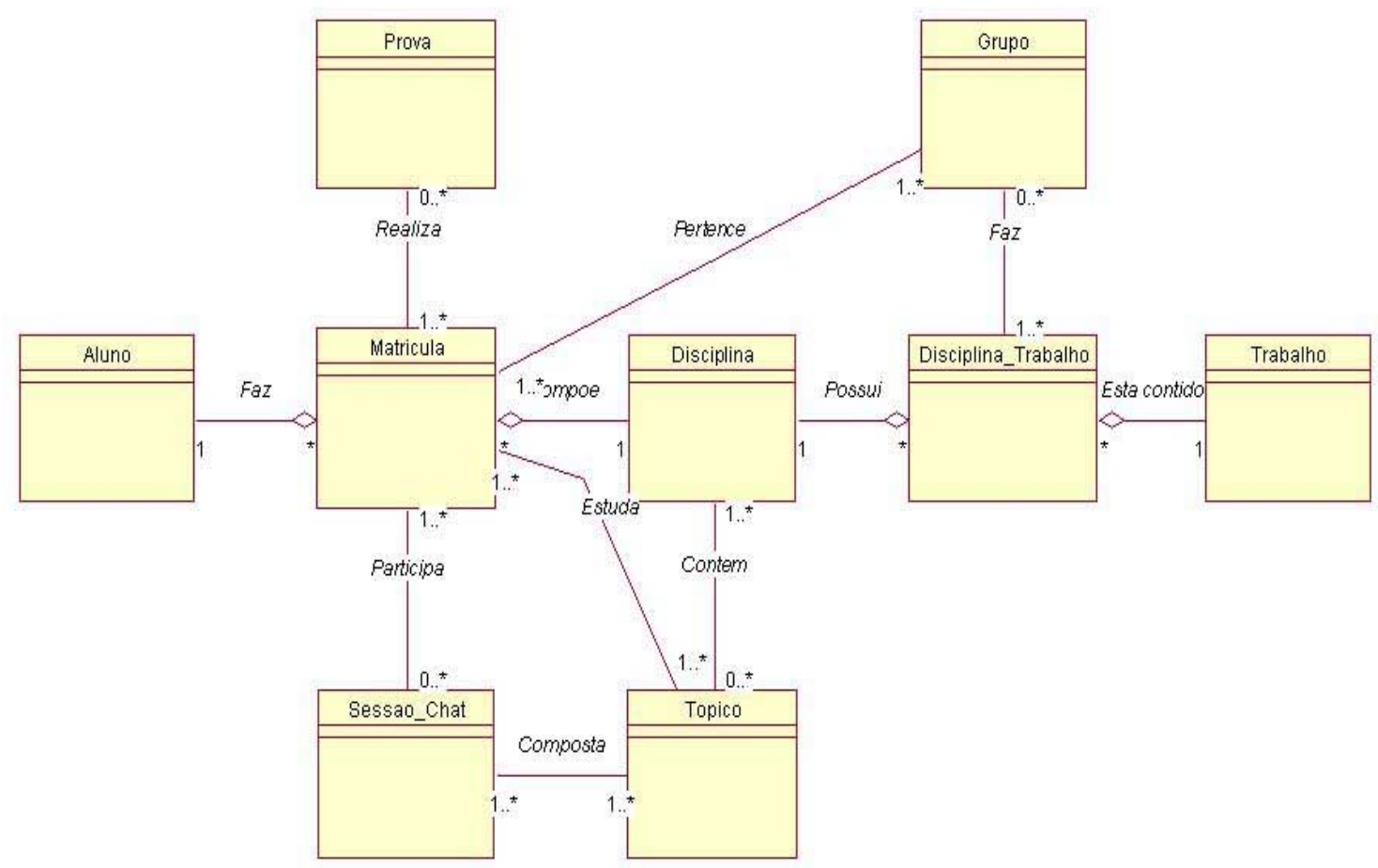

Figura 6.2 - Diagrama de Classes do StudyConf

As classes Aluno, Disciplina, Prova, Trabalho, Grupo, Tópico e Sessão_Chat foram criadas com o propósito de cadastramento e consultas destas. Já as entidades Matrícula e Disciplina_Trabalho são abstrações de agregação. 


\subsubsection{Modelo de armazenamento}

\subsubsection{M-REL}

As classes aluno e disciplina do diagrama de classes da Figura 6.2 podem ser modeladas através da representação M-REL, ficando:

$$
\begin{aligned}
& \text { Aluno }=\{\text { idaluno, login, password, nome, email }\} \\
& \text { Disciplina }=\{\text { iddisciplina, nome, notaminima }\}
\end{aligned}
$$

Um relacionamento de nome matrícula entre aluno e disciplina mostra-se de cardinalidade N:M (um aluno pode se matricular em várias disciplinas e uma disciplina pode ser feita por vários alunos). Desta forma, seguindo as regras de mapeamento, é possível definir a entidade Matricula:

$$
\text { Matrícula }=\{\text { idaluno, iddisciplina, data }\}
$$

As demais classes que compõe o M-REL do StudyConf são apresentadas na Figura 6.3:

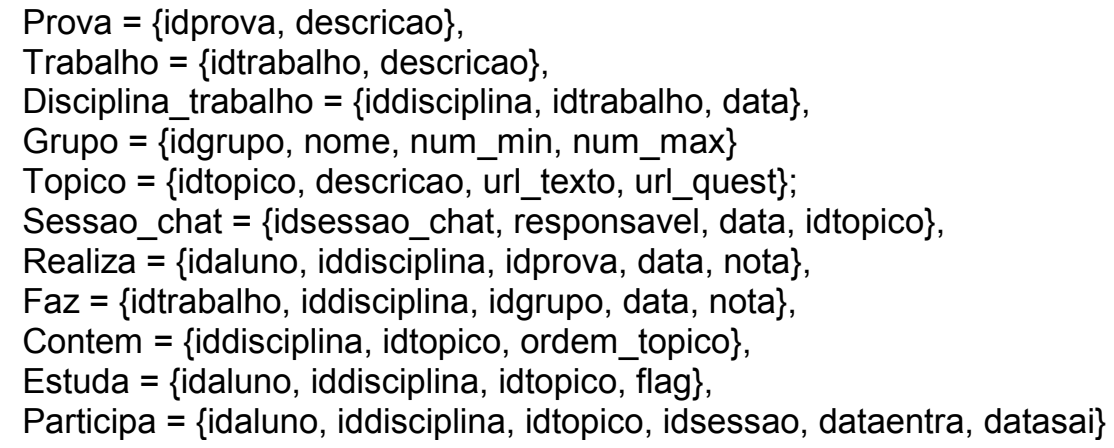

Figura 6.3 - Representação M-Rel das entidades do StudyConf

Definidas as entidades lógicas, pode-se especificar os DTDs correspondentes ao modelo relacional.

\subsubsection{DTDs}

Criado o Modelo Relacional, foram identificados elementos que fariam parte de um DTD correspondente à base de dados, denominada Didatico, do StudyConf. Os elementos correspondentes à base de dados são apresentado na Figura 6.4 


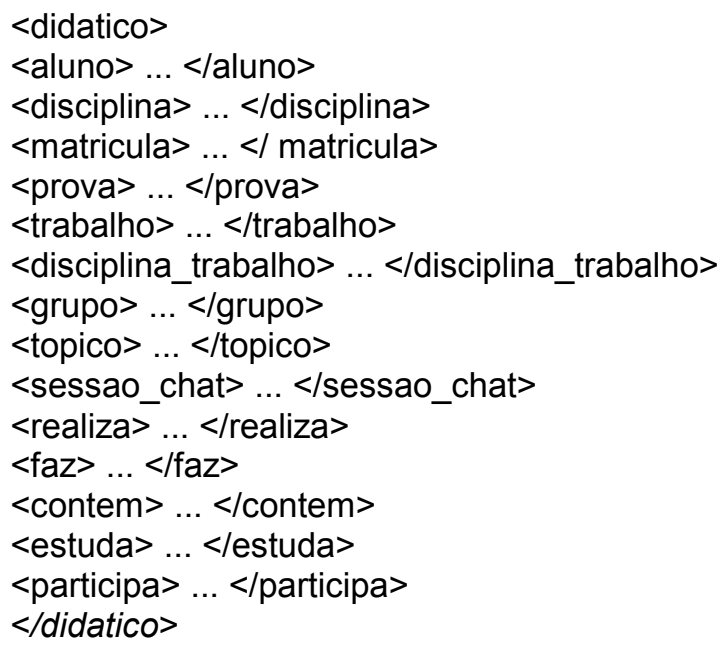

Figura 6.4 - Elemento correspondente às tabelas da base de dados do StudyConf

Como exemplo, os campos da tabela Aluno são mostrados como componentes do elemento $<$ aluno $>$ na Figura 6.5a. A Figura 6.5b indica o tipo do campo $<$ idaluno $>$.

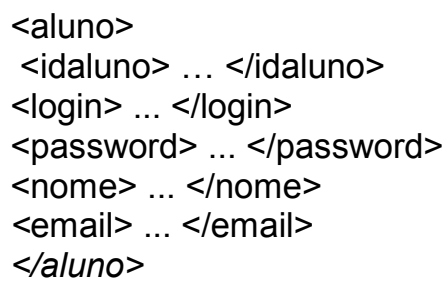

(a) <idaluno > type="id" $<$ idaluno>

(b)

Figura 6.5 - (a) Tabela aluno e seus elementos (campos) e (b) o campo idaluno com seu tipo.

Com base na identificação dos elementos do banco de dados, constrói-se o DTD para a tabela aluno, conforme indicado na Figura 6.6. 


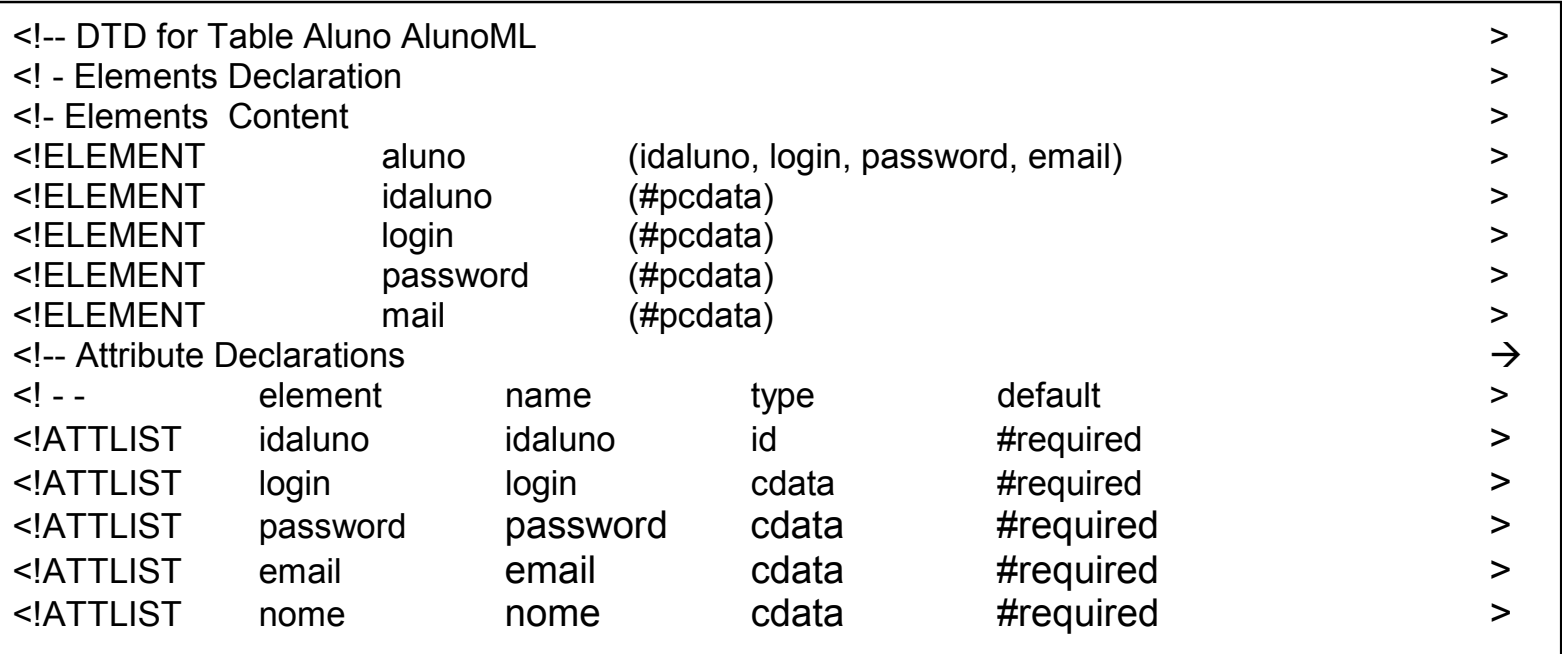

6.6 - DTD para a tabela aluno do banco de dados do StudyConf

\subsubsection{Documentos XML}

Um subconjunto XML pode ser usado para representar o conteúdo de uma base de dados de forma padronizada, estruturada e formalizada (Rel, 1998). Utilizando a estrutura hierárquica do DTD da Figura 6.6, um documento XML pode organizar o conteúdo de informações que recebe. Um exemplo é apresentado na Figura 6.7.

Através do módulo administrador da aplicação StudyConf pode-se gerar documentos XML específicos para cada tabela do banco de dados. Os documentos XML gerados são instanciados com o conteúdo dos campos armazenados nas tabelas do banco de dados. Na Figura 6.7 tem-se o exemplo de um documento XML gerado a partir do conteúdo da tabela Aluno que possui apenas um registro.

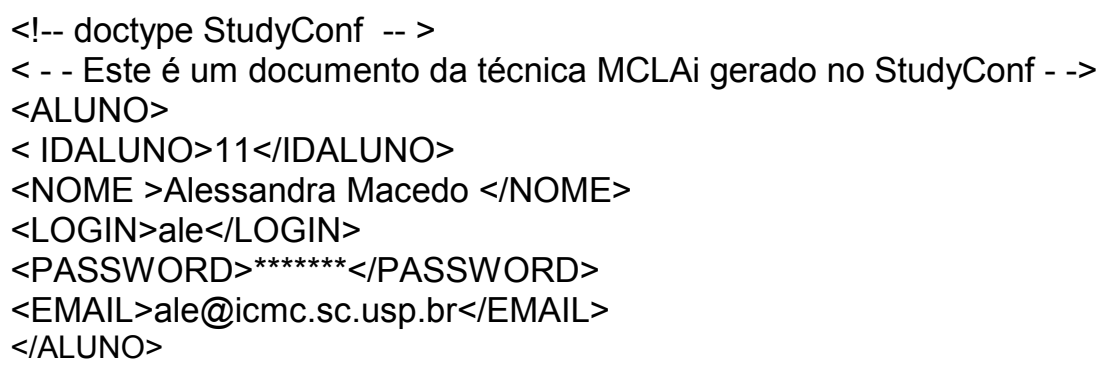

Figura 6.7 - Documento XML de uma instância da base de dados do StudyConf 
Na versão atual do StudyConf são gerados, opcionalmente, documentos XML a partir das tabelas do banco de dados; em versões futuras, poderá se optar pela seguinte modificação: criação automática, durante a utilização do ambiente, de documentos XML que podem ser percorridos por um parser para armazenar as informações dos documentos no banco de dados que comporta a aplicação para posterior recuperação.

Todas as entidades do modelo relacional do StudyConf foram convertidas em tabelas que compõem o banco de dados que suporta o ambiente e em documentos XML. Os documentos XML estão disponíveis no servidor Web do ambiente, e o banco de dados está armazenado e disponibilizado em um servidor de Banco de Dados PostgreSql, acessado na WWW através de recursos JDBC (Java DataBase Connectivity) e servlets.

A modelagem do StudyConf, usando UML e o modelo M-REL, ofereceu uma notação concisa para examinar o ambiente e seus elementos dentro do contexto da aplicação. A utilização das especificações XML para estruturar os documentos gerados auxiliou na implementação, ao facilitar o processamento dos mesmos para armazenamento e recuperação das informações.

\subsubsection{Modelo de navegação}

\subsubsection{Diagrama da aplicação}

O diagrama da aplicação do StudyConf pode ser visualizado na Figura 6.8. As unidades de apresentação representadas por páginas Web são diferentes das representadas por páginas de índice, sendo que as páginas Web possuem elos para outras páginas, além de possuir campos para entrada e saída de dados. 


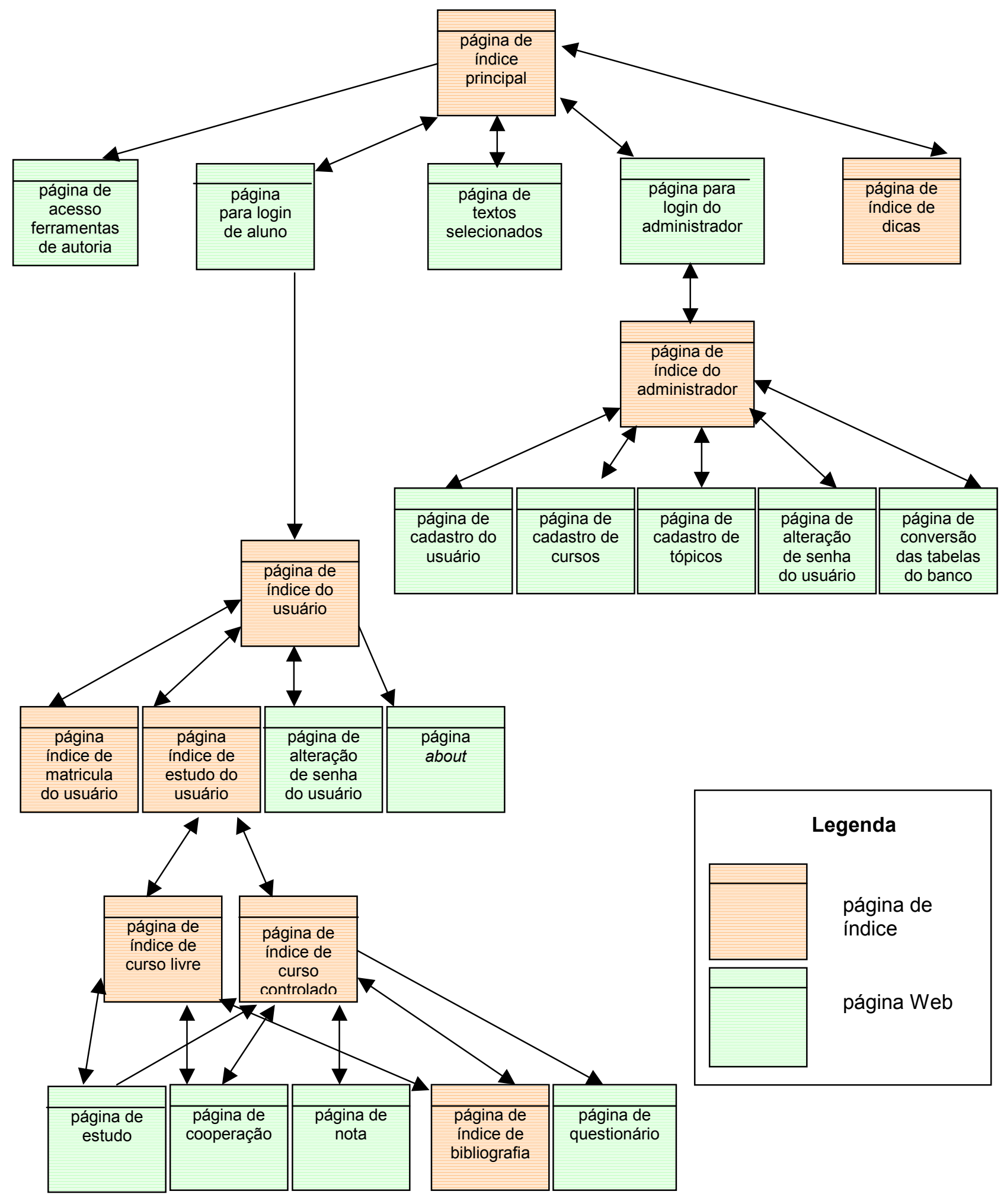

Figura 6.8 - Diagrama da Aplicação StudyConf 


\subsubsection{N-DTDs}

Cada unidade de apresentação do diagrama da aplicação da Figura 6.8 é especificada por um DTD. A unidade de apresentação - página de índice principal - pode ser visualizada na Figura 6.9 e o DTD que a especifica está na Figura 6.10.

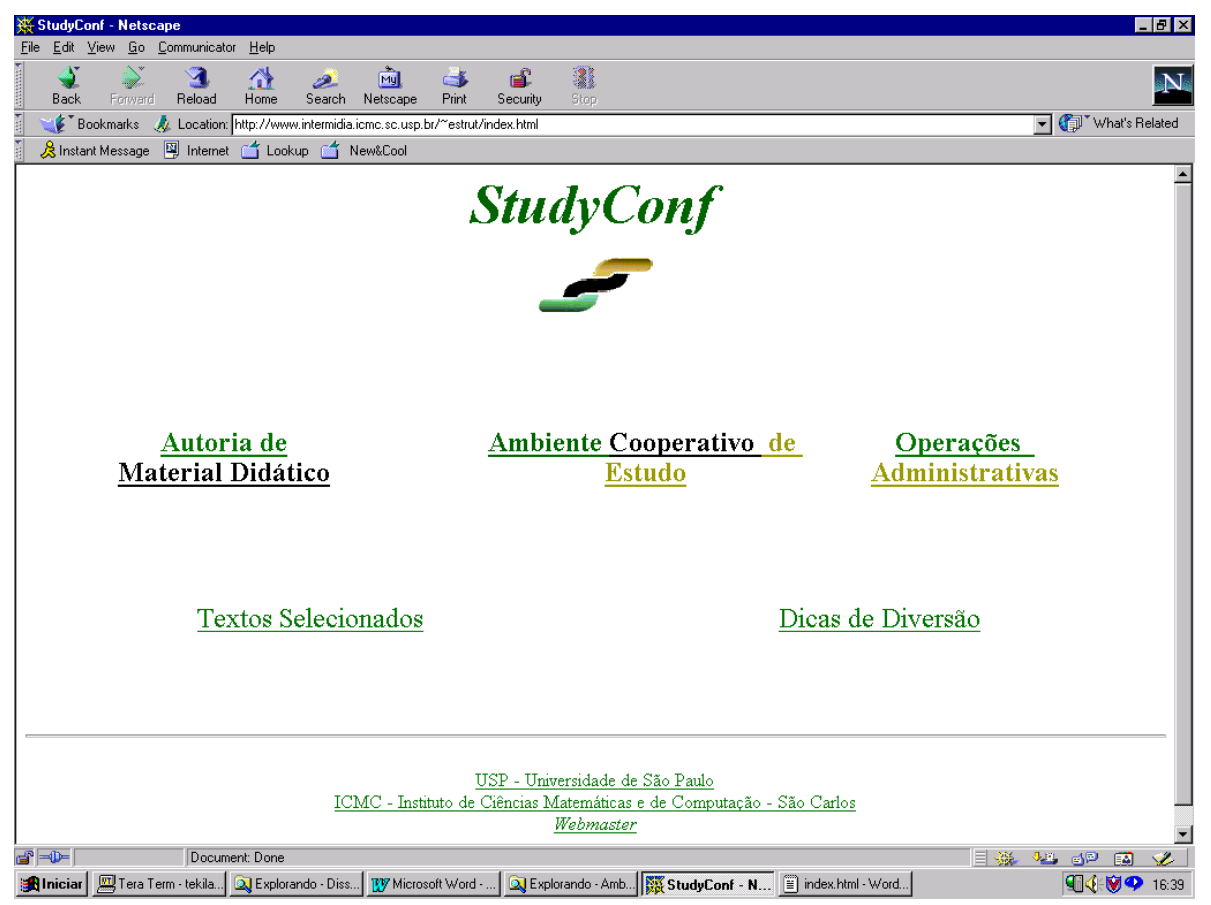

Figura 6.9 - Unidade de apresentação da página índice - página de índice principal

A página de índice da Figura 6.9 possui basicamente cinco links que serão os elementos do DTD da Figura 6.10. Cada elemento possui um atributo IDREF que especifica o destino do link.

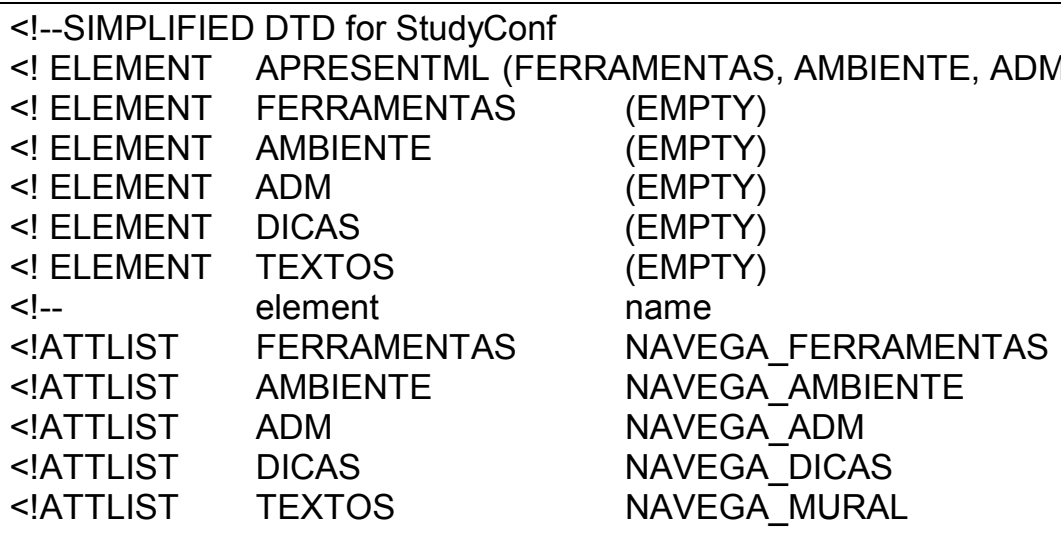

$\begin{array}{lr} & > \\ & > \\ & > \\ & > \\ & > \\ \text { type default } & --> \\ \text { IDREF “” } & > \\ \text { IDREF “LOGIN_ML.DTD” } & > \\ \text { IDREF “LOGINML.DTD” } & > \\ \text { IDREF “DICASML.DTD” } & > \\ \text { IDREF “TEXTOSML.DTD” } & >\end{array}$

Figura 6.10 - DTD da unidade de apresentação da Figura 6.9 
Para diferenciar do exemplo anterior que é de uma página índice, a Figura 6.11 apresenta uma unidade de apresentação representada por uma página Web - página de cadastro de usuários. Esta página Web contém basicamente cinco campos para entrada de informações. A página de cadastro de usuários é especificada pelo DTD da Figura 6.12.

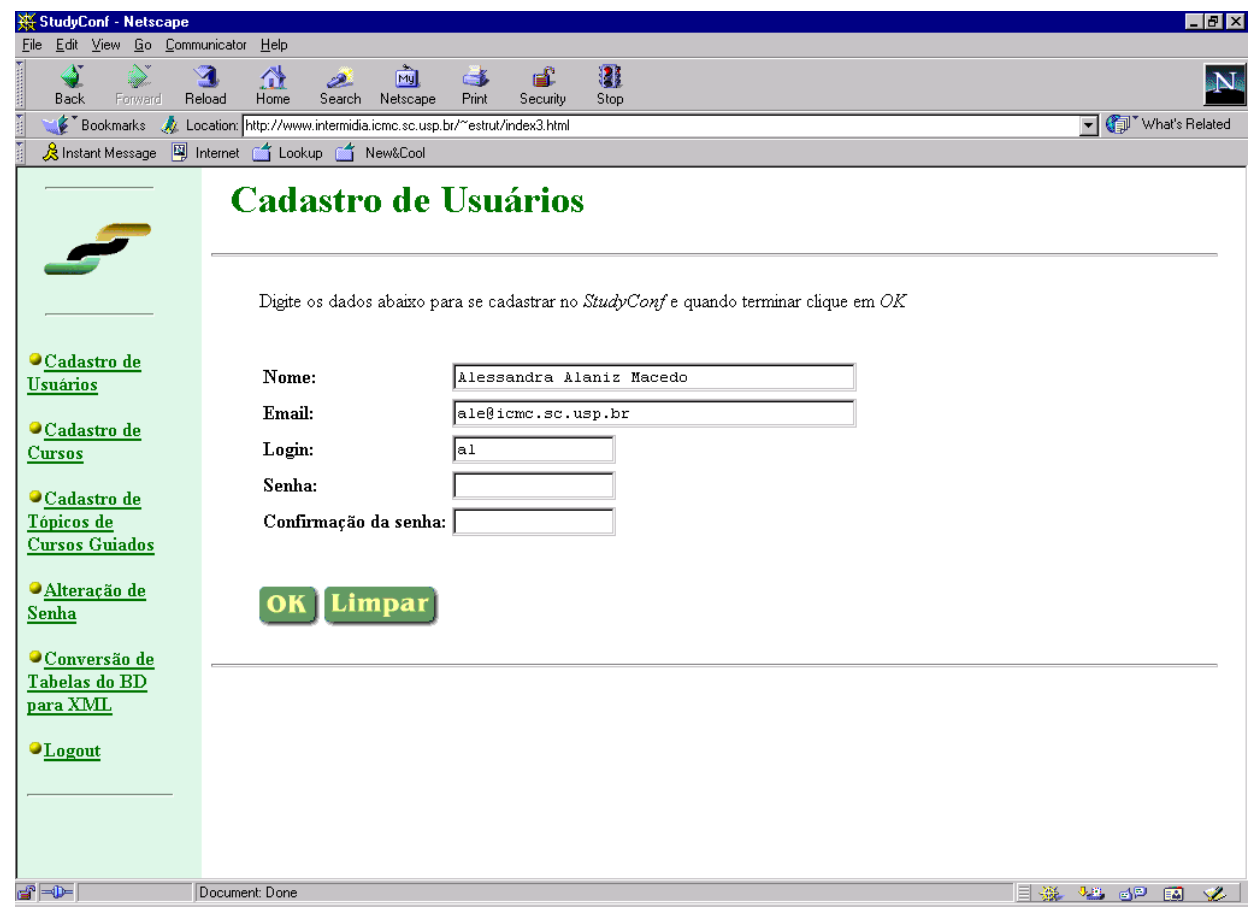

Figura 6.11 - Unidade de apresentação da página Web - página de cadastro de usuários

\begin{tabular}{llll}
\hline$<$ <--SIMPLIFIED DTD for cadastro de USUARIOS & \\
$<!$ ELEMENT & USUARIOML & (NOME, EMAIL, LOGIN, SENHA) \\
$<!$ ELEMENT & NOME & (\#PCDATA) & \\
$<!$ ELEMENT & EMAIL & (\#PCDATA) & \\
$<!$ ELEMENT & LOGIN & (\#PCDATA) & \\
$<!$ ELEMENT & SENHA & (\#PCDATA) & \\
$<!--$ & element & name & type \\
$<!$ ATTLIST & NOME & nome & CDATA \\
$<!$ ATTLIST & EMAIL & email & CDATA \\
$<!$ ATTLIST & LOGIN & login & CDATA \\
$<!$ ATTLIST & SENHA & password & CDATA
\end{tabular}

\begin{tabular}{lr|}
$-->$ \\
$>$ \\
$>$ \\
$>$ \\
$>$ \\
default \\
\#REQUIRED \\
\#REQUIRED & $>$ \\
\#REQUIRED & $>$ \\
\#REQUIRED & $>$ \\
\#RE & $>$
\end{tabular}

Figura 6.12 - DTD da unidade de apresentação da Figura 6.10

\subsubsection{Documentos XML}

As unidades de apresentação do StudyConf estão sendo apresentadas aos usuários através de páginas HTML. Entretanto, como já existem DTDs especificados para elas, basta definir o seu estilo através de padrões como XSL ou CSS e então apresentá-las com XML. 


\subsection{O SUPORTE À COOPERAÇÃO}

A cooperação na versão atual do StudyConf está baseada na ferramenta DocConf. A ferramenta DocConf original é brevemente apresentada na Seção 6.6.1. Na Seção 6.6.2 são mencionadas as alterações que foram realizadas para adaptar o DocConf ao StudyConf

\subsubsection{DocConf}

O DocConf é um ambiente de CSCW extensível que permite a configuração e execução de sessões de trabalho cooperativo, utilizando a Internet como plataforma de comunicação (Pimentel et al., 1998b). Para isso, fornece recursos de chat, whiteboard e votação, que permitem a troca de diferentes tipos de mensagens entre membros de um grupo.

O acesso ao ambiente pode ser feito através de uma aplicação cliente (Figura 6.13a), ou através de uma página da WWW (Figura 6.13b), utilizando um navegador compatível com applets Java. Independentemente da forma de acesso, o ambiente oferece ao usuário a mesma interface e as mesmas funcionalidades.

A versão atual do DocConf não oferece recursos de segurança de dados, apenas o controle de acesso. Todos os usuários devem se registrar antes de utilizar o ambiente. Novos usuários podem se registrar através do botão "Cadastra".

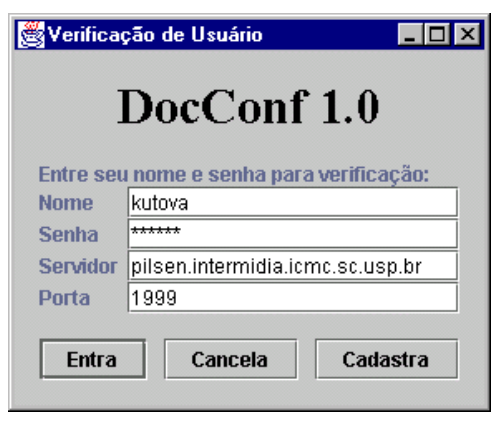

(a)

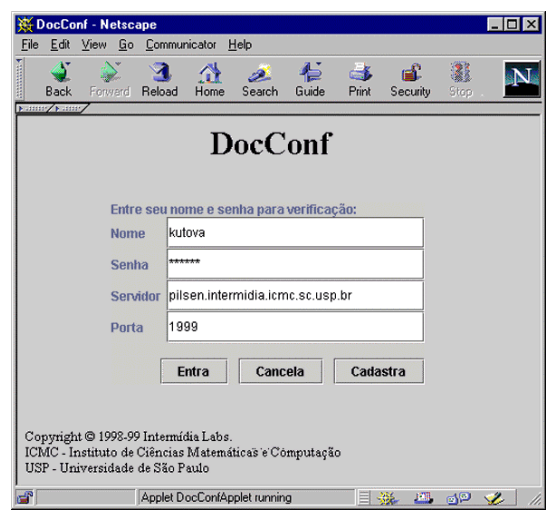

(b)

Figura 6.13 - Telas de acesso ao ambiente DocConf 
Uma vez conectado ao ambiente, o usuário pode criar uma nova sessão, entrar em uma sessão ativa, ou, ainda, fechar uma sessão que esteja vazia. O usuário pode participar de várias sessões simultaneamente, mas não há, entretanto, qualquer troca de informações entre sessões.

A tela de gerenciamento de sessões, apresentada na Figura 6.14, exibe uma lista dos usuários conectados ao ambiente e permite que o usuário altere seus dados de cadastro, consulte os dados de outro usuário e envie mensagens para qualquer usuário. Essas mensagens podem ser utilizadas, por exemplo, para convidar alguém para se juntar a uma sessão. Caso um usuário não deseje receber mensagens, ele pode ativar a opção "Não Incomodar", disponível no menu "Usuários".

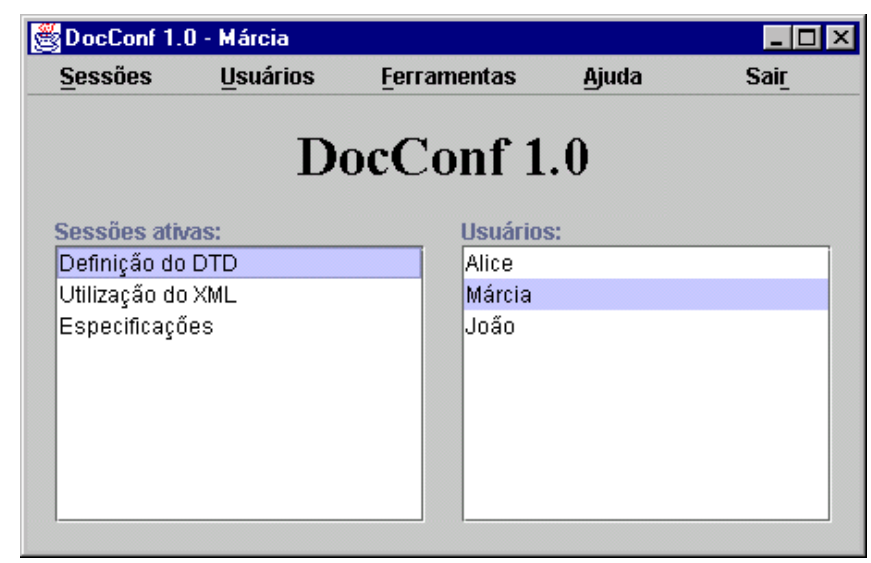

Figura 6.14 - Gerenciador de sessões do DocConf

A Figura 6.15 apresenta a tela de um cliente de uma sessão.

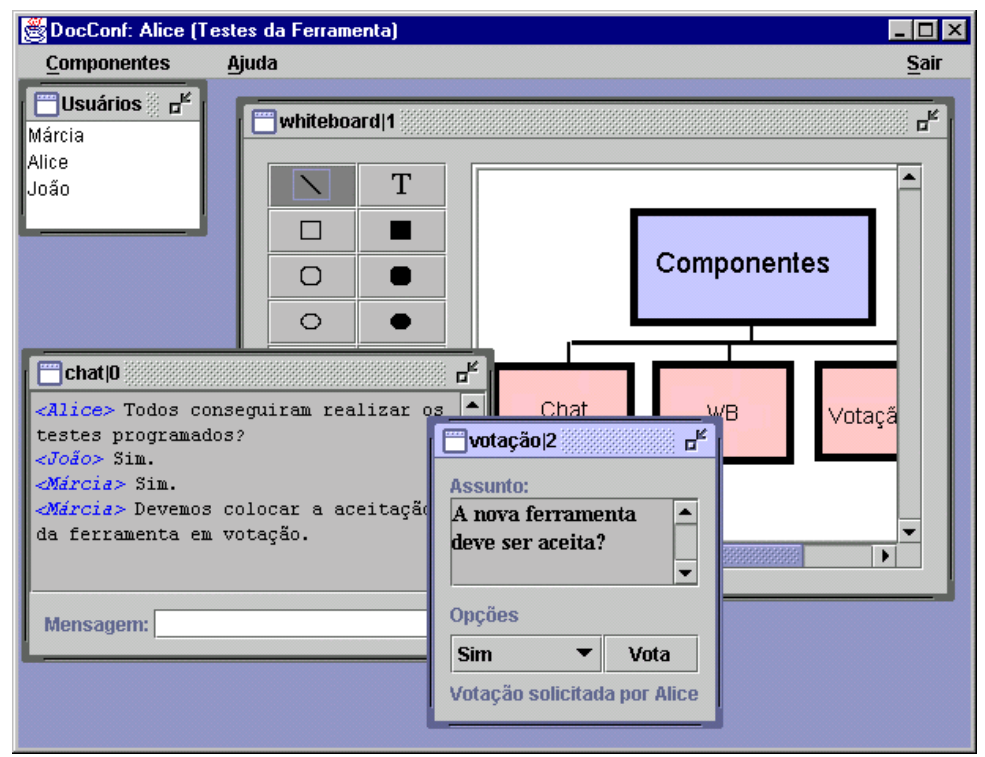

Figura 6.15 - Exemplo de um cliente de sessão 
Pela Figura 6.15, percebem-se três usuários conectados à sessão, Márcia, Alice e João, que interagem através dos recursos de chat, whiteboard e votação. Toda discussão entre os usuários é documentada em arquivos XML que ficam armazenados no servidor e disponíveis para consulta ou processamento.

\subsubsection{DocConf para o StudyConf}

Durante o estudo dos cursos disponíveis no StudyConf, o aluno poderá acionar a ferramenta DocConf através de uma opção na página de estudo. Entretanto, como os alunos só podem entrar em sessões vinculadas aos tópicos de cursos ou a cursos, todo o gerenciamento (criação, inicialização e encerramento) das sessões é realizado pelo próprio StudyConf. As sessões são previamente criadas durante a inserção dos cursos e tópicos pelo administrador, e as outras tarefas de gerenciamento das sessões são realizadas pelo StudyConf da seguinte maneira: quando o primeiro aluno ativa a ferramenta DocConf para um determinado tópico, o StudyConf inicializa a sessão; quando o último aluno sai, o StudyConf encerra a sessão. Estas tarefas são realizadas dentro de um servlet que cria uma página HTML, responsável por inicializar o applet do DocConf. DocConf é inicializado a partir da tela de cliente sessão como a da Figura 6.15, não necessitando acesso às telas das Figuras 6.13 e 6.14.

DocConf gera documentos XML que contém as discussões dos alunos sobre um tópico. Este documentos ficam armazenados no servidor e disponíveis para consulta ou processamento. Esta facilidade do DocConf ajuda professores a acompanharem e avaliarem seus alunos.

\subsection{IMPLEMENTAÇÃO}

\subsubsection{Metáforas utilizadas}

StudyConf utiliza a metáfora de um ambiente escolar convencional, no qual são considerados três categorias participantes: alunos, professores e administrador, que são os usuários do StudyConf.

O StudyConf simula um ambiente escolar convencional pois possui serviços similares aos oferecidos no ambiente real. Por exemplo; matrícula em cursos para posterior estudo, entrega de boletim de notas, indicação de referências bibliográficas extras, realização de questionários de 
avaliação, correção dos questionários, troca de informações entre alunos e entre aluno e professor durante o estudo; que são atividades cotidianas de qualquer escola, também estão presentes no StudyConf.

A metáfora de salas de reunião, da ferramenta DocConf, é utilizada durante a comunicação entre alunos e entre aluno e professor.

\subsubsection{Projeto de interfaces}

StudyConf não possui uma interface inovadora e atraente visto que se: pretendia- construir um ambiente rápido e eficiente na Internet, e também, o projeto não contava com um designer gráfico para operacionalizar a metáfora escolhida.

Apesar de simples, as interfaces pretendem ser limpas, consistentes, padronizadas e não ambíguas. Para tanto:

- foram selecionadas como cores predominantes no ambiente: o branco, o verde, o preto e o amarelo;

- foi utilizado apenas um tipo de fonte: Times New Roman, de tamanho 10;

- em algumas páginas, foram utilizados frames com o objetivo de facilitar a navegação dos usuários e, assim, tentar minimizar os problemas de desorientação e sobrecarga cognitiva.

Durante a composição da interface e do código do programa, foram necessários apenas editores de textos. As figuras do ambiente foram capturadas da Internet, com exceção do logan que foi criado exclusivamente para o StudyConf.

Para facilitar a descrição das interfaces do StudyConf, as páginas do ambiente são agrupadas em três tipos de páginas. São elas:

- página principal do StudyConf;

- páginas para realização de ações nos módulos aluno e administrador;

- páginas de estudo para cursos com navegação livre e controlada.

A seguir são apresentadas as interfaces do protótipo, de acordo com os três tipos citados. 
A página principal do ambiente permite o acesso aos módulos (aluno, administrador e professor), à página de entretenimento com dicas de diversão, e a textos selecionados sobre o StudyConf (Figura 6.16) .

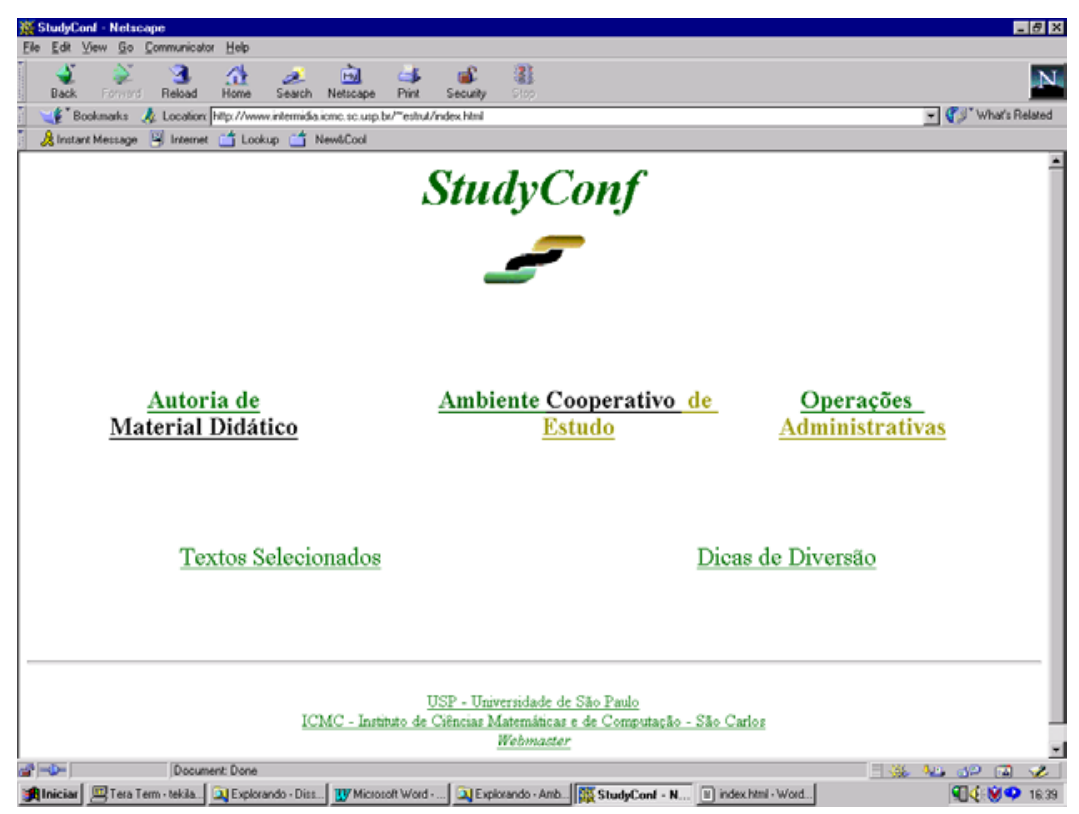

Figura 6.16 - Página principal do StudyConf

As páginas para realização de ações nos módulos aluno e administrador são divididas em dois frames verticais. Um frame exibe uma lista de possíveis ações no módulo, e o outro possui informações de ajuda sobre as ações ou formulários associados às ações. A página inicial do módulo administrador com informações de ajuda sobre as ações que podem ser realizadas neste módulo poder ser visualizada na Figura 6.17a. A Figura 6.17b exibe uma página do módulo aluno com o formulário para alteração de senha.

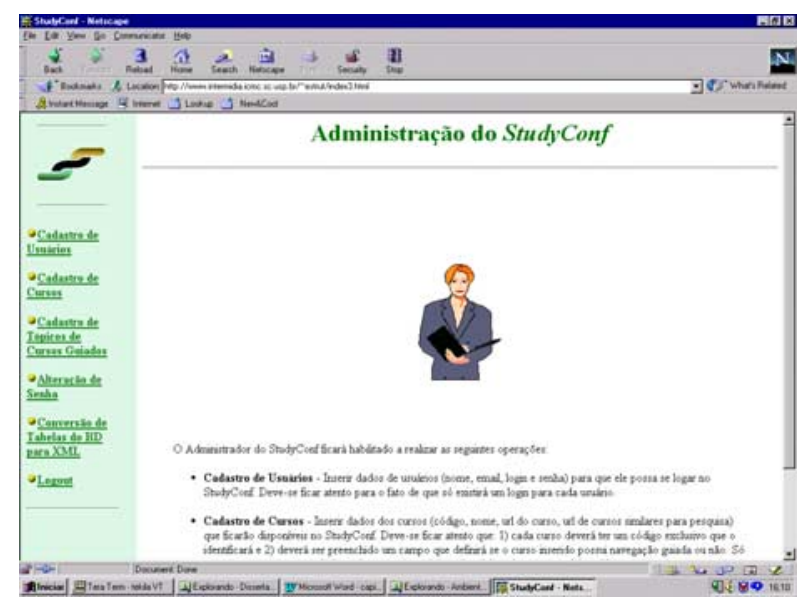

(a)

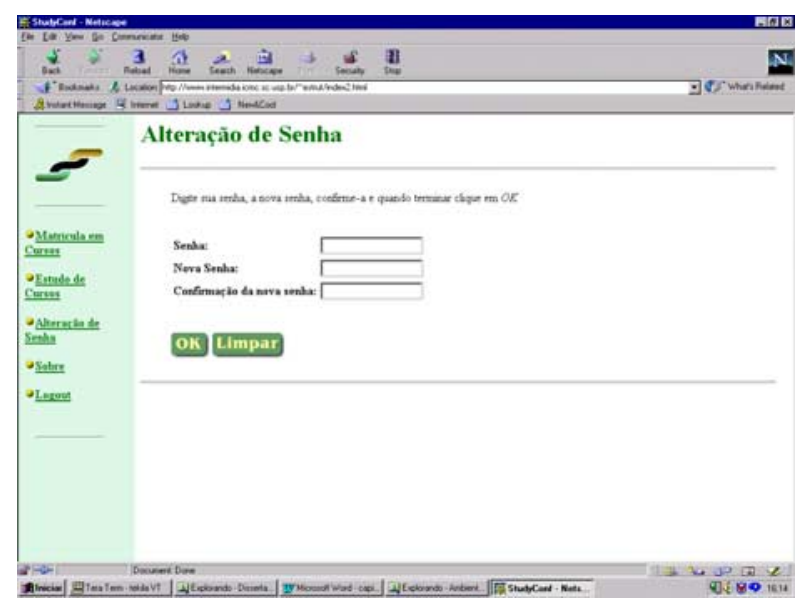

(b)

Figura 6.17 - Páginas para realização de ações nos módulos aluno e administrador 
Existem dois tipos de página de estudo: um para estudo de curso com navegação livre e outro para estudo de curso com navegação controlada. Os dois tipos de página são divididos em dois frames horizontais. O frame superior é para a apresentação do material didático, e o inferior para a lista de possíveis ações que varia de acordo com o tipo de curso estudado. Este formato de apresentação foi escolhido tentando dar maior destaque ao material didático apresentado.

As ações disponíveis no frame inferior para cursos com navegação livre são as seguintes: acesso à ferramenta de cooperação e comunicação, e acesso a uma página com referências bibliográficas extras. Já para os cursos com navegação controlada, as ações possíveis são: navegação para frente e para trás, leitura de boletim de notas, preenchimento de questionários, acesso à ferramenta de cooperação e comunicação, e acesso a uma página com referências bibliográficas extras. Para cursos com navegação controlada, existe no canto superior direito da página, um contador de tópicos estudados versus total de tópicos do curso. Um exemplo de página de estudo para cursos com navegação livre pode ser visualizada na Figura 6.18a. A Figura 6.18b apresenta um curso de navegação controlada.

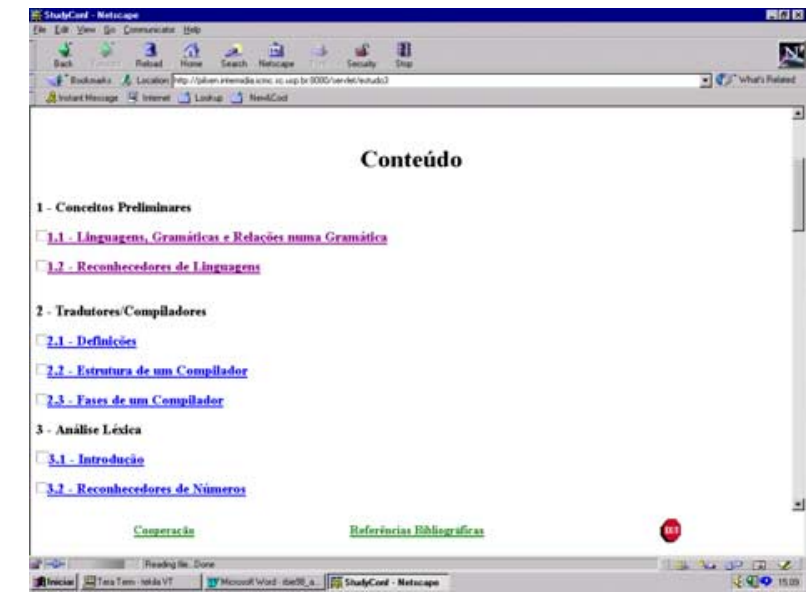

(a)

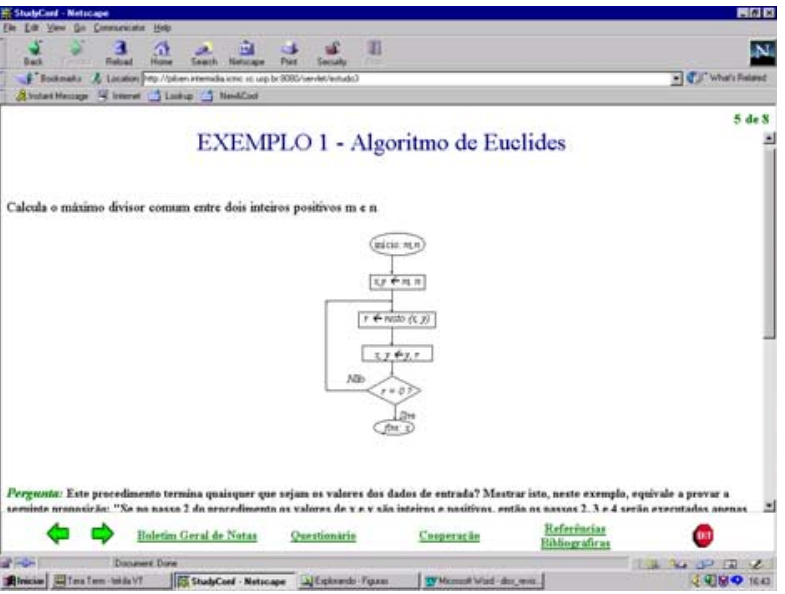

(b)

Figura 6.18 - Páginas de estudo para cursos com navegação livre e controlada

\subsubsection{Diretrizes de implementação da versão atual}

Para a implementação da versão atual do StudyConf foram tomadas algumas decisões baseadas em razões apresentadas a seguir. 
Por que foram adotadas as seguintes tecnologias: as linguagens Java e JavaScript, o banco de dados PostgreSQL, e a WWW como plataforma para disponibilização do ambiente? Como já foi mencionado, uma das premissas adotadas no projeto é que o ambiente produzido deveria ser utilizado em ambientes abertos e gratuitos como a WWW. É também por este motivo que um gerenciador de banco de dados de domínio público, no caso o DBMS PostgreSQL, e toda a programação está sendo feita em Java.

Qual o motivo da exigência de senha e login num ambiente que esta na WWW e pretende ser de domínio público? No momento o ambiente StudyConf ainda é um protótipo.

Por que foi disponibilizado, através do StudyConf, o download das ferramentas HyperBuilder, QuestBuilder, TaskBuilder e por que a ferramenta DocConf foi embutida no StudyConf? Estas ferramentas oferecem as funcionalidades requisitadas para o StudyConf, e, além disto, foram desenvolvidas pelo mesmo grupo de pesquisadores e por isto podem ser facilmente adaptáveis.

Qual a razão da utilização de servlets ao invés de applets? Isto ocorreu devido à necessidade da geração dinâmica de páginas HTML, além da independência de browsers durante a passagem de parâmetros do formulário HTML para o código Java.

Convém ressaltar que o StudyConf foi dividido em módulos para organização do ambiente e adequação a metáfora utilizada.

\subsection{EXEMPLO DE UTILIZAÇÃO}

Esta seção apresenta um exemplo de utilização do StudyConf. Suponha o seguinte cenário:

"Ana e Maria são duas universitárias que decidiram utilizar o StudyConf para estudar a disciplina de Teoria da Computação. Então, elas pediram para o administrador do ambiente cadastrá-las. Mais tarde, Ana e Maria receberam um e-mail informando os seus respectivos logins e senhas de acesso.

O curso de Teoria da Computação, um curso com navegação controlada apenas por tópicos e sem exercícios, já estava inteiramente disponível no ambiente. Este curso tinha sido 
desenvolvido por uma professora da universidade para seus alunos através da ferramenta de autoria de material didático - HyperBuilder.

As alunas marcaram um horário comum de estudo, à noite, para utilizarem o StudyConf. Ana não possuía um computador em casa, então teve que ir até o laboratório da universidade. Utilizando o computador do laboratório, Ana executou um browser de navegação e digitou o seguinte endereço: http://www.intermidia.icmc.sc.usp.br/ estrut. Ana pôde visualizar a página principal do ambiente. Maria, apesar de estar em casa, executava ações similares a Ana.

Na página principal do StudyConf, as estudantes selecionaram a opção Ambiente Cooperativo de Estudo que trouxe uma página para identificação. As estudantes digitaram suas senhas e $\operatorname{logins} "$.

A página principal do StudyConf pôde ser vista na Figura 6.16. A página de identificação pode ser visualizada na Figura 6.19. Depois de verificada a validade dos dados digitados na página da Figura 6.19, a página principal do módulo aluno é exibida (Figura 6.20).

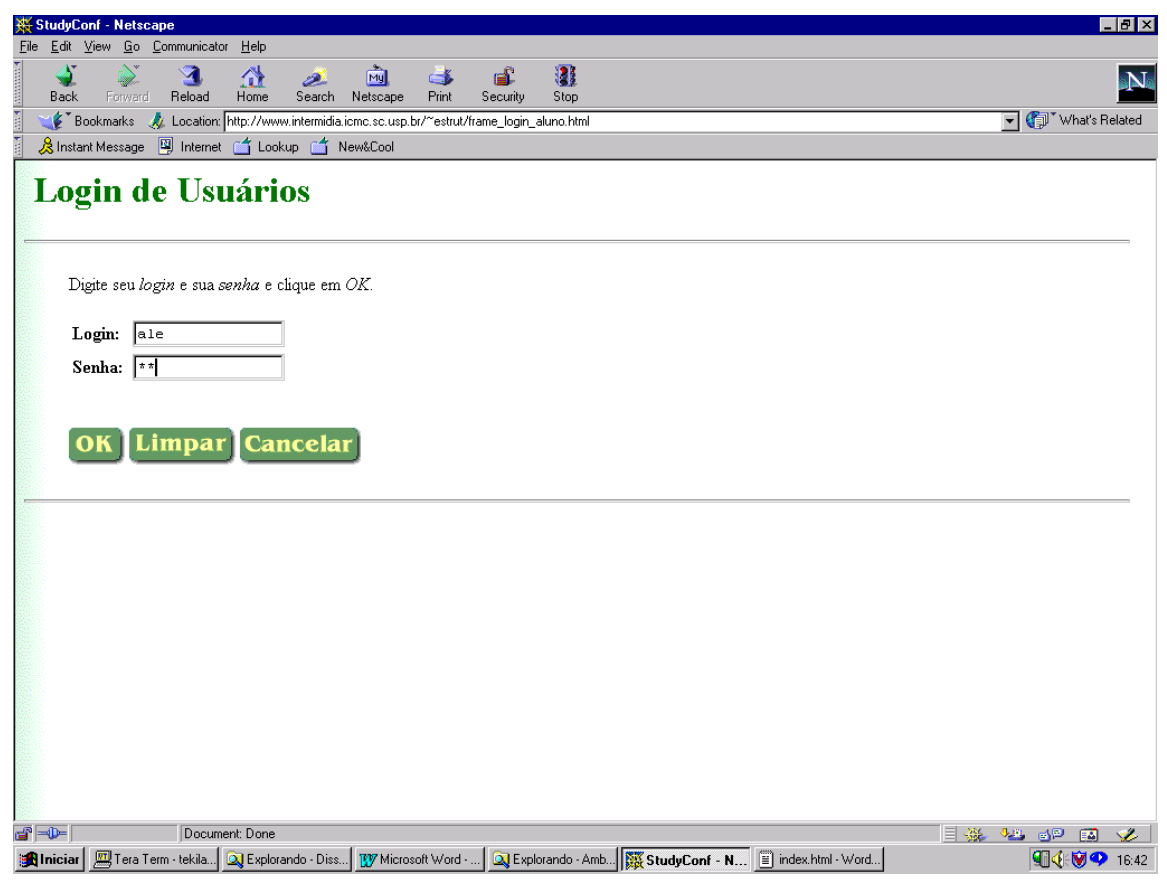

Figura 6.19 - Página de identificação para acesso ao ambiente de estudo 


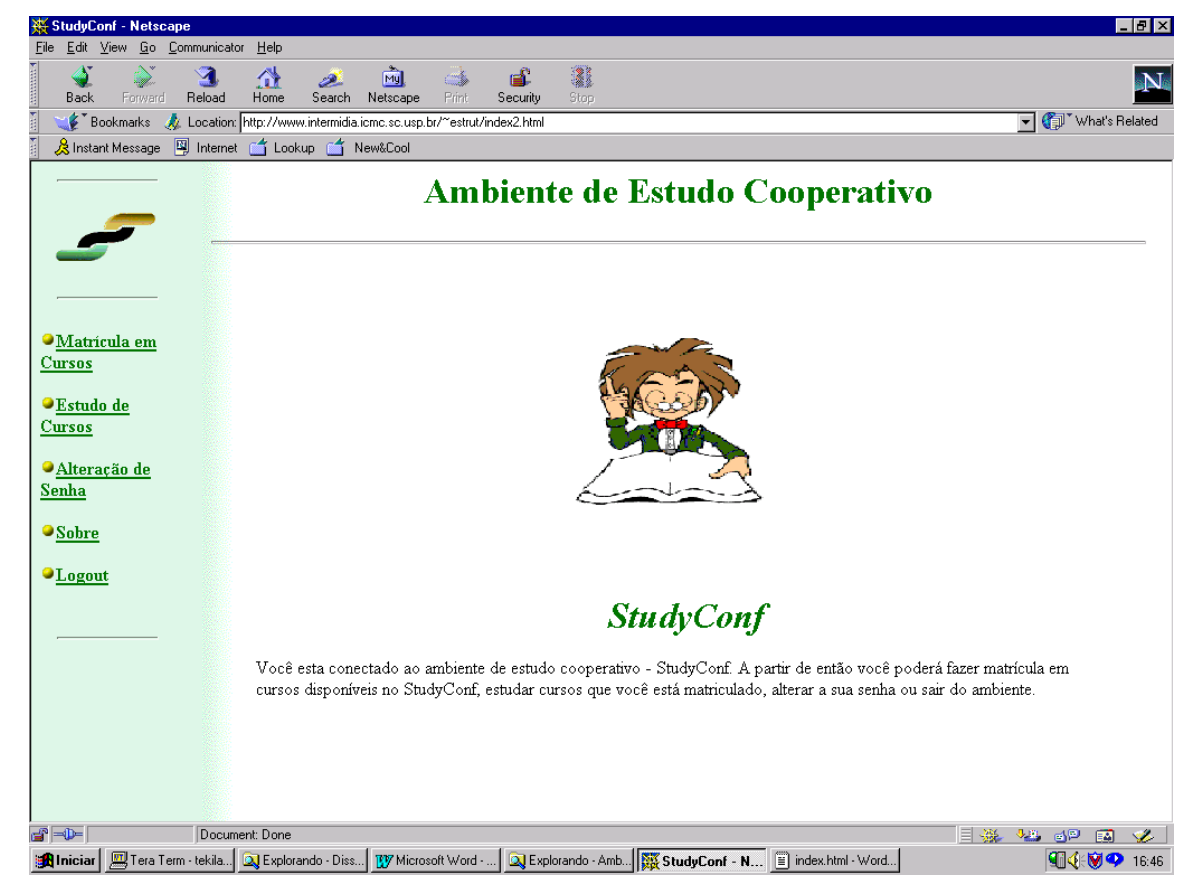

Figura 6.20 - Página principal do módulo aluno

"As alunas selecionaram a opção matricula, no frame mais à esquerda da página principal do módulo aluno, e assim visualizaram um menu que continha os cursos atualmente disponíveis para matricula no StudyConf. Como combinado, selecionaram o curso Teoria da Computação e receberam uma mensagem que dizia: Você está matriculado(a) no Curso de Teoria da Computação. Para iniciar seus estudos clique na opção <Estudo de Cursos $>$ do menu ao lado. Por curiosidade, Maria se matriculou também no curso de Compiladores que estava disponível para matrícula. Em seguida, elas selecionaram a opção <Estudo de Cursos $>$ como a mensagem tinha orientado".

O menu da página para seleção da disciplina a ser estudada, no caso da usuária Maria, é composto dos cursos de Teoria da Computação e de Compiladores, pois Maria estava matriculada em ambos os cursos (Figura 6.21). Entretanto, Ana, que só estava matriculada em Teoria da Computação, tinha apenas esta opção de curso para ser estudado. 


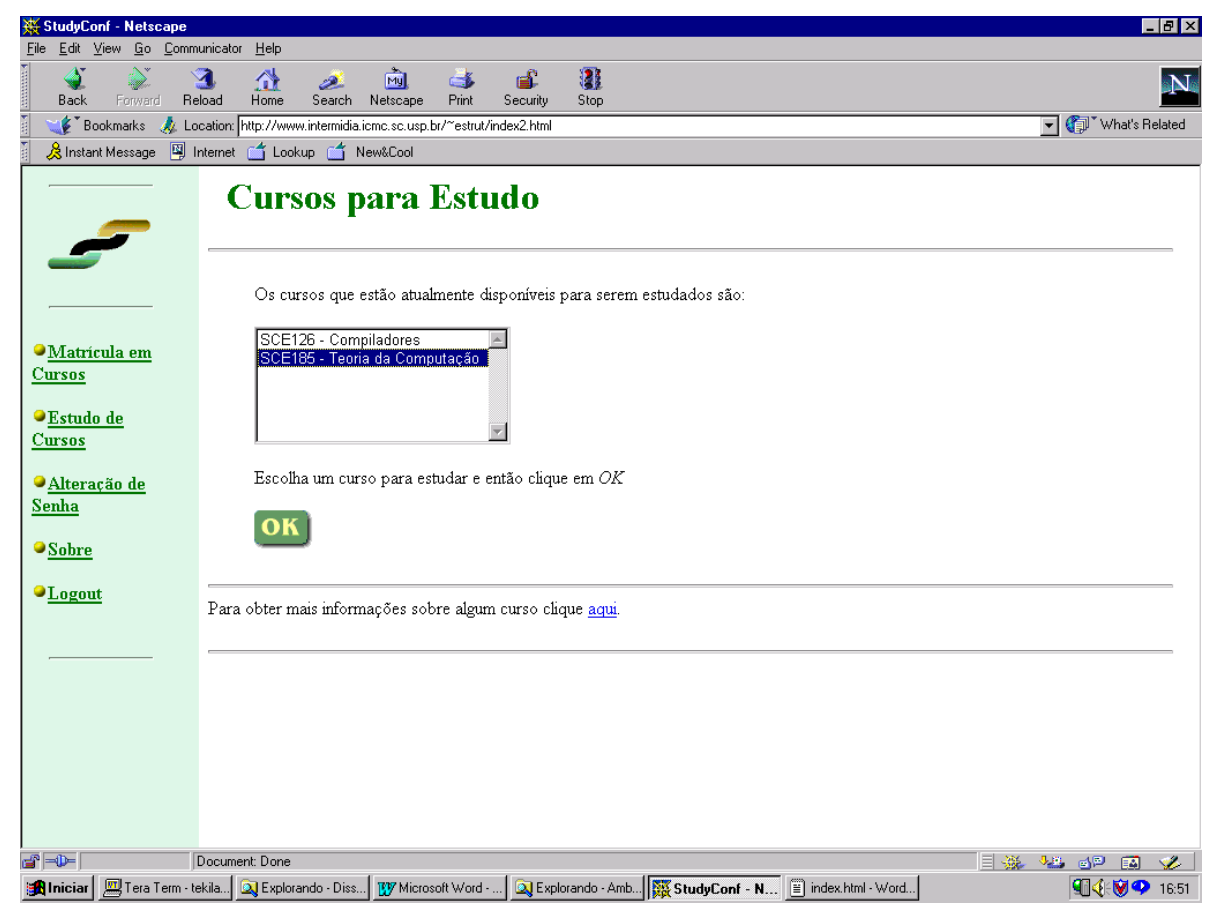

Figura 6.21 - Página para escolha de curso a ser estudado

“Ana e Maria selecionaram o curso de Teoria da Computação e puderam visualizar a primeira página de estudo deste curso”.

A primeira página de estudo do curso de Teoria da Computação é idêntica à da Figura 6.122. Caso, as alunas estudassem somente dois tópicos do curso, na próxima vez que elas utilizassem o StudyConf este disponibilizaria a página de estudo a partir do terceiro tópico. Entretanto, se as alunas quisessem rever os dois primeiros tópicos do curso, isto poderia ser feito, através da seta de backward existente na página de estudo como a da Figura 6.22. 


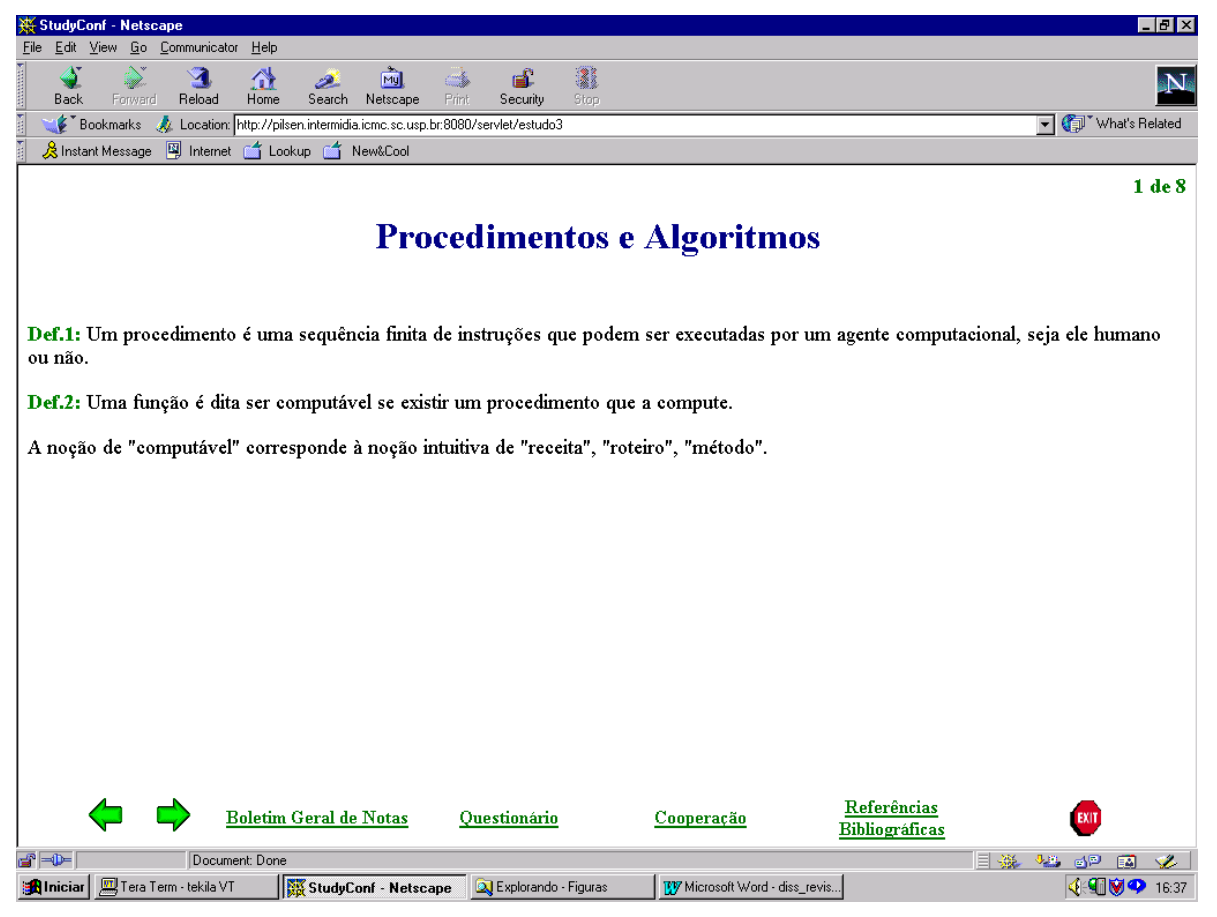

Figura 6.22 - Primeira página de estudo do curso de Teoria da Computação

"Quando terminaram de estudar o primeiro tópico, as estudantes pressionaram a seta forward, localizada na parte inferior da página de estudo. $O$ segundo tópico foi apresentado às estudantes, que refizeram o mesmo procedimento para ir para o terceiro tópico. Neste tópico surgiram dúvidas por parte de Ana, quanto ao conteúdo que vinha sendo apresentado. Ana, primeiramente, tentou acessar as referências bibliográficas extras disponíveis no ambiente”.

A página de referências bibliográficas extras, para o cenário descrito, pode ser vista na Figura 6.23 . 


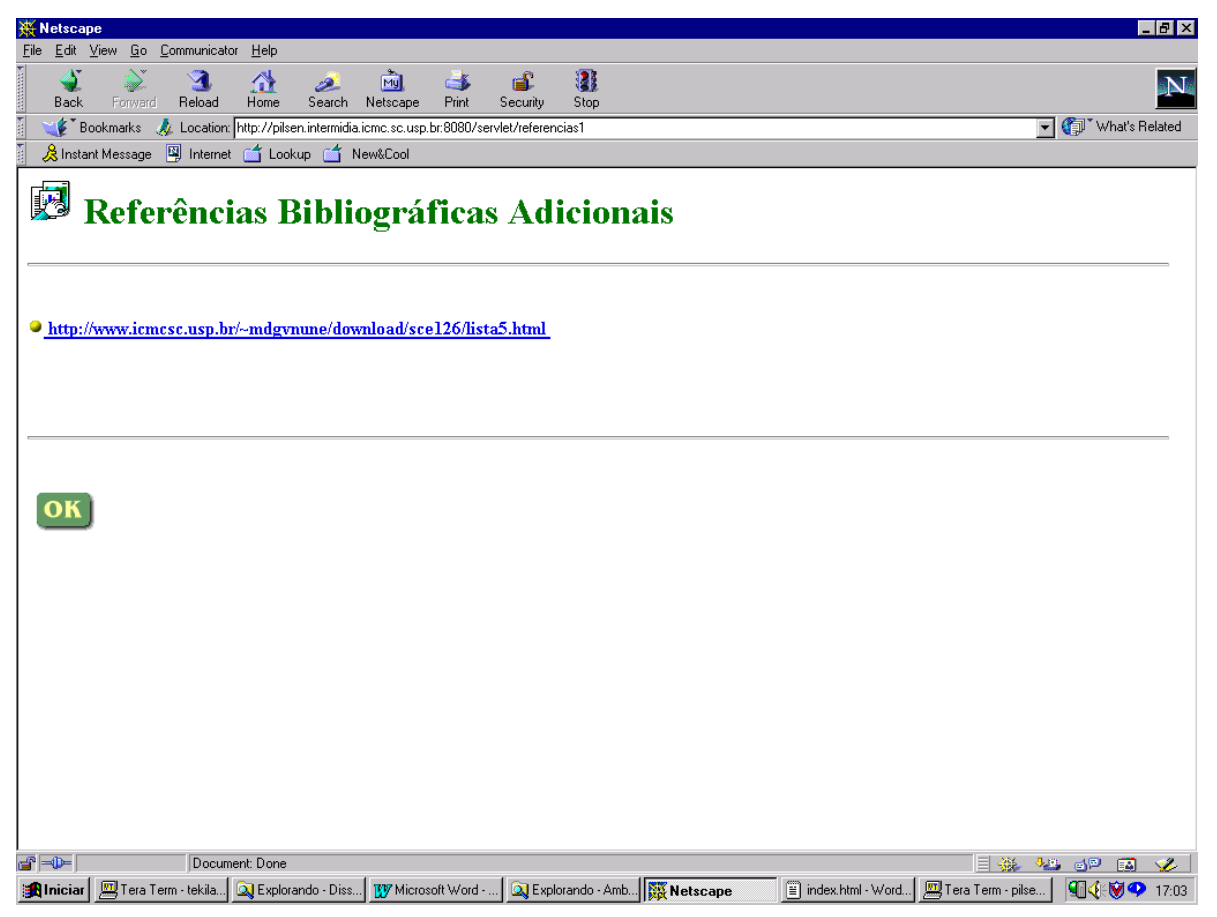

Figura 6.23 - Página de acesso a referências bibliográficas extras

Não achando suficiente o material extra, Ana resolveu ativar o link de Cooperação para ver se Maria poderia auxiliá-la. Ana e Maria, apesar de geograficamente separadas, puderam trocar informações e se ajudarem".

A página que indica o uso da ferramenta cooperativa durante o estudo do curso de Teoria da Computação pelas estudantes Ana e Maria pode ser vista na Figura 6.24. 


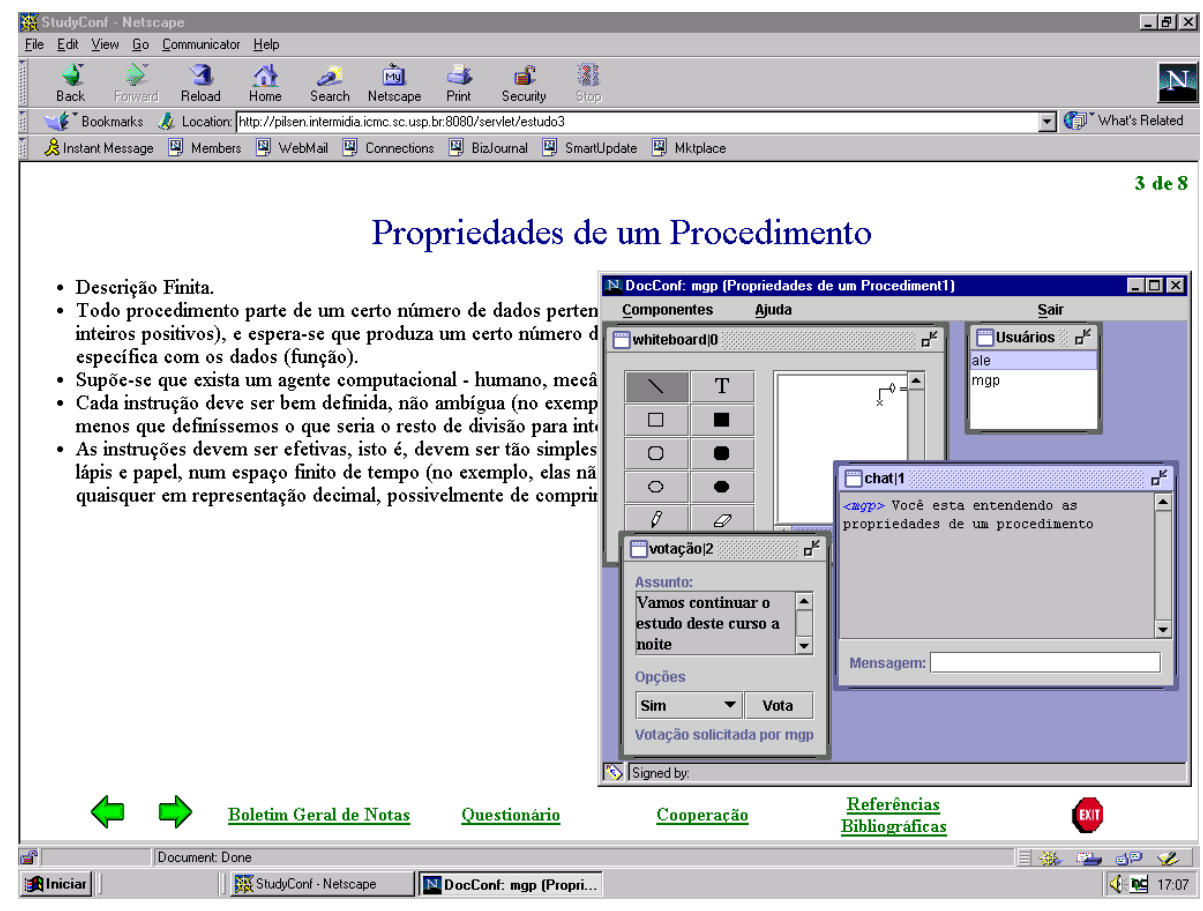

Figura 6.24 - Página exemplo de estudo cooperativo do StudyConf

Caso Ana e Maria não tivessem definido um encontro síncrono para a utilização do StudyConf, elas não seriam capazes de trocar informações, apesar delas poderem se comunicar com outros estudantes que, no mesmo momento, estivessem lendo o mesmo material.

\subsection{CONSIDERAÇÕES FINAIS}

As primeiras experiências com o StudyConf têm sido realizadas por meio da sua utilização por alguns professores do ICMC-USP, e por diferentes tipos de usuário-aluno: alunos novatos e alunos experientes em Computação. Alunos e professores têm demonstrado boa receptividade ao ambiente. Os professores têm colaborado, ainda, com sugestões para o aperfeiçoamento do StudyConf como, por exemplo, solicitando formas mais automatizadas para a organização e apresentação do material didático.

Atualmente, o StudyConf está em fase de testes de implementação. Em termos de apoio ao aprendizado cooperativo, experimentos controlados deverão ser conduzidos, como continuidade do trabalho aqui apresentado, para se avaliar seu impacto. 


\section{CONCLUSÕES}

A possibilidade de cooperação, sem restrições de tempo e espaço, tem sido considerada uma forte motivação para a criação e uso de ambientes cooperativos. $\mathrm{O}$ trabalho em grupo favorece o desenvolvimento da análise crítica e da aprendizagem de conceitos e estratégias e também aprimora qualidades pessoais, como liderança, comunicação e gerenciamento de tarefas. Em particular no contexto de sistemas CSCL, o processo de aprendizagem é motivado, pois os alunos contribuem com a sensação de posse da construção conjunta (Otsuka \& Tarouco, 1997). Alunos tímidos podem expor suas idéias mais facilmente e alunos mais agressivos, ou mais participativos, possivelmente não dominarão o tempo destinado à discussão como eles poderiam fazer em aulas expositivas (Gudzdial et al., 1997; Otsuka \& Tarouco, 1997). Em relação ao professor, ambientes cooperativos de estudo auxiliam no acompanhamento e avaliação dos alunos, de acordo com as informações armazenadas no sistema.

O ambiente apresentado nesta dissertação, o StudyConf, explora o uso das tecnologias cooperativas e de hipermídia para apoiar o estudo de hiperdocumentos disponíveis na WWW.

O StudyConf foi modelado de acordo com a técnica de modelagem MCLAi, cuja criação foi motivada pela necessidade de apoio às fases de projeto e implementação, tanto no nível lógico como de armazenamento, de aplicações Web. MCLAi procura orientar a modelagem de aplicações em sintonia com as recomendações do W3C, em particular no sentido de facilitar a especificação, a documentação e o intercâmbio de informações entre aplicações distribuídas na Web.

\subsection{CONTRIBUIÇÕES}

O desenvolvimento de protótipos do StudyConf e a pesquisa bibliográfica contribuíram para a definição da técnica de modelagem MCLAi. Tal técnica possui diversas propriedades interessantes para a modelagem de aplicações para a Web, uma vez que se baseia em padrões do 
W3C e em técnicas complementares bem estabelecidas como o diagrama de classes da UML e o modelo relacional (Macedo et al., 1999c).

A evolução do trabalho levou à implementação do ambiente StudyConf. Através do desenvolvimento do StudyConf, foram avaliadas diversas tecnologias para implementação de ambientes na WWW como, por exemplo, servlets, applets. Procurou-se utilizar tecnologias que fossem independentes dos recursos computacionais de hardware e software disponíveis.

Outra contribuição deste trabalho foi a adaptação da ferramenta cooperativa DocConf ao ambiente StudyConf. O DocConf supriu a necessidade de cooperação, entre alunos e entre professores e alunos, durante a realização do estudo dos cursos didáticos disponíveis no StudyConf. DocConf, além de fornecer os recursos de chat e whiteboard para comunicação, provê também apoio à votação (Pimentel et al., 1999). Tal funcionalidade é fundamental para apoiar a tomada de decisões durante o estudo dos hiperdocumentos disponíveis no StudyConf. Para todos os seus recursos de comunicação do DocConf são gerados documentos XML que contêm as discussões dos alunos sobre um tópico. Os documentos XML ficam armazenados no servidor e disponíveis para consulta ou processamento. Esta facilidade pode ser utilizada, por exemplo, na implementação de aplicações que auxiliem os professores durante a avaliação e acompanhamento de estudo de seus alunos. DocConf e StudyConf apesar de terem sido desenvolvidos em projetos diferentes, foram integrados cooperativamente pelos pesquisadores do ICMC.

O estado da arte para ambientes cooperativos utilizados em ambientes de ensino e o StudyConf foram temas do artigo: "StudyConf: Infra-estrutura de Suporte ao Aprendizado Cooperativo na WWW", apresentado na Revista Brasileira de Informática na Educação (RBIE) (Macedo et al., 1999b).

A pesquisa bibliográfica reportada nesta dissertação contribuiu diretamente para a produção de uma nota didática do ICMC intitulada "Ambientes Cooperativos: Tendências e Exemplos" (Macedo et al, 1999a). Este material é útil como fonte de referência nesta área em constante desenvolvimento, tendo contribuído, por exemplo, com levantamento do estado da arte associado à metodologia CSCW-SH, proposta durante o desenvolvimento de protótipos do DocConf. CSCW-SH foi proposta para apoiar a construção de aplicações colaborativas que utilizam 
hiperdocumentos para formalizar a estrutura das sessões. A metodologia, quei tema do artigo "Hiperdocumentos Estruturados no Suporte ao Trabalho Cooperativo em Sistemas Abertos Distribuídos", apresentado no SEMISH'98 (Pimentel et al., 1998b), que contou com a contribuição desta autora.

\subsection{TRABALHOS FUTUROS}

O trabalho aqui reportado deve ter continuidade tanto em termos da técnica MCLAi como no contexto da evolução do StudyConf.

No contexto da técnica MCLAi, trabalhos que podem ser desenvolvidos como extensão da técnica são:

- permitir o mapeamento do diagrama de classe que compõe a aplicação para o modelo de dados orientado a objetos;

- estender o modelo a fim de gerar OODTDs (Object Oriented DTDs), a partir da base de dados;

- analisar resultados decorrentes da utilização da MCLAi durante a construção de ferramentas para armazenamento, recuperação e apresentação de hiperdocumentos didáticos estruturados na WWW (Pires, 1999);

- estudar o uso conjunto da metodologia CSCW-SH com a MCLAi;

- utilizar os documentos XML gerados para apresentar interfaces do StudyConf, seguindo padrões recomendados pelo W3C, como, por exemplo, o XSL.

Como continuidade natural da implementação do ambiente StudyConf, a tarefa mais importante corresponde à execução de experimentos, para avaliação da interação do usuário com o ambiente StudyConf.

Além disso, como os documentos XML ficam armazenados no servidor e disponíveis para consulta ou processamento, devem ser implementadas aplicações que permitam a publicação desses documentos ou que auxiliem os professores durante a avaliação e acompanhamento de estudo de seus alunos. Essas tarefas são importantes no sentido de prover recursos tradicionais de CSCL ao ambiente. 
Finalmente, podem ser implementadas aplicações que forneçam funcionalidades tais como:

- blocos individuais e de grupo para anotações de estudo;

- mural de avisos;

- agendas para o professor e para o aluno;

- editor de texto cooperativo.

\subsection{CONSIDERAÇÕES FINAIS}

Neste capítulo foram apresentadas as conclusões deste trabalho, ressaltando-se também alguns dos trabalhos que podem ser realizados como continuidade deste.

De modo geral, o desenvolvimento de pesquisas que investigam a aplicação da informática na educação tem recebido cada vez mais espaço na comunidade científica de ciência da computação. Deste modo, é valido ressaltar que o crescimento do uso de sistemas computacionais em ambientes de ensino tem sido observado também em nível mundial, principalmente com o advento da Internet e a disseminação da WWW. Neste contexto, o desenvolvimento de um ambiente cooperativo que utiliza a Internet para estudo e discussão de hiperdocumentos didáticos disponíveis na WWW torna-se relevante.

Outros aspectos positivos obtidos através deste trabalho foram: a revisão bibliográfica das áreas de hipermídia, CSCW e CSCL produzida, a especificação da técnica MCLAi e a geração de oportunidades para a realização de novas tarefas associadas à investigação do uso integrado de tecnologias cooperativas e de hipermídia no apoio ao ensino. 
(ACD, 1998) Aprendizagem Cooperativa a Distância - Homepage, ago. 1998. Disponível em: http://www.kidlink.org/portuguese/brasil/acd/acd_index.htm/

(Aiken, 1992) AIKEN, M. Using a Group Decision Support System as a Teaching Tool. Journal of Computer-Based Instruction, v.19, n.2, p.82-85, 1992.

(Araújo, 1995) ARAÚJO, R.M..CSCW, Groupware e Internet. Disponível em: http://www.cos.ufrj.br/ renata/cscw/sumario.htm.

(AulaNet, 1999) AulaNet - Homepage, mai. 1999. Disponível em: http://www.les.inf.pucrio.br/download/index.htm

(Bacelo \& Becker, 1997) BACELO, A.P.T; BECKER, K. Uma ferramenta de apoio à discussão e deliberação em grupo. III Workshop Sistemas Multimídia e Hipermídia, p.119-130, 1997.

(Barros, 1994) BARROS, L. A. Suporte a ambientes Distribuídos para Aprendizagem Cooperativa. Tese de Doutorado - COPPE/UFRJ, 1994.

(Belvedere, 1998) Homepage do Belvedere, 30 de janeiro de 1998. Disponível em http://www.pitt.edu/ suthers/belvedere/

(Bentley et al, 1996) BENTLEY, R.; HORSTMANN, T.; SIKKEL, K.; TREVOR, J. The Architecture of the BSCW Shared Workspace System. Proceedings of the ERCIM Work. on CSCW and the Web, fev. 1996. Disponível em http://orgwis.gmd.de/projects/W4G/proceedings/bscw.html

(Berners-Lee et al., 1994) BERNERS-LEE, T.; CAILLIAU, R.; LUOTONEN, A; NIELSEN, H.F.; SECRET, A. The World Wide Web, Communications of ACM, v.37, n.8, p.76-82, 1994.

(Borges et al., 1995) BORGES, M.R.S.; CAVALCANTI, M.C.R.; CAMPOS, M.L.M. Suporte por Computador ao Trabalho Cooperativo, XV Congresso da Sociedade Brasileira de Computação, Canela, RS, 1995.

(Bosak, 1997) BOSAK, J. XML, Java, and the future of the Web, 1997. Disponível em http://sunsite.unc.edu/pub/sun-info/standards/xml/why/xmlapps.htm.

(Bra \& Aerts, 1996) BRA, P. D.; AERTS, A. Multi-User Publishing in the Web: DReSS, A Document Repository Service Station. Proceedings of the ERCIM Work. on CSCW and the Web, fev. $1996 . \quad$ Disponível em http://orgwis.gmd.de/projects/W4G/proceedings/dress.html.

(Bray \& DeRose, 1997) BRAY, T.; DEROSE, S. Extensible MarkUp Language (XML). Part 2 Linking. XML Principles, Tools and Techniques. v.2, n.4, p.67-82, set. 1997. 
(Brown, 1989) BROWN, H. Standards for Structured Documents. The Computer Journal, n.6, v.32, p.505-514, 1989.

(Brusilovsky et al., 1996) BRUSILOVSKY, P; SCHWARZ, E; WEBER, G. A tool for developing adaptative eletronic textbooks on WWW. Proc. WebNET'96.

(Catlin et al., 1989) CATLIN, T.; BUSH, P.; YANKELOVICH, N. InterNote: extending a hypermedia framework to support annotative collaboration. Second Annual ACM Conference Proceedings on Hypertext '89, p.365-378.

(Castro, 1997) CASTRO, M.A.S. Projeto de um Sistema de Auxílio a Preparação de Material Didático para uso na WWW. Tese de Mestrado - ICMSC-USP/São Carlos, mar. 1997.

(Castro et al., 1197) CASTRO, M.A.S., GOULARTE, R., REAMI, E.R., MOREIRA, E.S. Infraestrutura de Suporte a Editoração de Material Didático Utilizando Multimídia. Revista Brasileira de Informática na Educação, v.1, p.61-70, set. 1997.

(Chen, 1976) CHEN, P.S. The Entity-Relantionship Model - Toward a Unified View of Data. ACM Transaction on DataBase System, v.1, n.1, p.9-36, mar. 1976.

(Conklin \& Begeman, 1987) CONKLIN, J.; BEGEMAN, M. gIBIS: A Hypertext Tool for Team Design Deliberation. Hypertext'87, 1987.

(Connolly et al., 1997) CONNOLLY, D.; KHARE, R.; RIFKIN, A. The Evolution os Web Documents - The Ascent of XML: XML Priciples, Tolls and Techniques. v.2, n.4, p.119228, set. 1997.

(Connolly, 1998) CONNOLLY, D. The XML Revolution. Nature's, out. 1998. Disponível em http://helix.nature.com/webmatters/xml.html.

(CSILE, 1999) Homepage de CSILE - Computer-Supported Intentional Learning Environments, 1999. Disponível em http://www.ed.gov/pubs/EdReformStudies/EdTech/csile.html

(CSS, 1997) Cascading Style Sheets, 14 de agosto de 1997. Disponível em: http://www.w3.org/Style/CSS.

(Date, 1986) DATE, C.J. Introdução a Sistemas de Bancos de Dados. Editora Campus, $4^{\mathrm{a}}$ Edição, 1986.

(Decouchant \& Salcedo, 1996) DECOUCHANT, D.; SALCEDO, M.R. Alliance: A structured Co-operative Editor on the Web. Proceedings of the ERCIM Work. on CSCW and the Web, fev. $1996 . \quad$ Disponível em http://orgwis.gmd.de/projects/W4G/proceedings/alliance.html

(Dourish \& Bellotti, 1992) DOURISH, P.; BELLOTTI, V. Awareness and coordination in shared workspace. Proc. $4^{\mathrm{a}}$ Conference on Computer Supported Cooperative Work, p.107-114, 1992.

(Ellis et al., 1991) ELLIS, C.A; GIBBS, S.J.; REIN, G.L. Groupware: Some issues and experiences. Communication of the ACM v.34, n.1, p.1-29, 1991. 
(eWeb, 1997). eWeb Homepage, 1997. Disponível em http://ewebsite.com/.

(Gordon et al., 1996) GORDON, T.F.; NIKOS, K.; VOSS, H. Zeno - A Mediation System for Spatial Planning. Proceedings of the ERCIM Work. on CSCW and the Web, fev. 1996. Disponível em http://orgwis.gmd.de/projects/W4G/proceedings/zeno.html.

(GroupKit, 1998) GroupKit Homepage, mar. 1998. Disponível em http://www.cpsc.ucalgary.ca/projects/grouplab/groupkit/

(Guzdial, 1997) GUZDIAL, M. Information ecology of collaborations in educational settings: Influence of tool, CSCL'97. Eds.: R. Hall, N. Miyake, N. Enyedy. Toronto, Ontario, CA, p.83-90.

(Guzdial et al., 1997) GUZDIAL, M.; HMELO, C.E.; et al. Integrating and Guiding Collaboration: Lessons learned in computer-supported collaboration learning research at Georgia Tech. CSCL'97, Toronto, Ontario.

(Guzdial et al., 1998) GUZDIAL, M.; KONNEMAN, M.; WALTON, C.; HOHMANN, L.; SOLOWAY, E. Layering scaffolding and CAD on an integrated workbench: An effective design approach for project-based learning support. Interactive Learning Environments, v.1, n.1, p.1-37.

(Guzdial, 1998) GUZDIAL, M. Anchored Collaborative Learning Environments, jan. 1998. Disponível em: http://www.cc.gatech.edu/gvu/edtech/CaMILE.html

(Habanero, 1998) Habanero - Homepage, fev. 1998. Disponível em http://www.ncsa.uiuc.edu/SDG/Software/Habanero.

(Herwijnen, 1994) HERWIJNEN, E. Practical SGML. Kluwer Academic Publishers, Massachusetts, Second Edition, 1994.

(HTML, 1997) HTML 3.2 Reference Specification, 14 de janeiro de 1997. Disponível em http://www.w3.org/TR/REC-html32.html

(Isakowitz et al., 1998) ISAKOWITZ, T.; KAMIS, A; KOUFARIS, M. The Extended RMM Methodology for Web Publishing. Working Paper IS-98-18, Center for Research on Information Systems, (Currently under review at ACM Transactions on Information Systems), 1998.

(Ishii, 1991). ISHII, H. The Role of Hypertext for CSCW Applications. ACM. Hypertext'91 Panel, p.370-371.

(ISO, 1986) ISO/IEC Standard Generalized Markup Language - SGML. 1986:8879.

(ISO, 1992) ISO/IEC Hypermedia/Time-Based Structuring Language - HyTime. 1992:10744.

(ISO, 1996) ISO/IEC Document Style Semantics and Specification Language - DSSSL. 10179:1996. 
(Jacobson et al., 1998) JACOBSON, I; BOOCH, G.; RUMBAUGH, J. The Unified Software Development Process. Addison-Wesley Object Technology Series, 1999.

(JavaSun, 1999) Life Cicle of 1999. http://java.sun.com/docs/books/tutorial/servlets/lifecycle/index.html

(Johnson, 1999) JOHNSON, S. M. XML for the absolute beginner, abr. 1999. Disponível em http://www.javaworld.com/jw-04-1999/jw-04-xml.html

(Kouzes, 1997) KOUZES, R.. Collaboratories: Working Together Apart. Proceedings of 10th IEEE Real Time Conference, Beaune, France, p.647-649, set. 1997.

(Kouzes et al., 1996) KOUZES, R.T.; MYERS, J.D.; WULF, W.A. Collaboratories: Doing Science on the Internet. IEEE Computer, v.29, n.8, ago. 1996.

(Lee, 1990) LEE, J. SIBYL: A tool for managing group decision rationale. Proc. $3^{\circ}$ Conference on Computer Supported Cooperative Work, p.79-92, 1990.

(Lubich, 1995) LUBICH, H.P. Towards a CSCW Framework for Scientific Cooperation in Europe. Lecture Notes on Computer Science 889, 1995.

(Lucena et al., 1998) LUCENA, C.; FUKS, H.; et al. AulaNet-An Environment for the Development and Maintenance of Courses on the Web. Proc. ICEE'98-International Conference On Engineering Education, Rio de Janeiro/RJ, 1998.

(Macaulay, 1995) MACAULAY, L. Human-Computer Interaction for Software Designers. International Thomson Computer Press, p.136-172, 1995.

(Macedo et al., 1999a) MACEDO, A.; KUTOVA, M.A.S.; PIMENTEL, M.G.P. Ambientes Cooperativos: Tendências e Exemplos, . Nota Didática do ICMC nº 35, fev.1999.

(Macedo et al., 1999b) MACEDO, A.; PIMENTEL, M.G.P.; FORTES, R. StudyConf: InfraEstrutura de Suporte ao Aprendizado Cooperativo na WWW. Revista Brasileira de Informática na Educação (RBIE), set. 1999.

(Macedo et al., 1999c) MACEDO, A.; PIRES, D.; PIMENTEL, M.G.P.; FORTES, R. MCLAI: Modelagem Conceitual e Lógica de Aplicações para a Internet, artigo submetido ao Simpósio Brasileiro de Engenharia de Software (SBES), 1999.

(Megginson, 1998) MEGGINSON, D. SAX: The Simple API for XML, mai. 1998. Disponível em http://www.megginson.com/SAX/index.html.

(Meyrowitz, 1986) MEYROWITZ, N. Intermedia: The architectureand construction of an objectoriented hypemedia system and applications framework. Conference Proceedings on Object-Oriented Programming Systems, Languages and Applications, p.186-201, 1986.

(Mushroom, $\square 998$ ) Project Mushroom Homepage. Disponível em http://www.dcs.qmw.ac.uk/research/distrib/Mushroom 
(NCSA, 1998) Getting Started with CORE2000 version C2K_3.0, jun. 1999. Disponível em: http://www.emsl.pnl.gov:2080/docs/collab/userdoc/core2.000/help/core2000help.html.

(NetMeeting, 1999) NetMeeting - Homepage, jan. 1999. Disponível em: http://www.chitown.com/netmeeting/index.html

(Nielsen, 1990) NIELSEN J. Hypertext and Hypermedia, Academic Press, Inc, New York, 1990.

(Nunamaker et al., 1991) NUNAMAKER, J.F. Eletronic meeting ssytems to support group work. Communications of the ACM, ver.37, n.7, p.40-61, jul. 1991.

(Nunes et al., 1998) NUNES, C.C.R.; RIBEIRO, J.N.G.; FERRAZ, C.AG. Investigando Educação a Distância e o Projeto Virtus na UFPE. Anais do IX Simpósio Brasileiro de Informática na Educação. Fortaleza, Ceará, Brasil, 17 de novembro de 1998.

(O’Neill et al., 1995) O’NEILL, D.K.; EDELSON, D.C.; GOMEZ, L.M.; DÁMICO L. Learning to Wave Collaborative Hypermedia into Classroom Pratice. Proceedings of the CSCL'95, 1995.

(Otsuka \& Tarouco, 1997) OTSUKA, J.L.; TAROUCO, L.M.R. Proposta de um Sistema de Apoio à Aprendizagem Colaborativa Baseado no WWW. VII Simpósio Brasileiro de Informática na Educação, 1997.

(Pansanato \& Nunes, 1999) PANSANATO, L.E.; NUNES, M.G.V. EHDM: Método para Projeto de Hiperdocumentos para Ensino. Anais do V Simpósio Brasileiro de Sistemas Multimidia e Hipermidia, Goiânia, jun. 1999.

(Paolini \& Garzotto, 1999) PAOLINI, P; GRAZOTTO, F. Design Patterns for WWW Hypermedia: Problem and Porposals. Hypertext'99: Workshop on Hypermedia Development; Design Patterns in Hypermedia, fev. 1999.

(Pimentel \& Hagui, 1996) PIMENTEL, M.G.C., HAGUI, S.H. Usando a WWW como ferramenta de apoio ao ensino. Anais do VII Simpósio Brasileiro de Informática na Educação, p.55-68, nov. 1996.

(Pimentel et al., 1998a) PIMENTEL, M.G.C.; SANTOS, JR., J.B.; FORTES, R.P.M. Modelagem, Autoria e Apresentação de Documentos Didáticos Estruturados. Anais do IV Simpósio Brasileiro de Sistemas Multimídia e Hipermídia. Rio de Janeiro, Rio de Janeiro, Brasil, p.211-222, mai. 1998.

(Pimentel et al., 1998b) PIMENTEL, M.G.C.; KUTOVA, M.A.S.; MACEDO, A.A.; FORTES, R.P.M., TEIXEIRA, C.A.C. Hiperdocumentos Estruturados no Suporte ao Trabalho Cooperativo em Sistemas Abertos Distribuídos. Anais do XXV Seminário Integrado de Software e Hardware, Belo Horizonte - MG, Brasil, p.158-173, 7 de agosto de 1998.

(Pimentel et al., 1998c) PIMENTEL, M.GC.; FORTES, R.P M., SANTOS, Jr.J.B. Modeling, Authoring and Presenting Structured Documents in the WWW. Journal of Universal Computer Science (JUCS), Spring Verlag, v.4, n.11, p.825-838, 1998. 
(Pimentel et al., 1999) PIMENTEL, M.G.C.; KUTOVA, TEIXEIRA, C.A.C. Registering WebBased Conferencing with Structured Xml Documents. WebNet'99.

(Pires, 1999) PIRES, D.F. FARAH - Ferramentas para Armazenamento, Recuperação e Apresentação de Hiperdocumentos Didáticos Estruturados na WWW. Monografia de Qualificação de Mestrado. ICMC-USP-São Carlos. 1999.

(Puntambekar et al. 1997) PUNTAMBEKAR, S.; NAGEL, K.; GUZDIAL, M. Intra-group and intergroup: An Exploration of Learning with Complementary Collaboration Tools. Proceedings of CSCL'97. Toronto, Ontário, Canadá, p.207-214, 1997.

(Rada et al., 1998) RADA, R.; CARGIL, C.; KLENSIN, J. Consensus and the Web. CACM v.41, n.7, pp.17-22, 1998.

(Rel, 1998) XML Representation of a Relational Database, 1998. Disponível em: http://www.w3.org/XML/RDB.html.

(Rodrigues \& Soares, 1998) RODRIGUES, R.F.; SOARES, L.F.G. Integração dos Sistemas HyperProp e WWW. IV Simpósio Brasileiro de Sistemas Multimídia e Hipermídia, Rio de Janeiro, p.175-186, 1998.

(Santoro et al., 1998) SANTORO, F.M.; BORGES, M.R.S.; SANTOS, N. Um Framework para Estudo de Ambiente de Suporte à Aprendizagem Cooperativa. IX Simpósio Brasileiro de Informática na Educação. Fortaleza, Ceará, Brasil, nov. 1998.

(Santos et al., 1997) SANTOS, G.H.R.; VIEIRA, F.M.C.; HASEGAWA, R.; NUNES, M.G.V. SASHE: Autoria de Aplicações Hipermídia para o Ensino. VII Simpósio Brasileiro de Infromática na Educação. São José dos Campos, São Paulo, Brasil, p.425-440, nov. 1997.

(Santos, 1998) Santos, N. O Que Há de Novo em Aprendizagem Cooperativa na Internet? IX Simpósio Brasileiro de Informática na Educação, Fortaleza, Ceará, Brasil, nov. 1998.

(Santos \& Ferreira, 1998) SANTOS, N.; FERREIRA, H. Aprendizagem Cooperativa Distribuída na Biblioteca Kidlink-Brasil. Revista Brasileira de Informática na Educação, v.2, 1998.

(Santos et al., 1998a) SANTOS, A.C.; ZANFOLIM, T.I., KAYO, R.M.; GALINA, S.V.R. Awareness of the Decision Making Tool of the SACE-CSCW Environment. Proceedings of IV International Workshop on Groupware. Armação de Búzios, Rio de Janeiro, Brasil, p.129-142, set. 1998.

(Santos et al., 1998b) SANTOS, A.C.; ZANFOLIM, T.I.; KAYO, R.M.; SILVA, B.S.G. Percepções do Usuário em um Ambiente de Trabalho Cooperativo para Apoio na Tomada de Decisão em Grupo. Anais do I Workshop sobre Fatores Humanos em Sistemas Computacionais: Compreendendo Usuários, Construindo Interfaces. Maringá, Paraná, Brasil, p.1-10, out. 1998.

(Shabo et al., 1997) SHABO, A.; NAGEL, K.; GUZDIAL, M. JavaCAP: A Collaborative Case Authoring Program on the WWW. Proceedings of CSCL'97. Toronto, Ontário, Canadá, p.241-249, 1997. 
(Shum \& Hammond, 1994) SHUM, S.; HAMMOND, N. Argumentation-Based design rationale: what use at what cost?. International Journal of Human-Computer Studies, n.40, 1994.

(Soares et al., 1994) SOARES, L.F.G.; RODRIGUEZ, N.L.R.; CASANOVA, M.A. Modelo de Contextos Aninhados: Um Modelo Conceitual Hipermídia, Revista Brasileira de Computação, v.7, n.2, p.35-48, 1994.

(Soares et al., 1995) SOARES, L.F.G. et al. HyperProp: Uma Visão Geral. Anais do I Workshop em sistemas Distribuídos, p.40-46, São Carlos, 1995.

(Streitz, 1991) STREITZ, N. The role of hypertext for CSCW applications. ACM Hypertext'91 Panel, p.369-375, 1991.

(Walh, 1997) WALH, N. A Guide to XML. XML: Principles. Tools and Techniques, v.2, p.97-109, set. 1997.

(Walther, 1996) WALTHER M.; Supporting Development of Synchronous Collaboration Tools on the Web with GroCo. Proceedings of the ERCIM Work. on CSCW and the Web, fev. 1996. Disponível em http://orgwis.gmd.de/projects/W4G/proceedings/groco.html.

(WebCT, 1997) World Wide Web Course Tools, 1997. Disponível em http://www.webct.com/webct.

(WebSaber, 1998) Homepage do WebSaber, jul. 1998. Disponível em http://beatles.les.inf.pucrio.br/websaber/ambiente/indice.htm.

(XLink, 1998) XML Linking Language (XLink), mar. 1998. Disponível em: http://www.w3.org/TR/WD-xml-link.html.

(XML, 1999) The Extensible Markup: XML 1.0, abr. 1999. Disponível em: http://www.w3.org/XML.

(XPointer, 1998) XML Pointer Language (XPointer), mar. 1998. Disponível em: http://www.w3.org/TR/WD-xptr.

(XSL, 1999) Extensible Stylesheet Language, abr. 1999. Disponível em: http://www.w3.org/Style/XSL. 